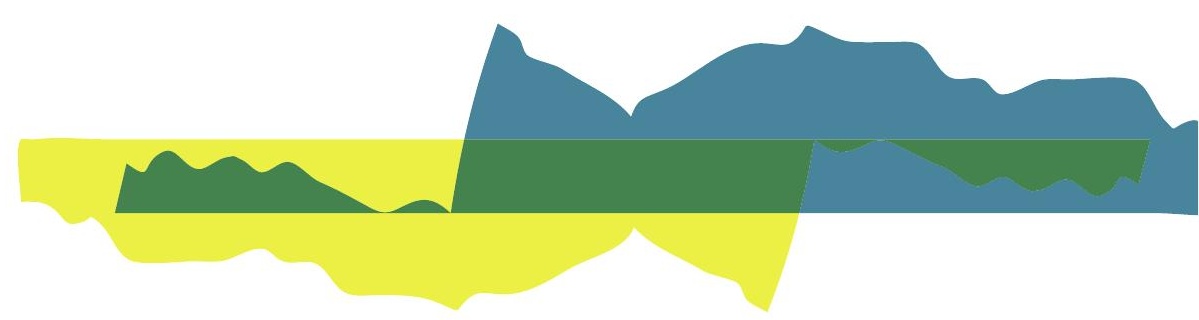

Understanding

policy and institutional

strategies to support

the participation of

women and women

organisations within

UNFCCC-led climate

change governance

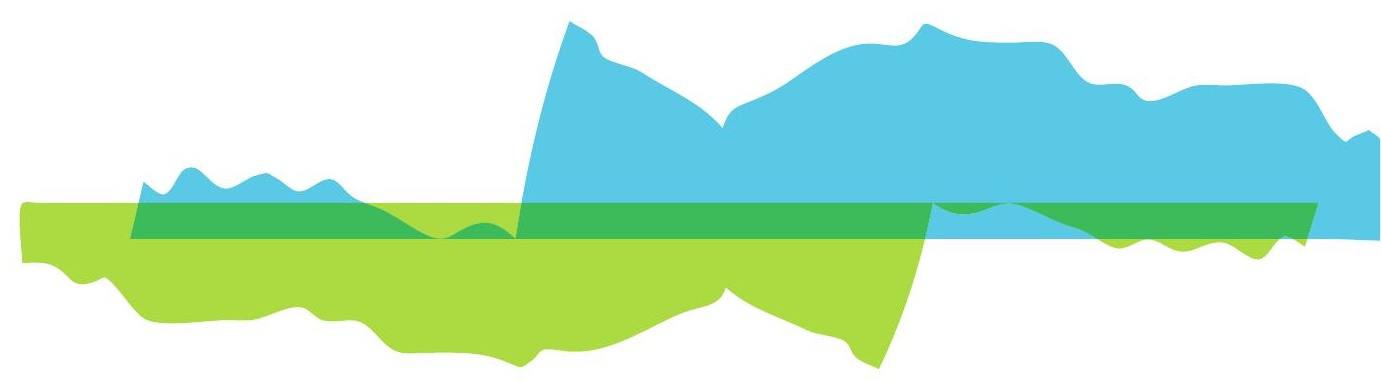

\title{
Svetlana Frenova
}

University of Twente

Faculty of Behavioural, Management and Social Sciences

Department of Technology, Policy and Society 


\section{UNDERSTANDING POLICY AND INSTITUTIONAL STRATEGIES TO SUPPORT THE PARTICIPATION OF WOMEN AND WOMEN ORGANISATIONS WITHIN UNFCCC-LED CLIMATE CHANGE GOVERNANCE}

\section{SVETLANA FRENOVA}

University of Twente Faculty of Behavioural, Management and Social Sciences

Department of Technology, Policy and Society 


\section{UNDERSTANDING \\ POLICY AND INSTITUTIONAL \\ STRATEGIES TO SUPPORT \\ THE PARTICIPATION OF WOMEN AND \\ WOMEN ORGANISATIONS WITHIN \\ UNFCCC-LED CLIMATE CHANGE \\ GOVERNANCE}

prof.dr. J.T.A. Bressers

dr.ing. J. Popović

prof. dr. W. Harcourt

prof. dr. E.D. Brown

prof. dr. M. McCall

The work described in this thesis was performed at the Section of

Governance and Technology for Sustainability, Faculty of Behavioural,

Management and Social sciences, University of Twente, P.O. Box 217, 7500

AE, Enschede, The Netherlands.

Cover design: Richard Taylor

Printed by: IPSKAMP printing

Lay-out: Richard Taylor

ISBN: 978-90-365-5339-1

DOI: $10.3990 / 1.9789036553391$

(c) 2022 Svetlana Frenova, The Netherlands. All rights reserved. No parts of this thesis may be reproduced, stored in a retrieval system or transmitted in any form or by any means without permission of the author. Alle rechten voorbehouden. Niets uit deze uitgave mag worden vermenigvuldigd, in enige vorm of op enige wijze, zonder voorafgaande schriftelijke toestemming van de auteur.

UNIVERSITY OF TWENTE.

Faculty of Behavioural, Management and Social sciences (BMS) Section of Governance and Technology for Sustainability (CSTM) Enschede, The Netherlands

\section{DISSERTATION}

to obtain

the degree of doctor at the University of Twente, on the authority of the rector magnificus,

$$
\text { prof.dr.ir. A. Veldkamp, }
$$

on account of the decision of the Doctorate Board, to be publicly defended

on Thursday 17 March 2022 at 16.45 hours

by

\section{Svetlana Frenova}

born on the 22nd of September, 1979

in Moscow, Russia

This dissertation has been approved by:

$$
\text { Supervisor }
$$

Co-supervisor

dr. F.H.J.M. Coenen prof. dr. ir. J.S. Clancy 


\section{ACKNOWLEDGEMENTS}

First and foremost I would like to express my gratitude to my supervisors Prof. Dr Joy S. Clancy and Dr Frans Coenen. My supervisors have had an elephantine task to support me through this process during the pandemic. Despite everything being turned upside down, they managed to provide thorough support with their comments and guidance. I am extremely grateful for Joy's and Frans's supervision and want to acknowledge that their contribution and influence stretch beyond this thesis. My supervisors have helped me to develop and deploy more systemic thinking on policy analysis and the importance of gender equality issues, which I will continue to work with in my professional life. More importantly, I will remember not to let the ${ }^{\star \star \star \star \star \star \star \star \star ~}$ grind me down.

I am extremely grateful for my partner's continuous support and believing in me. Andy's support has the most profound effect on my ability to carry on with my research and writing

Also, this thesis would have not been possible without my exposure to the international negotiations and to the work of the UNFCCC's financial instruments. I have been lucky enough to work with leading international organisations of the UN system and the Green Climate Fund. I have met a lot of knowledgeable and passionate people on my path, who donated their expertise and have impacted my thinking and vision. I am grateful for the support of my colleagues and professional network and I hope to be able to give my knowledge and voice to foster conversations on gender equality and women empowerment within and outside my work.

Finally, I would like to dedicate this thesis to all women who think that they are not enough, and to all men who believe that they can make a difference in gender equality. Being a women immigrant born on the outskirts of Moscow (Soviet Union), I have always felt an enormous pressure to prove myself, and I have always been admiring women who dare and aim for more. Chantal, Marielle, Hayatte - thank you for being an inspiration and elevating other women.

\section{TABLE OF CONTENTS}

\section{Chapter 1: Introduction}

1.1 Rationale for the research

1.2 Problem statement and research questions

1.3 Objectives and research questions

1.4 Overarching methodology

1.5 Structure of the thesis

\section{Chapten 2: Setting the scene}

2.1 Historical background

2.2 Multi-level UNFCCC-led decision making

2.2.1 Decision making by the UNFCCC COP

2.2.2 The UNFCCC's Financial Mechanisms

2.2.3 National level UNFCCC-led decision making

2.3 Conclusions

Chapter 3: Theoretical perspectives on the

participation of women and women organisations

in climate change governance

3.1 Introduction

3.2 The UNFCCC as a climate change governance framework

3.3 Participation in climate change governance

3.4 Women and women organisations as climate change policy actors

3.4.1 Women as climate change policy actors

3.4.2 Women organisations as policy actors

3.5 Strategies to improve the participation of women and women organisations

3.5.1 Policy strategies to improve participation

3.5.2 Institutional strategies to improve participation

3.6 Conclusions

Chapter 4: Analysis of COP/CMP/CMA policy strategies supporting the participation of women and women organisations in the UNFCCC

4.1 Introduction

4.2 Problem statement and research questions

4.3 Methodology

4.4 Results

4.4.1 Policy strategies for the participation of women and women organisations

4.4.2 Analysis of policy controversies

4.5 Discussion

4.6 Conclusions 
Chapter 5: Legitimising the engagement

of women and women organisations in

UNFCCC-led climate change governance:

The example of Georgia

5.1 Introduction

5.2 Problem statement and research questions

5.3 Methodology

5.3.1 Describing the existing approaches to legitimation

5.3.2 Analysing the quality of legitimation

5.4 Findings

5.4.1 Description of legitimation

5.4.2 Analysis of the quality of legitimation

5.5 Discussion

5.6 Conclusions

Chapter 6: Orchestrating the participation

of women organisations in UNFCCC-led

climate finance decision making

6.1 Introduction

6.2 Orchestration: The participation of non-state actors in multi-layered governance frameworks

6.3 Problem statement and research questions

6.4 Methodology

6.5 Results

6.5.1 Existing orchestration approaches

6.5.2 The quality of orchestration

6.6 Discussion

6.7 Conclusions

\section{Chapter 7: Climate finance allocation practices}

to support women's empowerment: GCF case-study

7.1 Introduction

7.2 Problem statement and research questions

7.3 Methodology

7.3.1 The quality of the integration of women's empowerment issues

7.3.2 Variations in the integration of women's empowerment issues

within the GCF's energy investments

7.4 Findings of energy portfolio analysis

7. within the GCF's energy investments

7.4.2 Comparison of small- and utility-scale energy investments from the perspective of the integration of women's empowerment
7.4.3 Comparison of GCF energy investments implemented by different types of accredited entities from the perspective of the integration of women's empowerment

7.4.4 Comparison of climate investments implemented in dedicated mitigation energy projects vs. cross-cutting energy projects

7.5 Discussion

7.6 Conclusions

\section{Chapter 8: Conclusion}

8.1 Key findings from the existing discourses on the participation of women and women organisations

8.2 Approach of the thesis

8.3 Overview of the key findings

8.3.1 Policy strategies that support the participation of women and women organisations

8.3.2 Institutional strategies that support the participation of women and women organisations

8.4 Contributions

8.4.1 Theoretical contributions

8.4.2 Methodological contributions

8.4.3 Policy contributions

8.5 Areas for future research

\section{References}

Summary

Samenvatting

About the author

Annex 1. Policy frame analysis of women's engagement

in UNFCCC-led climate change governance

Annex 2. Policy frame analysis of the engagement of women organisations in UNFCCC-led climate change governance

Annex 3. Policy frame analysis of the engagement of other actors associated with gendered functions and outcomes in UNFCCC-led climate change governance

Annex 4. Analysis of GCF energy portfolio from the perspective of women empowerment 


\section{LIST OF FIGURES}

Figure 1. Concept map of the thesis

Figure 2. Number of UNFCCC decisions referring to gender issues

in 2001-2019

Figure 3. Key UNFCCC policy developments related to gender

and women's engagement issues

Figure 4. Three levels of UNFCCC-led governance architecture

Figure 5. UNFCCC's decision making governed by COP/CMP/CMA

Figure 6. Governance of the UNFCCC's Financial Mechanisms and funds

Figure 7. National level UNFCCC-led decision making

Figure 8. UNFCCC-guided legitimation channels

Figure 9. Dynamics in the attention to women's participation across

legitimation channels 2009-2020 (combo chart)

Figure 10. Orchestrating the engagement of women organisations in

UNFCCC-led climate finance decision making

Figure 11. Existing orchestration approaches

Figure 12. The composition of the WGC (as of 2021)

Figure 13. Overview of the GCF energy generation and access portfolio

Figure 14. Analysis of the GCF energy portfolio from the perspective of

women's empowerment (WE)

Figure 15. The integration of women's empowerment issues in energy

generation projects implemented at utility and small scales

Figure 16. Variations in the integration of women's empowerment issues

in energy generation projects implemented by international

and direct access entities

Figure 17. Variations in the integration of women's empowerment issues

in public vs. private energy generation projects

Figure 18. Variations in the integration of women's empowerment issues

in cross-cutting vs. dedicated mitigation energy generation projects

\section{LIST OF TABLES}

Table 1. Overview of case-studies selection

Table 2. Sources of legitimation for women (in UNFCCC decisions and project documents adopted in 2009-2020)

Table 3. Sources of legitimation for women organisations (in UNFCCC decisions and project documents adopted in 2009-2020)

Table 4. Women's empowerment results areas in climate investments

Table 5. Assessment criteria for the quality of policy

and institutional strategies

\section{ABBREVIATIONS}

AF Adaptation Fund

AFB Adaptation Fund Board

BINGO Business and industry non-governmental organisations

BR Biennial Report

BUR Biennial Update Report

CEDAW Convention on the

Elimination of all Forms of

Discrimination Against Women

CMA Conference of the Parties that

serves as the meeting of the Parties to the Paris Agreement

CMP Conference of the Parties that serves as the meeting of the Parties to the Kyoto Protocol

COP Conference of the Parties

CSOs Civil society organisations

CTCN Climate Technology Centre and Network

DAE Direct Access Entity

ENGO Environmental non-

governmental organisations

GAP Gender Action Plan

GCF Green Climate Fund

GCT Gender and Climate Tracker

GEF Global Environmental Facility

GHG Greenhouse gases

IPCC Intergovernmental Pane

on Climate Change

IPO Indigenous peoples organisations
LDCF Least Developed

Countries Fund

LGMA Local government and municipal authorities

MDG Millennium Development Goals

NAMA Nationally Appropriate

Mitigation Actions

NC National Communication

NGOs Non-governmental

organisations

OECD Organisation for Economic

Cooperation and Development

RINGO Research and independent

non-governmental organisations

SBI Subsidiary Body for

Implementation

SBSTA Subsidiary Body for Scientific and Technological Advice

SCCF Special Climate Change Fund

SCF Standing Committee on Finance

SDG Sustainable Development Goals

SIDS Small Island Developing States

TNA Technology Need Assessment

TUNGO Trade union non-

governmental organisations

UNFCCC United Nations Framework

Convention on Climate Change

WGC Women and Gender

Constituency

YOUNGO Youth non-governmental

organisations 
CHAPTER 1: Introduction

UNDERSTANDING POLICY AND INSTITUTIONAL STRATEGIES TO SUPPORT THE PARTICIPATION OF WOMEN AND WOMEN ORGANISATIONS WITHIN UNFCCC-LED CLIMATE CHANGE GOVERNANCE

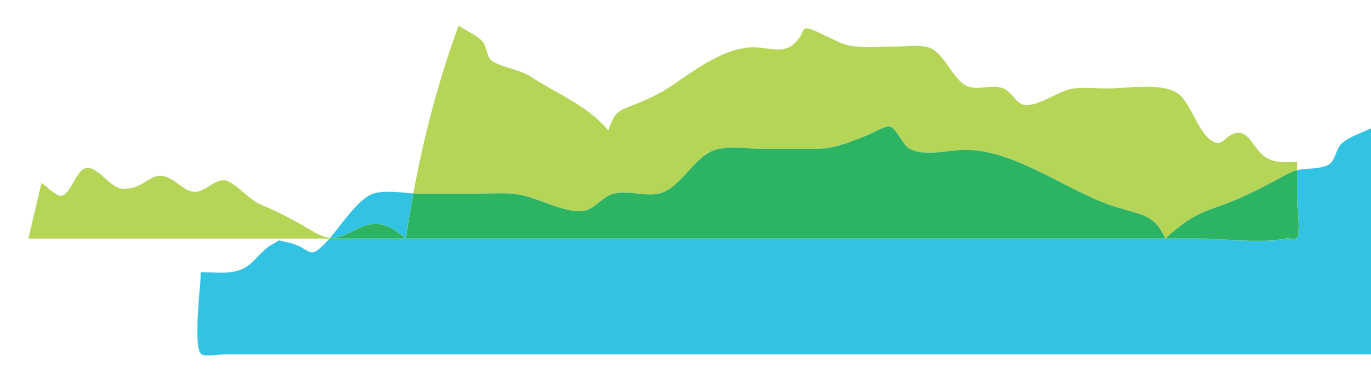




\subsection{RATIONALE FOR THE RESEARCH}

The research is focused on the participation ${ }^{1}$ of women and women organisations ${ }^{2}$ in climate change decision making (including the associated climate finance decision making) guided by the UNFCCC. The choice for the topic of this research was driven by my personal interest, which comes from over 15 years of professional experience with multilateral climate change decision making. In addition to my insights as a practitioner, an investigation of the academic literature, which is presented in Chapter 3, increased my confidence in the timeliness of the research.

The research is aligned with policy and public interest in gender equality and climate change, which has grown over the last decades. In the last four years, 33 countries have announced climate change as a national emergency and an increasing number of governments have started developing national low carbon and climate resilient strategies. ${ }^{3}$ Women's rights and political participation have been under political deliberation for almost 40 years, since the adoption of the Convention on the Elimination of All Forms of Discrimination against Women (CEDAW) in 1975. However, initially, these discourses (i.e. climate change and gender equality) developed in parallel. The intersection of climate change and gender equality has only recently begun receiving attention in the academic literature and in policy deliberations (see Chapter 2).

Against the backdrop of growing attention to climate change issues, existing climate change policymaking has been criticised for a lack of ambition and transparency, as well as limited collaboration with a range of stakeholders (Abbott 2014; Meadowcroft 2009). Scholars suggest that wider participation, including of lobbying groups and indigenous communities, can play an important role in improving climate change decision making, lead to an enhanced level of climate change ambitions, and foster the implementation of more inclusive climate change policies (Chan et al. 2015; Larson 2002; Biermann et al. 2009). Broader participation of various stakeholders has been at the centre of climate change agendas, because climate change solutions require global action to produce innovative and transformative ideas and halt the global temperature rise (Winkler

Within the context of the UNFCCC-led governance, which is a political process, it is difficult to delineate political representation from public participation. Therefore I use a broader term participation, which encompasses both forms of participation.

2 Institutions and arrangements that have three essential elements: associate themselves with women as a group, use explicitly gendered language, and ideas that are expressed by women representing women (McBride and Mazur, 2013).

$3 \mathrm{https}: / /$ climateemergencydeclaration.org/climate-emergency-declarations-cover15-million-citizens/ (accessed in February 2021).
2016; Boodoo, Mersmann, and Olsen 2018; Pelling 2011; Olsen and Fenhann 2016; Park 2012; Williams 2016). Participation presents a very challenging topic within the context of climate change governance, whose complexity has increased considerably over the last decade due to increased number of policies adopted and issues that have been identified in relation to climate change. Generally, the intricacy of the multi-level United Nations Framework Convention on Climate Change (UNFCCC) decision making has not been captured adequately in the existing research. In particular, even though the UNFCCC is the main forum of global climate change governance (Dorsch and Flachsland 2017), there has been limited attention to UNFCCC-led climate finance (Bird, Watson, and Schalatek 2017). This thesis makes a contribution to understanding of the governance of the UNFCCC.

Language referring to gender issues has been present in UNFCCC policies for almost 20 years and women and women organisations are an important part of these policy narratives (Chapter 2). Women and women organisations represent new governance actors, whose roles in climate change governance are understudied and not well understood. However their contribution through participation could be important for making climate change policies more ambitious, equal and gender-responsive, as hinted by some studies, because women, who own traditional knowledge ${ }^{4}$ can drive transformation and innovation and increase the gender equality and sustainability of climate change actions (Alston 2013; Hebtezion 2013; Salehi et al. 2013). Importantly, while some scientists have looked at the role of women in climate change decision making, women organisations are mostly overlooked in the climate change governance literature. However, the abilities of women organisations to synthesise the positions of various women groups and to lobby for gender equality are well recognised in feminist literature (True 2003; Annesley and Gains 2010; McBride and Mazur 2013; Mackay, Kenny, and Chappell 2010; Larson 2002).

This thesis looks holistically at decision-making practices across the three layers of the UNFCCC-led governance: decision making by the Conference of the Parties (COP), decision making by the UNFCCC's Financial Mechanisms, and decision making at the national level (see Section 2.2 for further detail).

Policymakers have been pressured by civil society to demonstrate that they do not only acknowledge participatory rights and provide the least represented groups with opportunities to participate in decision making, but that the participation of these groups is instrumental in providing contributions to the development of climate solutions. (Dauvellier et al., 2016; Kronsell, 2013; Tanaka

${ }^{4}$ Knowledge that is passed on from generation to generation within a community. 
\& Bhandari, 2016; UN WOMEN, 2016; Doss et al., 2011). The inclusion of women and women organisations requires progressive engagement practices (AroraJonsson 2011; Resurrección 2013; Tuana 2013). Aiming merely at inclusiveness of participatory processes without focusing sufficiently on the instrumental value of participation ${ }^{5}$ could be detrimental for addressing climate dilemmas, because tackling climate change issues requires solutions that are tangible and developed with the consideration of the limited time that is left to halt irreversible damage from climate change. I adopt the term meaningful to refer to participation that supports and considers both the quality of participatory processes and the outcomes of these participatory processes (Burns and Heywood 2004)

However, the existing evidence on instrumental participation (such participation that contributes to the development of climate change solutions) is mixed and extremely limited (Annesley and Gains 2010) and has been criticised for a lack of attention to the democratic credentials of participatory practices (Nasiritousi, Hjerpe, and Bäckstrand 2016; UN WOMEN 2016; Dauvellier et al. 2016; Tanaka and Bhandari 2016; Kronsell 2013; Doss et al. 2011). In response to this, this thesis offers an integrated approach to understanding the participation of women and women organisations within the UNFCCC-governance system. The research argues that understanding of the existing policy and institutional strategies that are guided by various UNFCCC-led processes and institutions is important for enabling meaningful participation of women and women organisations. Well designed and implemented policy and institutional strategies can not only increase visibility of women and women organisations (Chapter 4 and 5), but could also enhance their contribution to the development of climate change policies and solutions (Chapter 6), and strengthen the development of their agency through women empowerment (Chapter 7).

The thesis relies on a set of concepts that highlight the role of policy and institutional strategies in supporting meaningful participation. The concept map of the thesis is presented in Figure 1. These concepts are further discussed in Chapter 3 .

${ }^{5}$ Instrumental participation implies that participation is used for achieving specific policy and implementation goals, for example resolving climate change issues and policy dilemmas, enhancing gender responsiveness of climate finance, improving implementation of climate change policies inter alia through the integration of local and traditional knowledge.

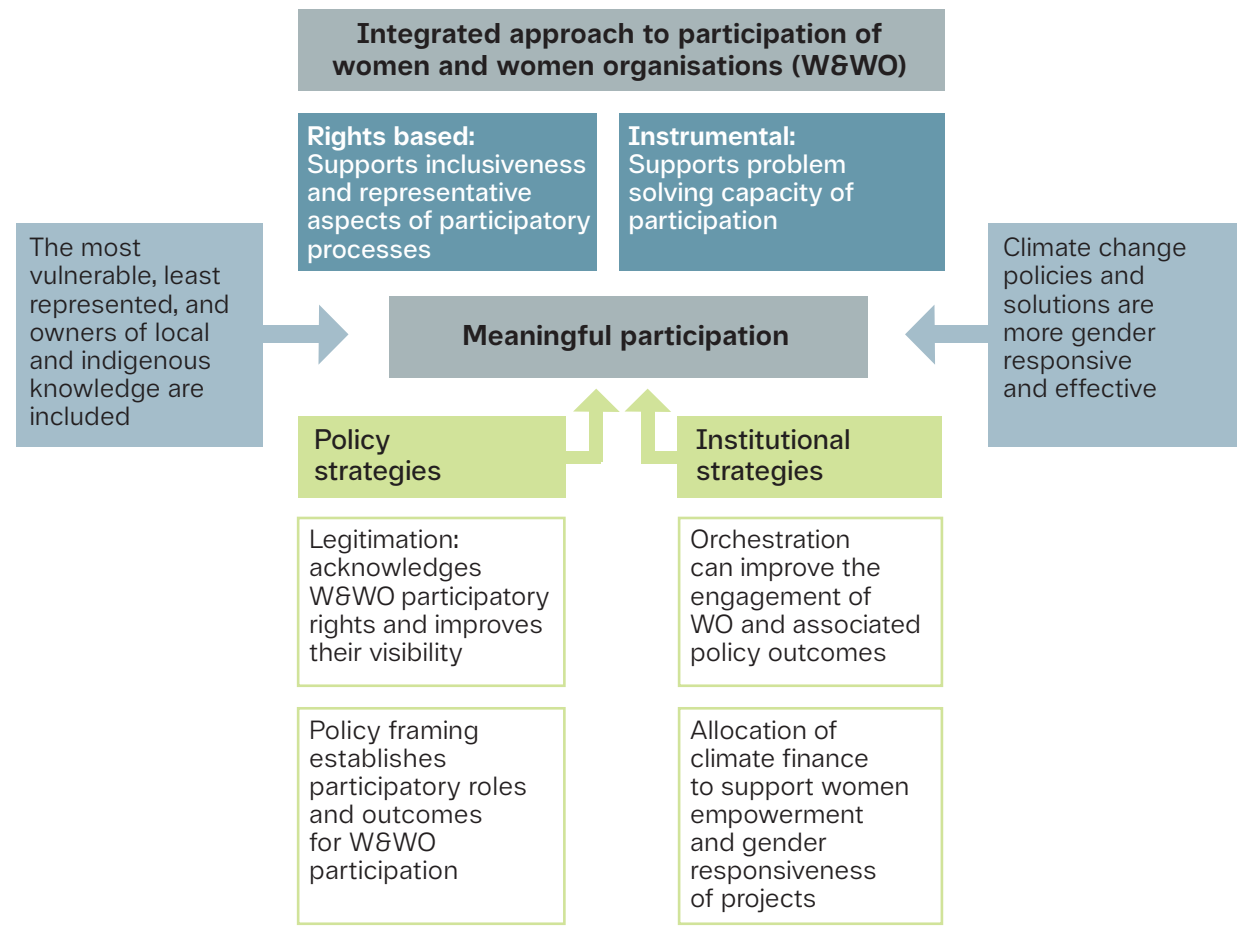

Figure 1. Concept map of the thesis

(Prepared by the author)

The research assists policymakers and practitioners through a description and critical analysis of the existing policy and institutional strategies that support the participation of women and women organisations in the multi-level UNFCCC-led governance system. The analysis of policy strategies (Chapters 4 and 5) focuses on the inclusiveness of policy language in relation to various types of women groups and women organisations and acknowledges the instrumental value of their participation in UNFCCC-led decision-making processes. In addition to complex UNFCCC policy strategies, the thesis analyses institutional strategies for understanding how knowledge produced by policies is transmitted and diffused to practice.

Given the novelty of the research, the thesis proposes and tests initial ideas for understanding the participation of women and women organisations and the quality of institutional and policy strategies using a set of carefully devised single-case studies that could be further expanded to other policy, institutional and national settings. 


\subsection{PROBLEM STATEMENT AND RESEARCH QUESTIONS}

Given the urgency and scale of the climate change problems, it is important to devise climate change policies and solutions that are considerate of gender dimension and are based on local and community knowledge and interests (Harcourt 2018). Women are recognised by policymakers as a stakeholder group whose contribution is imperative for the development and implementation of climate change policies and solutions. For example, the UNFCCC's decisions ${ }^{6}$ suggest that the implementation of its policy ambitions would be more difficult without the involvement of women (UNFCCC 2020, 2016). However, scientific discourse on the role of women is full of contradictions and there is a need for greater examination of their role and contribution in the development of climate change policies and solutions (Vandenbeld 2015).

Women organisations are recognised institutional actors who represent women's interests. Within the UNFCCC, they are mandated to integrate gender equality issues in climate change policies (True, 2003). The UNFCCC's Decision 3/CP.25 (UNFCCC 2019a) acknowledges the role of women organisations in improving the gender responsiveness of climate finance. These recognitions have raised an interest in the contribution that women and women organisations can make in climate change policy formulation and implementation, including climate finance related policies. While the issue of climate finance has been scrutinised by many scholars, existing studies tend to focus on fragments of the existing climate finance decision making, e.g. the UNFCCC's Financial Mechanisms and national level climate funds (Westphal et al. 2015; Terpstra, Carvalho, and Wilkinson 2013; Schalatek 2018; Nakhooda 2013), without looking holistically at decision making across all levels.

Working with gender issues within political processes guided by UN such as UNFCCC has been associated with a few challenges. First of all, working on the intersection of gender issues within political processes guided by UN is known for being extremely challenging and associated with policy contradictions and collusions (Baksh and Harcourt 2015). Secondly, there is a notion that the complexity of UNFCCC's policy discourses has been disincentivising the participation of newcomers including women (Villagrasa 2002). Thirdly, participation has been challenged due to fragmentation of the UNFCCC's governance, because decision making across different levels does not always

${ }^{6}$ Decision is a term that is used by the UNFCCC in relation to policy documents, guidance, action plans and strategies that are deliberated and adopted by COP/CMP/CMA. offer consistent opportunities for governance actors (Marquardt 2017; Bécault and Marx 2016).

Within this context, the research strategy adopted in this thesis responds to the need to (1) increase knowledge on the existing policy and institutional approaches that support the participation of women and women organisations across multi-level UNFCCC-led governance and (2) develop a better understanding of the quality ${ }^{7}$ of existing policy and institutional practices to enable meaningful participation of women and women organisations and ensure the implementation of the UNFCCC's policy ambitions. Therefore this thesis contributes, in two ways, to the knowledge and understanding of the participation of women and women organisations across the multi-level UNFCCC-led governance.

1. There is limited knowledge and evidence on the quality of policy strategies that support the engagement of women and women organisations.

It is well recognised that the UNFCCC's policies have ambiguous language and their rationale and strategies for the engagement of women and women organisations are not well understood (Eyben and Napier-Moore 2009). As demonstrated in Chapter 2, within the UNFCCC's diverse and complex policy narratives, the engagement of women and women organisations has been linked with an array of policy issues, which have gradually evolved from gender balance to linkages with the more complex issues of climate finance effectiveness, enhanced climate actions, and gender-responsive climate policies. These policy narratives are supported by vague terms, such as "gender responsive" or "gender sensitive", which are not yet properly defined or understood by practitioners and the scientific community (Verloo 2016; Jahan 1995). It is recognised that ambiguous language is frequently used as a solution to overcome deadlocks in the UNFCCC's negotiations, however, the use of ambiguous language leads to difficulties with policy implementation (Dekker 2017; Cavaghan 2012). This suggests that greater discursive scrutiny of the UNFCCC's policies is required to make policy strategies and subsequent implementation more robust (Cavaghan 2012; Arnall, Kothari, and Kelman, 2014).

No analysis of UNFCCC policy strategies and their quality with regards to the participation of women and women organisations has been conducted so far. The lack of understanding of the existing policy strategies and their

I develop specific quality criteria for each institutional and policy strategy. These quality criteria are introduced and discussed in Chapter 4, Chapter 5, Chapter 6 and Chapter 7. 
limitations could be detrimental to the implementation of these policies and lead to symbolic participation of women and women organisations, rather than meaningful participation that results in the development of climate change solutions that are considerate of gender inequalities. Policy strategies that support the engagement of women and women organisations in multi-level UNFCCC-led governance are not well understood and no systemic analysis on the various UNFCCC governance levels has yet been conducted. This thesis uses policy framing and legitimation as examples of policy strategies that grant political authority to certain actors (such as women and women organisations) and enable their contribution to policymaking (Tallberg and Zürn 2019). Legitimation as a policy strategy allows policymakers to increase visibility of certain actors. Policy framing is a form of legitimation, which is used by policymakers as an approach to not only make certain actors more visible, but also to narrate specific problems and solutions in relation, for example, to the roles of certain actors and their contribution to policymaking (Koon, Hawkins, and Mayhew 2016).

\section{There is a lack of knowledge and evidence on the quality of the existing} institutional strategies that support the mobilisation of women and women organisations in UNFCCC-led climate finance decision making.

Institutional strategies need to be considered in addition to policy strategies (which describe discursive practices used by the UNFCCC), because studying discursive practices alone is not enough for understanding how knowledge produced by policies is interpreted and applied in practice (Bacchi and Bonham 2014; Bhatia 2007). In this thesis, institutional strategies are the technical and organisational approaches implemented by the UNFCCC's bodies, Financial Mechanisms and organisations at the national level that enable the participation of women and women organisations in UNFCCC-led decision making. The thesis considers two specific institutional strategies - orchestration in relation to supporting the engagement of women organisations in UNFCCCled climate finance decision making and allocation of climate finance using gender mainstreaming to support women's empowerment. Orchestration is a recognised institutional strategy that is used to improve the participation of non-state actors (Abbott et al. 2015). The UNFCCC uses orchestration to enhance the instrumental participation of non-state actors, including women organisations, and improve its decision making processes with the knowledge and connections of non-state actors (Hale and Roger 2014; Bäckstrand and Kuyper 2017). Orchestration is implemented with the support of intermediaries, who have access to relevant actors and are capable of mobilising them to ensure that they contribute to decision making ${ }^{8}$. So far, the orchestration of women organisations, who are recognised by the UNFCCC (the orchestrator) as important non-state actors in relation to climate finance (Decision 3/CP.25), has not been studied.

Women's empowerment is important to ensure the instrumental contribution of women to policymaking processes and to enable more transformative rightsbased participation processes that reduce social marginalisation and suppor just collective action (Eyben and Napier-Moore 2009). The UNFCCC's Financial Mechanisms have developed gender policies that highlight the importance of gender mainstreaming to support the development of low-carbon and climateresilient solutions based on the principles of gender equality and women's empowerment (GCF/B.09/23:88, 2009). However, there is limited evidence and knowledge on how women's empowerment is supported through climate finance allocation practices driven by gender policies developed by the UNFCCC's Financial Mechanisms.

\subsection{OBJECTIVES AND RESEARCH QUESTIONS}

Within the context of climate change governance, there is a need to support more meaningful participation of women and women organisations, because indicative evidence shows that it leads to better and more transformative climate change solutions, which are necessary to limit the global temperature rise (Winkler 2016; Boodoo, Mersmann, and Olsen 2018; Pelling 2011; Olsen and Fenhann 2016; Park 2012; Williams 2016). Meaningful participation is a term that refers to both aspects of participation, i.e. the quality of participatory processes and the outcomes of these participatory processes (Burns and Heywood 2004). As was stated in Section 1.2, this thesis contributes to:

- the understanding of the existing policy and institutional strategies in terms of how they are defined and implemented; and

- to identify approaches in which these strategies could be improved to achieve more meaningful engagement of women and women organisations across the UNFCCC-led governance levels.

${ }^{8}$ The UNFCCC-led climate finance orchestration set up, including relevant intermediaries, is analysed in Chapter 6.

9 https://unfccc.int/sites/default/files/resource/cp2019_L03E.pdf(accessed in June 2021) 
This is achieved using the following two research strategies:

- Describing and analysing the quality of the UNFCCC's policy strategies that guide how the participation of women and women organisations is understood and shaped across the three levels of UNFCCC-led decision making; and

- Describing and analysing the quality of the institutional strategies of UNFCCC-guided institutions that are utilised to mobilise women and women organisations.

The thesis is developed with a notion that the term quality is a contested and subjective concept, which implies how well something is fit for purpose (Coenen, Huitema, and O'Toole 1998). The thesis looks at how select institutional and policy strategies that support the participation of women and women organisations are fit for engaging women and women organisations. The thesis proposes various definition of quality that are context based and applicable to the policy and institutional strategies analysed as part of this thesis. Chapters $4,5,6$ and 7 provide detailed description on how quality is defined for each institutional and policy strategy, i.e. policy framing, legitimation, orchestration and climate finance allocations.

The research strategies answer the following two research questions:

\section{What is the quality of policy strategies that support the participation} of women and women organisations?

Improving knowledge of policy strategies that support the participation of women and women organisations within UNFCCC-led climate change governance should enhance the meaningful participation of these actors in the development of climate change policies and solutions and support the implementation of the UNFCCC's policy goals. The thesis considers legitimation and policy framing as policy strategies that acknowledge the roles and contribution of specific actors in policymaking and makes these actors more visible (Seckinelgin 2009; Bulkeley et al. 2014). The question is addressed in Chapters 4 and 5 . Chapter 4 describes policy framings that support the participation of women and women organisations in decisions by the COP, the Conference of the Parties that serves as the meeting of the Parties to the Paris Agreement (CMA), and the Conference of the Parties that serves as the meeting of the Parties to the Kyoto Protocol (CMP) and reflects on the quality of these policy strategies. The quality is assessed through the identification of discursive controversies and completeness of policy framings.
Chapter 5 builds on the findings of Chapter 4 and presents an analysis of the legitimation of the decisions adopted at the three levels of the UNFCCC-led governance (the CMP/CMA/COP, UNFCCC's Financial Mechanisms, and the national level), using the example of Georgia. The chapter provides insights into the quality of the existing legitimation using the following criteria: visibility of women and women organisations at the national UNFCCC-led decision making (based on experts' opinion), indication of participation of women and women organisations at the national UNFCCC-led decision making and consistency of policy definitions used at the international and national UNFCCC-led decision making.

\section{How well are institutional strategies operationalised to support} the mobilisation of women and women organisations in UNFCCC-led climate finance?

The thesis considers two examples of specific institutional strategies orchestration in relation to women organisations, and the allocation of climate finance guided by institutional gender policies to support women's empowerment. The answers to Question 2 are provided in Chapter 6 and Chapter 7. Chapter 6 scrutinises the quality of the existing orchestration practices that are used by the UNFCCC to support the mobilisation of women organisations in climate finance decision making. Under UNFCCC, the Standing Committee on Climate Finance (SCF) and Women and Gender Constituency (WGC) are the key intermediaries that support the orchestration of women organisations. To analyse the quality of orchestration of women organisations in UNFCCC-led climate finance decision making, I use the following criteria: the extent of engagement of the relevant intermediaries in climate finance meetings, the extent of the mobilisation of women organisations by the intermediary, consistency across the policy framings used by the orchestrator and intermediaries in relation to women organisations, presence of challenges and barriers to the involvement of women organisations in UNFCCC-led climate finance decision making (based on expert's opinion). The quality of orchestration is demonstrated using documentary evidence of the actual engagement of women organisations in the SCF's meetings and the WGC's network together with an analysis of the consistency of policy language with regards to engaging women organisations. The analysis is supported by experts' opinions on the challenges and barriers to the participation of women organisations in UNFCCC-led climate finance decision making.

Chapter 7 provides evidence on the quality of climate finance allocation practices (from the perspective of integration of women's empowerment issues) within the Green Climate Fund's (GCF) funding (UNFCCC's main Financial Mechanism), and more specifically within the GCF's energy portfolio, which represents the largest funding area of the GCF. To analyse the quality of 
climate finance allocation in terms of supporting women's empowerment, I use the following criteria: the presence of references and specific targets indicating project commitments related to women's empowerment across five impact areas, i.e. education, health, governance, access to information, and economy. The chapter also reflects on various factors, such as institutional and capacity issues of implementing agencies, that could impact the extent of integration of women's empowerment issues within UNFCCC-led climate finance.

\subsection{OVERARCHING METHODOLOGY}

This thesis uses case studies as the main research strategy and each of the research questions is answered through carefully selected cases that represent a specific level of UNFCCC-led decision making (Table 1).

Table 1. Overview of case-studies selection

\begin{tabular}{l|l|l|l}
\hline $\begin{array}{l}\text { Type of } \\
\text { strategy }\end{array}$ & $\begin{array}{l}\text { Name of } \\
\text { strategy }\end{array}$ & Targeted level & Chapter \\
\hline \multirow{2}{*}{ Policy } & Policy framing & International: COP/CMP/CMP & Chapter 4 \\
\cline { 2 - 4 } & Legitimation & $\begin{array}{l}\text { International: COP/CMP/CMP } \\
\text { UNFCCC's Financial Mechanisms: GEF/GCF/AF } \\
\text { National: Georgia }\end{array}$ & Chapter 5 \\
\hline \multirow{2}{*}{ Institutional } & Orchestration & International: SCF & Chapter 6 \\
\cline { 2 - 4 } & $\begin{array}{l}\text { Allocation of } \\
\text { climate finance }\end{array}$ & UNFCCC's Financial Mechanisms: GCF & Chapter 7 \\
\hline
\end{tabular}

Given the novelty of the research topic, single case studies are chosen to test the initial ideas and provide an in-depth outlook on women and women organisations' participatory processes and outcomes within the specific setting, i.e. UNFCCC-led multi-level governance (Denscombe 2017). Neither policy nor institutional strategies for the engagement of women and women organisations in UNFCCC-led governance have been studied in the literature. However case studies do not provide a holistic answer, the single-case study approach is useful for illustrative purposes, since on the one hand, it describes how participation is shaped at the various levels of UNFCCC-led governance, and on the other hand, it demonstrates a methodology for studying participation within multi-level governance frameworks. The methodological approach used by the thesis could be extrapolated to different climate finance policy settings and the analytical insights produced by the case studies could be used for expanding theories on both multi-level climate change governance and the abilities of women and women organisations to contribute to climate change decision making (in other words, their agency).

The case studies were carefully selected to demonstrate how the participation of women and women organisations is operationalised within three different settings of UNFCCC-led decision making, i.e. the COP, the Financial Mechanisms and the national level:

- The UNFCCC COP level is covered by the two case studies presented in Chapter 4 and Chapter 6, which analyse policy and institutional strategies respectively, and present evidence on how the participation of women and women organisations is supported by the UNFCCC's governing and constituted bodies. More specifically, Chapter 4 applies policy frame mapping to analyse how women and women organisations' participation is framed in policies and decisions adopted by the COP (including the CMA and the CMP). Chapter 6 demonstrates how policy constructs developed by the COP in relation to women organisations (as per Chapter 4) are translated into practice and how women organisations are mobilised within UNFCCC led climate finance decision making. It uses the example of the Standing Committee on Finance (SCF), which is one of the key climate finance decision making constituted bodies of the UNFCCC.

- The Financial Mechanisms are covered in a case study in Chapter 7, which analyses the existing climate finance allocation practices by the GCF. The GCF is selected as a case study, because it is the most significant source of climate finance under the UNFCCC. Also, unlike the UNFCCC's other Financial Mechanisms, the GCF was created with a mandate to deliver gender responsive climate finance from the outset.

- The national level is studied using the example of Georgia (Chapter 5), which is selected due to its relatively developed UNFCCC-led climate finance governance landscape that presents various avenues for the involvement of women and women organisations in UNFCCC-led climate change policy processes at the national level. A single country case study is taken as a starting point for testing the methodology for studying participation across the three levels of the UNFCCC-led governance, which could be further expanded to other national settings. 
While each chapter with a case study has a detailed description of the methodology, I would like to introduce the methodological choices and provide a rationale for the selection of certain methods in the current section. Three types of analysis methods have been used:

\section{Policy frame mapping}

\section{Content analysis}

3. Interviews with the UNFCCC's experts, including international and national experts and representatives of women organisations.

Policy frame mapping (as a form of content analysis) has been applied to study the vast number of policy texts and analyse policy strategies that support the participation of women and women organisations within the UNFCCC processes. Frame mapping is a key policy discourse analysis method (Verloo 2016) (Chapter 4). Frame mapping has been conducted using specifically introduced policy frames and with the support of ATLAS.ti software. ATLAS. ti allowed me to code and categorise different policy framings that are used in relation to the participation of women and women organisations, such as anticipated functional roles, outcomes and entry points for their participation.

Content analysis is used to describe the approaches to legitimation across various UNFCCC-led policy channels. The content analysis was carried out using ATLAS Software to identify the sources of legitimation and to study how women and women organisations are defined in the UNFCCC (COP, CMA, and CMP), UNFCCC's Financial Instruments (the GCF, GEF and AF), and the national level.

In total, 746 policy decisions have been studied for the analysis of policy strategies:

- 575 official decisions of the UNFCCC COP;

- 144 decisions by UNFCCC's Financial Mechanisms, including 30 by the Global Environmental Facility (GEF), ${ }^{10} 86$ by the $\mathrm{GCF}^{11}$ and 28 by the Adaptation Fund $(\mathrm{AF}) i^{12}$ and

- 27 documents at the national level in Georgia.

\footnotetext{
10 https://www.thegef.org/documents/policies-guidelines (accessed in March 2021).

11 https://www.greenclimate.fund/about/policies (accessed in March 2021).

$12 \mathrm{https}$ ://www.adaptation-fund.org/documents-publications/operational-policiesguidelines (accessed in March 2021)
}

For the analysis of institutional strategies, content analysis using ATLAS.ti has been conducted to identify how women organisations are defined and referred to in working and technical documents. In total, 397 working decisions and technical documents have been studied:

- 214 substantive SCF documents, including annual reports, background papers, guidance on financial mechanisms, and records on the outcomes of the meetings;

- 31 official submissions of the WGC and their members;

- 120 records of WGC interventions made at the UNFCCC's meetings; and

- 32 project documents of the GCF's supported energy projects.

For the analysis of the policy strategies for the engagement of women, policy texts were analysed using the terms "women" and/or "female/s". For the analysis of the policy strategies for the engagement of women organisations, I studied fragments of policy texts associated with the use of women and/or gender in the names and descriptions of institutionalised or semi-institutionalised actors.

In addition to content analysis methods, I used semi-structured interviews with key UNFCCC and national experts and representatives of women organisations have been conducted to triangulate the findings of the policy discourse and content analysis. Due to social distancing and travel restriction rules because of the COVID-19 pandemic, interviews were conducted remotely. In total, 10 UNFCCC and climate finance policy experts (including nine women) were interviewed for the purposes of this research.

\subsection{STRUCTURE OF THE THESIS}

The thesis consists of eight chapters, four of which present empirical findings. Chapter 1 introduces the problem statement and research questions. Chapter 2 gives an overview of the history of the integration of a gender perspective within UNFCCC policy narratives, demonstrates the complexity of the existing discourse, and introduces the UNFCCC architecture, which accommodates multi-level and multi-actor policy planning. Chapter 2 sets the scene for the substantive chapters that untangle the logic of the UNFCCC's existing discourse and improve understanding on the policies' position with regards to the role and opportunities for women and women organisations across the three levels of the UNFCCC-led decision making. 
Chapter 3 summarises the existing theoretical perspectives from both climate governance and feminist scholarship and demonstrates what analytical constructs are emerging around the participation of women and women organisations within climate change governance frameworks. The chapter concludes with the key conceptual and methodological takeaways that guide the empirical part of the thesis.

Chapter $4^{13}$ introduces the concept of policy strategies that guide the participation of women and women organisations based on the analysis of the UNFCCC's policies adopted by the COP, CMA and CMP. The study utilises policy discourse analysis to untangle the logic of complex UNFCCC decisions and offers insights into how policy frame mapping can be applied to contextualise the engagement of various stakeholder groups within UNFCCCled policymaking, including women and women organisations. In addition, the chapter provides recommendations for policymakers on improving existing policy strategies.

Chapter $5^{14}$ builds on the analysis conducted in Chapter 4 and describes the existing legitimation approaches across the three levels of the UNFCCC-led governance. It assesses their quality and provides an example of how policies adopted at the international level to support the participation of women and women organisations are diffused into practice at the national level. The chapter identifies how women and women organisations are defined in the policy texts adopted by the COP, the UNFCCC's Financial Mechanisms and at the national level of the UNFCCC-led climate change planning, and it analyses the consistency of these definitions. In addition to policy issues, the chapter identifies additional capacity challenges and barriers that affect the participation of women and women organisations in the national UNFCCC-led decision making.

Chapter $6^{15}$ analyses the GCF's institutional practices and provides evidence on how women's empowerment issues are considered for the allocation of climate finance using the example of the GCF's energy portfolio. The chapter proposes

${ }^{13}$ Chapter 4 is under review for publication in Climate Policy Journal:

https://www.tandfonline.com/journals/tcpo20

${ }^{14}$ Chapter 5 is under review in the World Journal:

https://www.mdpi.com/journal/world

${ }^{15}$ Chapter 6 is published as a peer-reviewed book chapter: Frenova S. Climate finance allocation practices to support gender-responsive energy transitions. In

Engendering the Energy Transition. Theory meets policy and practice: South meets North. Eds: Clancy, Joy, Gül zerol, Nthabiseng Mohlakoana, Mari lle Feenstra, and Lillian Sol Cueva. Palgrave Macmillan (2020). a methodology for gauging the extent to which women's empowerment considerations are applied within climate finance investments and offers insights for policymakers on what institutional and capacity factors could affect the consideration of women's empowerment issues within climate finance projects. Chapter $7^{16}$ provides evidence on the mobilisation of women organisations in the SCF's decision making and reflects on the quality of their mobilisation. The chapter demonstrates how orchestration as an institutional strategy is designed and applied to support the participation of women organisations in UNFCCC-led climate finance decision making at the international level. It also provides policy recommendations for enhancing the orchestration of women organisations in UNFCCC-led climate finance decision making.

Chapter 8 concludes with a summary of the key findings and recommendations to address the limitations of existing policy and institutional strategies to support the participation of women and women organisations in the multi-leve UNFCCC-led governance. In addition, the chapter presents methodological theoretical and policy reflections that could guide further policy development and research.

${ }^{16}$ Chapter 7 is published as Frenova S. Orchestrating the participation of women organisations in the UNFCCC-led climate finance governance. Climate (2021): 9(9). UNFCCC-led climate finance governance. Climate (2021): 9(9). 


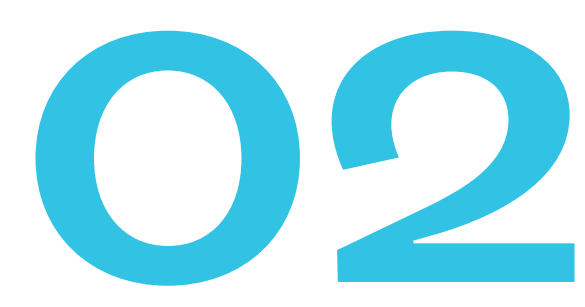

\section{CHAPTER 2: \\ Setting the scene}

UNDERSTANDING POLICY AND INSTITUTIONAL

STRATEGIES TO SUPPORT THE PARTICIPATION

OF WOMEN AND WOMEN ORGANISATIONS WITHIN

UNFCCC-LED CLIMATE CHANGE GOVERNANCE

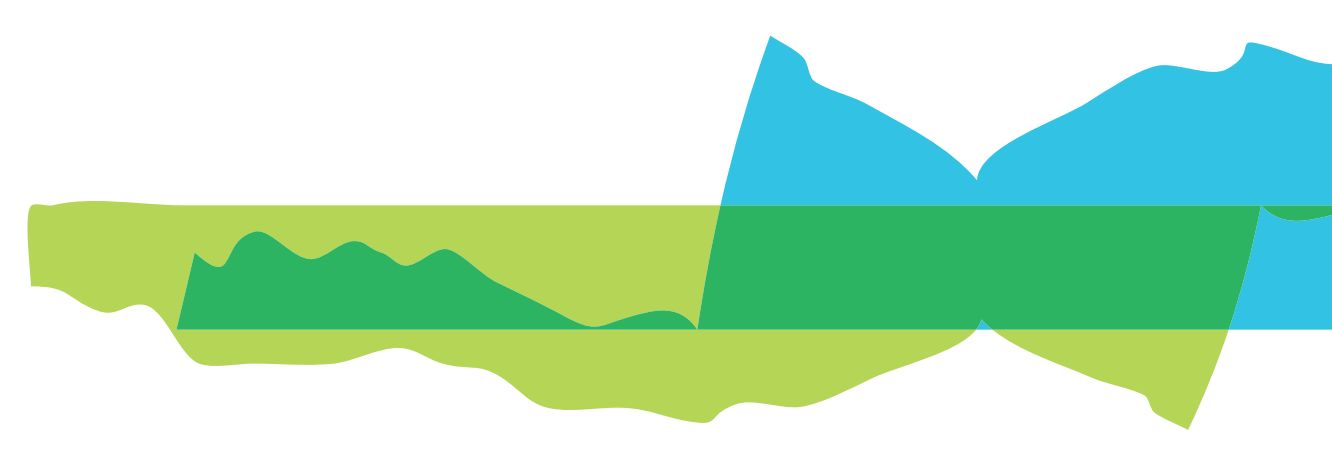




\section{CHAPTER 02}

The chapter provides a historical overview of the integration of a gender perspective within UNFCCC policy narratives and demonstrates how complex the existing UNFCCC policy discourses and architecture are. The chapter lays the foundation for substantive chapters that further unpack the complexity of the existing policy and institutional strategies that guide participation within this complex setting.

\subsection{HISTORICAL BACKGROUND}

The attention to women and women organisations as specific types of actors has increased considerably in the UNFCCC's policies in the last 12 years. The first reference to women's participation was made in $2001 .{ }^{17}$ Following a quiet period, attention to gender issues within the UNFCCC has been on the rise since 2008 (Figure 2). According to the Gender and Climate Tracker (GCT), ${ }^{18}$ there are 70 decisions with references to gender issues, including 13 decisions on improving women's participation in UNFCCC bodies (as of January 2021). The GCT specifically tracks the following gender issues: gender equality, gender mainstreaming, gender balance and recognition of women as vulnerable groups.

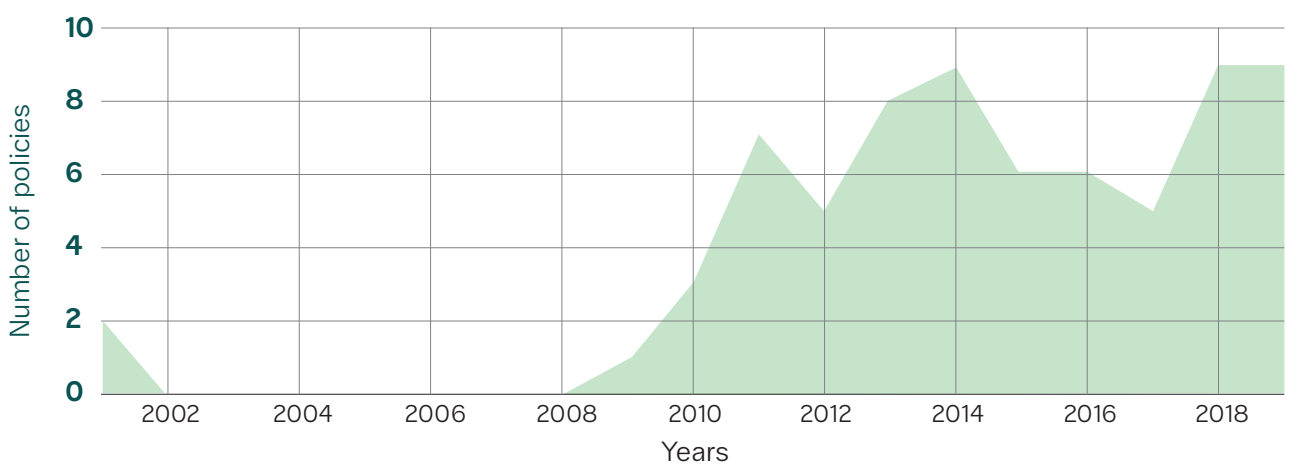

Figure 2. Number of UNFCCC decisions referring to gender issues in 2001- 2019 (Prepared by the author based on GCT data)

The UNFCCC has been actively engaging with gender equality agendas and gender balanced participation. Figure 3 provides a historical perspective on the integration of gender equality issues and the key policy milestones related to the importance of women and women organisations' engagement in UNFCCC policymaking.

7 Decision 36/CP.1 on improving the participation of women in the representation of Parties in bodies established under UNFCCC and the Kyoto Protocol.

18 The Gender and Climate Tracker is an online platform that provides data on gender equality mandates within climate policies at the global and national levels: https:// genderclimatetracker.org/ (accessed in February 2021).

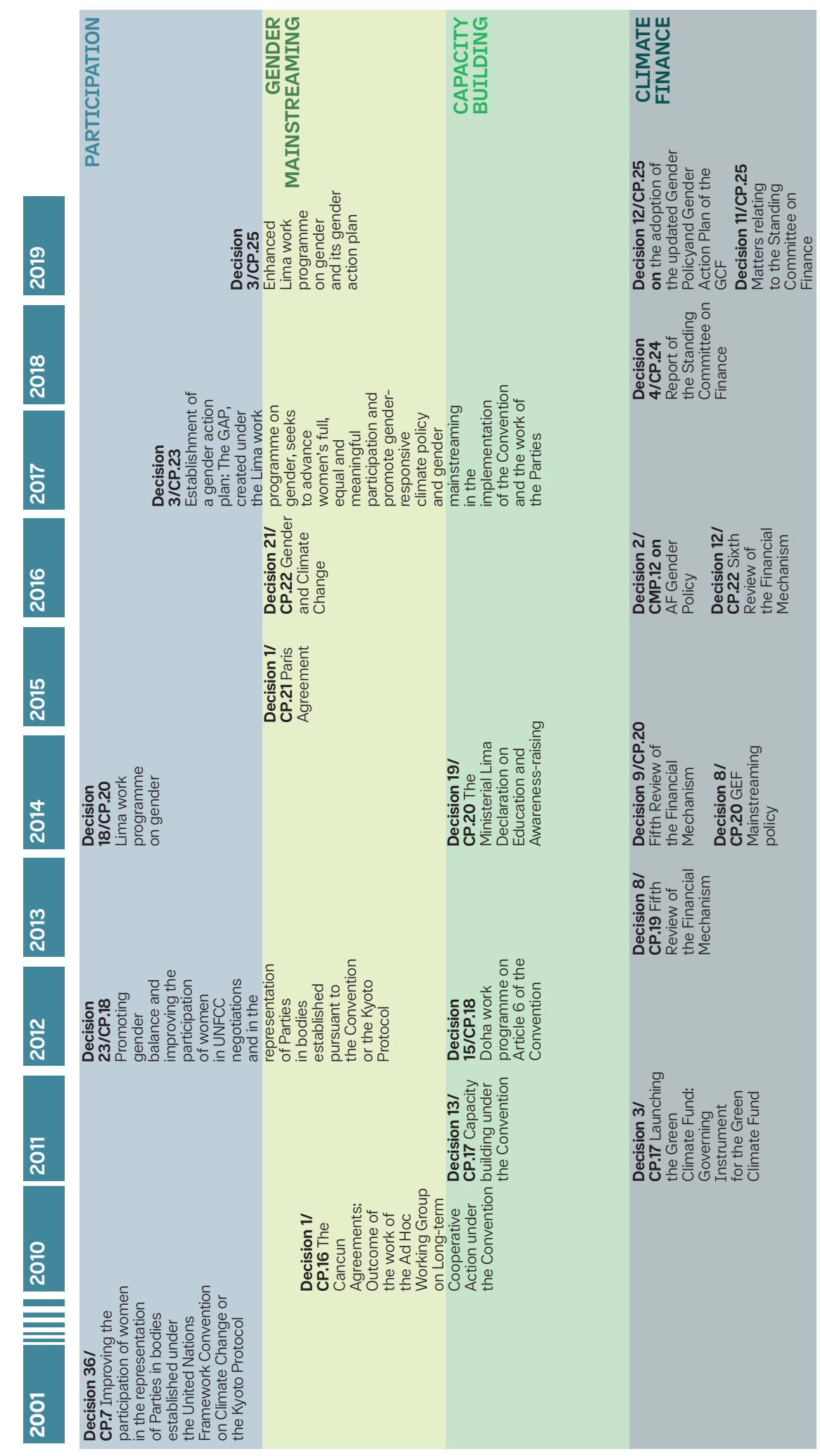


The first decision noting the importance of women's participation was adopted in 2001, i.e. Decision 36/CP.7 on improving the participation of women in the representation of Parties in bodies established under UNFCCC and the Kyoto Protocol (UNFCCC 2002b). The decision refers to the Beijing Declaration of the Fourth World Conference on Women (1995) which highlights the need for women's participation in decision making processes for achieving equality, development, and peace. Following the Beijing Declaration, gender mainstreaming was adopted as the key approach for promoting gender equality, including inter alia through the participation of women (Cavaghan 2012).

Decision 36/CP.7 acknowledged the need for the participation of women from a rights-based perspective which triggered a set of subsequent decisions recognising the need to enhance women's participation in UNFCCC bodies and processes. The decision also required the UNFCCC Secretariat to retain information on the gender composition of its bodies.

Almost nine years after the adoption of Decision 36/CP.7, the Cancun Agreement (Decision 1/CP.16) (UNFCCC 2011) acknowledged that gender considerations are key for planning climate change mitigation and adaptation actions. The Cancun Agreement noted that strengthening capacities at the subnational, national, and regional levels is key to enhancing the engagement of women. Aside from the importance of the rights-based dimension of the participation of women, the Cancun agreement hinted at the instrumental value of women's engagement by noting that "the effective participation of women is important for effective climate action on all aspects of climate change".

Decision 13/CP.17 (UNFCCC, 2012) emphasised the role of women in developing countries as key recipients of capacity building, which is noted by the decision as essential for the effective implementation of climate change commitments. Similarly, the Doha Work Programme on Article 6 of the Convention (Decision 15/CP.18 adopted in 2012) (UNFCCC 2013) recognised the rights and roles of women and grass-root communities as one of the key stakeholders of capacity building efforts leading to better adaptation to the impacts of climate change.

Decision 23/CP.18 (UNFCCC 2013) adopted the goal of gender balance with an ambition to achieve 50\% representation of women in UNFCCC bodies The decision emphasised the instrumental value of women's participation by suggesting that the participation of women leads to more effective and gendersensitive climate policy that addresses the needs of women and men equally.

The Lima Work Programme on gender (Decision 18/CP.20) (UNFCCC 2015b) continued highlighting the instrumental value of women's participation and underlined the connection between gender balanced participation and gender-responsive climate policies. The decision established a two-year work programme to guide the effective participation of women in UNFCCC bodies and thus develop gender-responsive climate policy. Furthermore, the Lima Ministerial Declaration on Education and Awareness-raising (Decision 19/ CP.20) (UNFCCC 2015b) acknowledged that the engagement of women, as well as that of indigenous and local communities, is critical within education and public awareness programmes that are required for implementing effective climate change policies. The Lima Work Programme on gender was supported with the Gender Action Plan (GAP) (Decision 3/CP.23), which aims at advancing women's participation and promoting gender-responsive climate policy in the implementation of the Convention. The GAP calls for gender mainstreaming, the consideration of gender equality and the empowerment of women in the implementation of the UNFCCC (UNFCCC 2018b). The work on promoting women's participation was further extended with the Enhanced Lima Work Programme on Gender and its Gender Action Plan (Decision 3/CP.25) (UNFCCC 2020). The Enhanced Lima Work Programme states that "full, meaningful and equal participation and leadership of women in all aspects of the UNFCCC process and in national and local-level climate policy and action is vital for achieving long-term climate goals". The Enhanced Lima Work Programme on gender and its Gender Action Plan links the participation of women with more gender-responsive implementation and means of implementation (e.g. climate finance) and opportunities for raising climate change ambitions. In addition, Decision 3/CP.25 acknowledges the role of women organisations in improving the gender responsiveness of climate finance.

The 21st meeting of the UNFCCC COP (also known as COP21) in December 2015 led to the adoption of the Paris Agreement (Decision 1/CP.21) (UNFCCC 2015a), which is one of the key policies that formalised the importance of participatory and gender responsive approaches. Within the Paris Agreement, women are noted as vulnerable groups, whose needs have to be considered within the context of climate change adaptation. The Paris Agreement recognises that gender equality and women's empowerment need to be respected and promoted while taking action to address climate change. Article 9 of the Paris Agreement states that the provision of climate finance should take into account the needs of vulnerable people and communities. Shortly after the adoption of the Paris Agreement, Decision 21/CP.22 on Gender and Climate Change came into force (UNFCCC 2016). The Decision reiterated the instrumental value of women's participation in the UNFCCC's process and bodies and its link with gender-responsive climate policies. The Decision notes that further work is required to enhance gender-responsiveness of climate policies and policies related to climate finance (the key means of implementation of the UNFCCC). The Decision also establishes the notion of national gender focal points for UNFCCC-led climate change policy development and implementation. 
Separately, decisions that guide the work of the UNFCCC's Financial Mechanisms have started acknowledging the importance of gender perspective. A larger portion of decisions guides how climate finance should be mobilised and implemented by the UNFCCC's Financial Mechanisms through the development of Gender Policies, i.e. Decision 8/CP.20) (UNFCCC 2015b) and Decision 2/ CMP.12 (UNFCCC 2017). As noted earlier, among all the Financial Mechanisms, the GCF is the only entity that was established as a gender responsive fund from the outset. Decision 3/CP.17 (Launching the Green Climate Fund: A governing instrument for the Green Climate Fund) notes that the GCF should take a gender-sensitive approach within its operations, strive towards gender balance and "develop mechanisms to promote the input and participation of .. civil society organizations, vulnerable groups, women and indigenous peoples" (UNFCCC, 2012:66).

The UNFCCC notes two further things in relation to the inclusion of gender perspective in climate finance. First of all, the UNFCCC encourages the inclusion of gender-related aspects in reporting on climate finance, as well as the extent of involvement of the public, local communities and indigenous people (Decision 4/CP.24 and Decision 12/CMA.1) (UNFCCC 2019b). Second, a gender perspective is noted as important for understanding the effectiveness of Financial Mechanisms. For instance, Decision 8/CP.19 (UNFCCC 2014) and Decision 12/CP.22 (UNFCCC 2016) note that the effectiveness of the Financial Mechanisms should be assessed based on the extent to which they contribute to gender-sensitive approaches.

\subsection{MULTI-LEVEL UNFCCC-LED DECISION MAKING}

Climate change governance frameworks have evolved considerably over the last two decades, but the UNFCCC has remained at the centre of global efforts to mobilise multilateral public climate finance to support climate change mitigation and adaptation (Cohen 2018). Since its establishment in 1992 and full operationalisation in 1994, UNFCCC decision making has also evolved. For example, attention to climate finance has increased considerably, because transformation to low-carbon and climate resilient development requires an unprecedented scale of funding (Williams 2016; Bird 2015; Pickering et al. 2013).

A commonly referred to characteristic of climate change governance and the UNFCCC is that it works across different levels (Ostrom 2010; Newig and Fritsch 2009; Monica Di Gregorio et al. 2019; Carter 2005; Bulkeley et al. 2014). For example, UNFCCC-led decision making has three distinct levels: (1) decision making at the international level conducted by UNFCCC parties, i.e. countries which are signatories to the Convention (Conference of the Parties COP level); (2) decision making by the UNFCCC's Financial Mechanisms, which are institutions with independent management structures that are guided by the UNFCCC's decisions; and (3) UNFCCC-guided decision making at the national level. Figure 3 presents a simplified scheme to elucidate the UNFCCC architecture across these layers.

Within the context of multi-level climate change decision making, participation is necessary to diffuse international norms and good practices to national contexts (Finnemore 1996) and for the establishment of common formal and informal rules across scales (Annesley and Gains 2010). The remainder of this section provides more details on participatory opportunities for both state and non-state actors at each level of UNFCCC-led decision making (as per Figure 4).

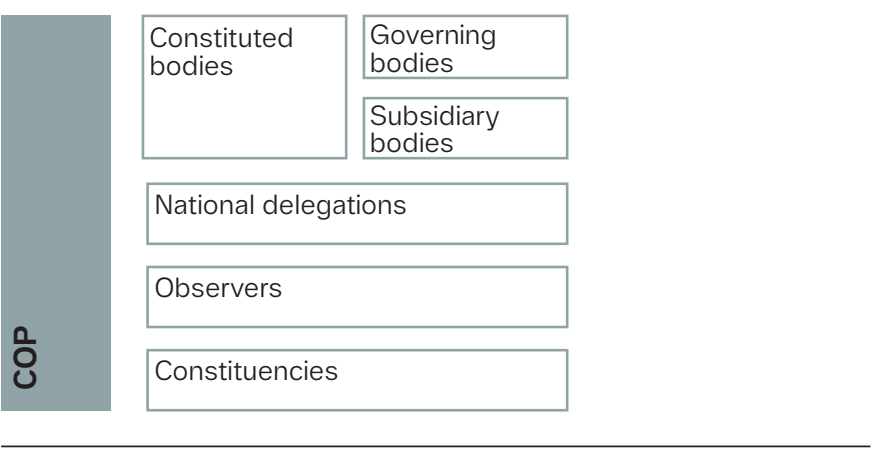

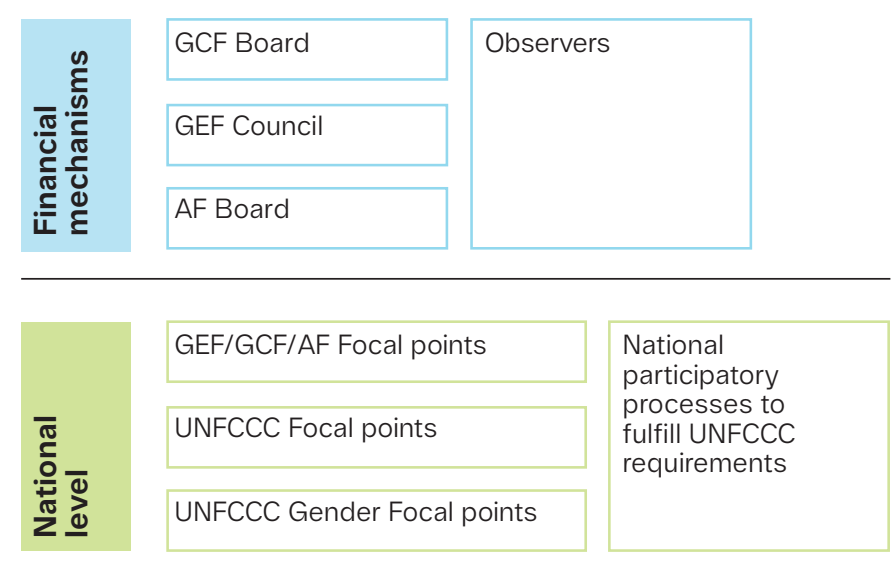

Figure 4. Three levels of UNFCCC-led governance architecture (Prepared by the author) 


\subsubsection{Decision making by the UNFCCC COP}

Figure 5 provides additional details to Figure 4 and demonstrates the institutional setup of UNFCCC decision making by the COP, with a focus on embedded climate finance institutions and bodies that are of crucial mportance for providing policy and technical guidance on climate finance decision making. Figure 5 also provides useful insights on the participatory entry points that exist within the decision making setup by the COP. Figure 5 summarises the information regarding the UNFCCC's governing processes as described on the UNFCCC's web page. ${ }^{19}$

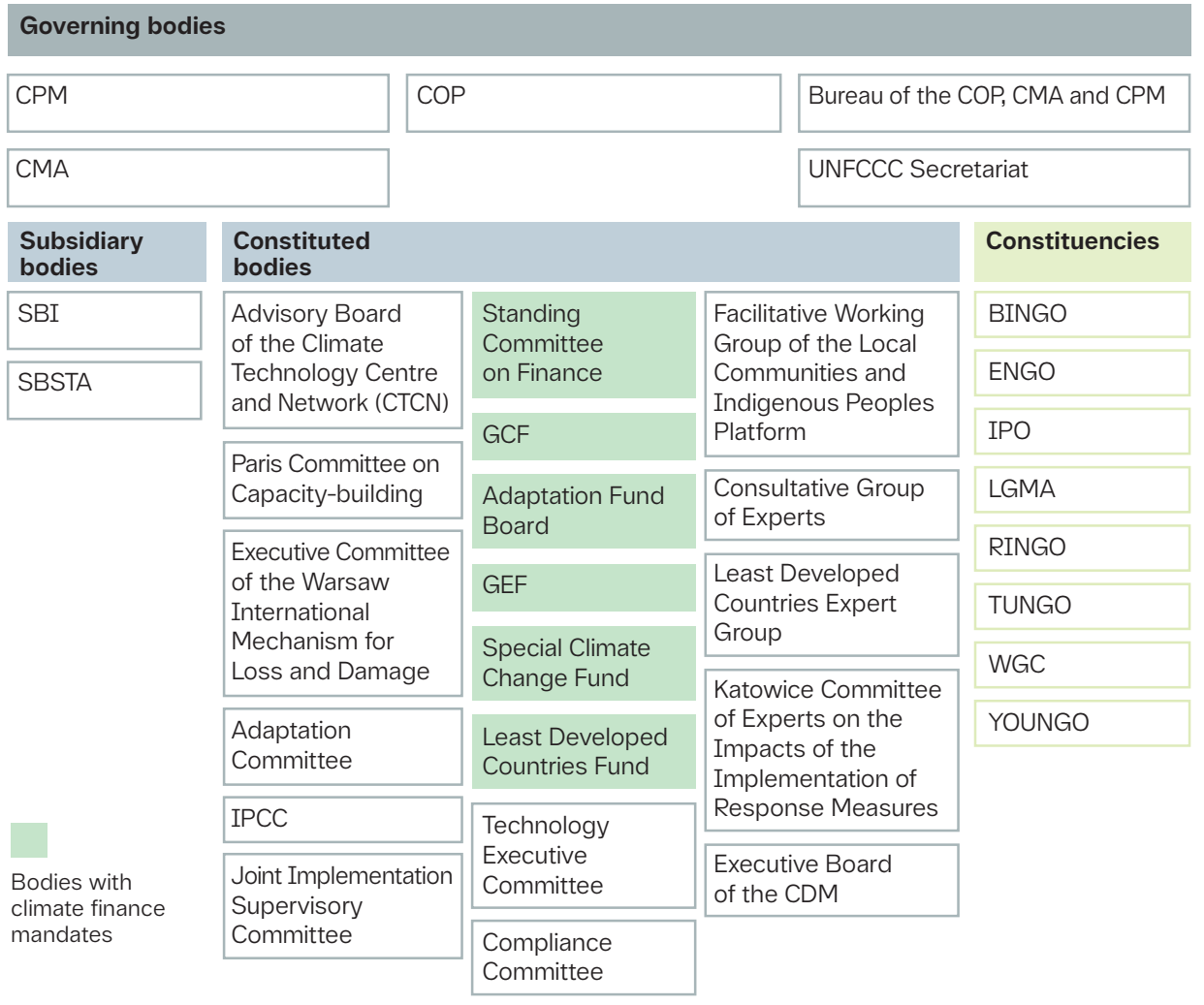

Figure 5. UNFCCC's decision making governed by COP/CMP/CMA ${ }^{20}$ (Prepared by the author)

19 https://unfccc.int/process-and-meetings/bodies/the-big-picture/what-aregoverning-process-management-subsidiary-constituted-and-concluded-bodies (accessed in February 2021).

${ }^{20}$ Based on https://unfccc.int/process-and-meetings/bodies/the-big-picture/whatare-governing-process-management-subsidiary-constituted-and-concluded-bodies (accessed in February 2021).
The COP is the supreme governing body of the Convention and is comprised of the representatives of all country signatories to the UNFCCC. In total, the UNFCCC was signed by 197 countries, who send national delegations comprised of different public sector agencies and occasionally NGOs that participate in policy deliberations (Skovgaard and Gallant 2015). Under the UNFCCC developed countries are expected to provide financial, technological, and other assistance to developing countries (Bach and Davidson 2016). In total, there are three groups of countries which participate in UNFCCC-led decision making: ${ }^{21}$

1. Annex | includes industrialised countries that are members of the Organisation for Economic Co-operation and Development (OECD) and countries with economies in transition, e.g. the Russian Federation, the Baltic States, and several Central and Eastern European States.

2. Annex II includes those Annex I countries which are members of the OECD. These countries are required to provide financial resources to enable developing countries to undertake low-carbon and climate resilient actions. Funding provided by Annex II Parties is channelled mostly through the Convention's financial mechanisms.

3. Non-Annex I countries include developing countries. They are recipients of climate finance and require investment, insurance, and technology transfer

Aside from the main Convention, there are two associated international policy agreements under the framework of the UNFCCC, i.e. the Kyoto Protocol and the Paris Agreement. The COP serving as the meeting of the Parties to the Kyoto Protocol is referred to as the CMP and the COP serving as the meeting of the Parties to the Paris Agreement is referred to as the CMA. The CMP and CMA are supreme governing bodies guiding the implementation of the Kyoto Protocol and the Paris Agreement, respectively (Figure 5). The work of the COP CMP, and CMA is supported by Bureaus of the COP, CMP, and CMA, which are comprised of the representatives of the UNFCCC's country signatories. The main function of the Bureaus is to provide advice on the work of the UNFCCC Secretariat and guide the organisation of working and meeting sessions. The UNFCCC secretariat provides administrative and technical support for UNFCCC negotiations.

Other supporting decision-making bodies are elected from the representatives of country signatories and tasked with various responsibilities. For example, the UNFCCC subsidiary bodies provide support to the governing bodies on various matters. The Subsidiary Body for Scientific and Technological Advice

${ }^{21} \mathrm{https}$ ///unfccc.int/process/parties-non-party-stakeholders/the-big-picture/what-areparties-non-party-stakeholders (accessed in February 2021). 
(SBSTA) provides scientific and technological advice, and the Subsidiary Body for Implementation (SBI) assists with the assessment and review of the implementation of the UNFCCC, Paris Agreement, and Kyoto Protocol, and advises the Secretariat on how to enhance climate change ambitions. The constituted bodies (or technical subsidiary bodies) have limited membership and provide technical support and guidance to the Parties on various matters such as capacity building, climate finance, loss and damage, technology transfer, etc. (see Figure 5). Within the constituted bodies, there is a range of bodies that are mandated to provide technical guidance on climate finance issues, i.e. the Standing Committee on Climate Finance (SCF), the Adaptation Fund Board (AFB), the Green Climate Fund (GCF), the Global Environment Facility (GEF), which includes the Special Climate Change Fund (SCCF) and the Least Developed Countries Fund (LDCF), which are managed by the GEF.

The SCF was established as part of the Cancun Agreement adopted during COP16. The SCF was founded to improve the delivery of climate finance, enhance the effectiveness of the Financial Mechanisms of the Convention, and support measurement, reporting and verification (MRV) of funding provided to developing countries. The SCF includes 20 members that represent the developed (Annex I Parties) and developing countries parties (non-Annex I Parties), including those from the Least-Developed Countries and Small Island Developing States (SIDS), who are especially vulnerable to climate change. Members are expected to have knowledge of climate change and development finance. In accordance with UNFCCC Decision 36/CP.7, membership of the SCF is assigned with consideration of gender balance. The SCF assists the UNFCCC with the coordination of climate change finance, including the mobilisation of financial resources, and measurement, reporting and verification of funding resources.

The GCF and the GEF (including the SCCF and the LDCF), the main operating entities of the Financial Mechanisms of the UNFCCC, and the AFB are mandated to report to the COP on the disbursement and implementation of climate finance. While these entities present constituted bodies and are requested to report to the COP and operate in line with the COP's guidance, they also are set up as separate institutions with appropriate governance structures. ${ }^{22,23,24}$ This additional layer of governance is presented in Figure 6.

In addition to the participation of state representatives of country signatories (Parties to the UNFCCC), there are several opportunities for non-state (non-

22 https://www.greenclimate.fund/about/governance (accessed in February 2021).

${ }^{23} \mathrm{https}: / /$ www.thegef.org/about/organization (accessed in February 2021).

24 https://www.adaptation-fund.org/about/governance/board/ (accessed in February 2021) party) actors to participate in the UNFCCC. First of all, non-party organisations can be admitted as independent observer organisations to the UNFCCC process. ${ }^{25}$ Also, there are caucuses of different civil society, industry and business organisations, which systematically communicate with the Secretariat and country signatories and share their positions. These caucuses have been formed into constituencies, which are voluntary, non-binding coordination mechanisms. ${ }^{26}$ As of January 2020, there were nine constituencies: Business and industry NGOs (BINGO), Environmental NGOs (ENGO), Farmers Indigenous people organisations (IPO), Local government and municipal authorities (LGMA), Research and independent NGOs (RINGO), Trade union NGOs (TUNGO), Women and Gender, and Youth NGOs (YOUNGO). ${ }^{27}$

\subsubsection{The UNFCCC's Financial Mechanisms}

The UNFCCC has established two key Financial Mechanisms to facilitate the implementation of the Convention, the GCF and the GEF, ${ }^{28}$ and three special funds, the AF, the SCCF, and the LDCF. During the 21st meeting of the Parties (COP21), the GEF and the GCF were assigned as the key Financial Mechanism of the Convention.

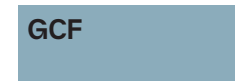

Board

Secretaria

Observers

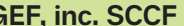

LDCF

AF

Assembly

Counci

Secretariat

Observers

Secretariat

Observers

Figure 6. Governance of the UNFCCC's Financial Mechanisms and funds (Prepared by the author)

25 https://unfccc.int/process-and-meetings/parties-non-party-stakeholders/non-partystakeholders/statistics-on-non-party-stakeholders/statistics-on-admission (accessed in February 2021).

${ }^{26} \mathrm{https}: / /$ unfccc.int/process-and-meetings/parties-non-party-stakeholders/non-partystakeholders/side-events-and-exhibits/admitted-ngos\#eq-2 (accessed in February 2021)

27 https://unfccc.int/process-and-meetings/parties-non-party-stakeholders/non-partystakeholders/statistics-on-non-party-stakeholders/statistics-on-admission (accessed in February 2021).

${ }^{28} \mathrm{https}$ ://unfccc.int/topics/climate-finance/the-big-picture/introduction-to-climatefinance (accessed in February 2021). 
The AF was established in 2001 to finance adaptation projects from proceeds generated through the Clean Development Mechanism (CDM) of the Kyoto Protocol. The GEF has been operational as a financial mechanism since the Convention's entry into force in 1994. The GCF was established in 2010 and designated as a financial mechanism of the convention in 2011. The SCCF and LDCF were established under the GEF's auspices. As noted above, the UNFCCC's Financial Mechanisms and funds have specific governance structures which oversee their operations (see Figure 6). The governance approaches of each of the UNFCCC's Financial Mechanisms and funds are described below.

\section{a. GCF governance}

The GCF is the only stand-alone multilateral financing entity with a sole mandate to implement the UNFCCC. The COP guides the GCF's policies and operations through the Board, which is comprised of developed and developing country signatories to the UNFCCC. The GCF Secretariat is accountable to the Board and is in charge of the day-to-day operations of the GCF. The GCF welcomes observers' inputs to its policies and the Board's decisions (from both civil society organisations and the private sector) and provides opportunities to contribute to decision making by the Board, i.e. two representatives of civil society and private sectors are invited to participate in the Board meetings..$^{29}$ Following the completion of accreditation for observer status, observer organisations can make interventions during meetings at the invitation of the Board's Chairs and they can communicate their position to the Board's members.

Of the Financial Mechanisms, the GCF is the only entity that was created with a gender equality mandate from the outset (Schalatek 2019). Decision 3/CP.17 on launching the Green Climate Fund says that the GCF should take a gender-sensitive approach in its operations, strive towards gender balance and "develop mechanisms to promote the input and participation of ... civil society organizations, vulnerable groups, women and indigenous peoples" (UNFCCC, 2012:66)

b. GEF governance

The GEF Council is the main governing body, which is comprised of 32 members from developed and developing countries, as well as economies in transition. The Council is in charge of the development and adoption of GEF policies and programmes, including those related to the operations of the LDCF and SCCF. The GEF Assembly is another governing body that is composed of all member countries and it is mandated to review GEF policies and operations every

29 https://www.greenclimate.fund/sites/default/files/document/guidelines-observerparticipation-accreditation.pdf (accessed in February 2021). four years. The GEF Secretariat coordinates the implementation of adopted policies and programmes, inter alia in consultation with relevant stakeholders. The GEF Updated Vision to Enhance Civil Society Engagement with the GEF, adopted in 2017, encourages civil society stakeholders to participate in the GEF's events and replenishment process, as well as council Consultations and Meetings, and highlights the importance of the GEF Civil Society Organisations (CSO) Network. ${ }^{30}$ In addition, the GEF has established the Indigenous People Advisory Group ${ }^{31}$ to ensure better engagement and contribution of indigenous people in the GEF's programmes and projects.

c. AF governance

The AF is managed by the AFB, $70 \%$ of which is comprised of developing countries. The AF Secretariat provides administrative and technical support for the implementation of the AF's policies and projects. The AF has encouraged the establishment of the AF NGO Network, which was initiated by Germanwatch, ${ }^{32}$ to improve CSO's engagement in the AF's activities. ${ }^{33}$ The AF has not developed its own observer accreditation process to support the participation of CSOs in the Board's meetings. However in 2021, the AF Board acknowledged the need to enhance civil society participation and engagement in the work of the Board. ${ }^{34}$

\subsubsection{National level UNFCCC-led decision making}

There are a few functional roles and processes in place at the national level which define policy development and planning on climate change issues (see Figure 7). The Paris Agreement (Article 4, paragraph 2) requires each Party to prepare, communicate and maintain Nationally Determined Contributions (NDCs) to reduce national emissions and adapt to the impacts of climate change. ${ }^{35}$ Parties are required to update NDCs at least every five years starting from 2020 (UNFCCC / Technology Executive Committee 2017)

30 https://www.thegef.org/sites/default/files/council-meeting-documents/EN_ GEF.C.53.10.Rev_.01_CSO_Vision_0.pdf (accessed in February 2021).

${ }^{31}$ https://www.thegef.org/content/indigenous-peoples-advisory-group (accessed in February 2021).

32 Germanwatch is an independent environmental NGO that lobbies for socially equitable climate change mitigation and adaptation: https://germanwatch.org.

${ }_{33} \mathrm{https}$ ://www.adaptation-fund.org/af-ngo-network-civil-society-leading-stepsachieve-adaptation-climate-change-vulnerable/ (accessed in February 2021).

34 https://www.adaptation-fund.org/wp-content/uploads/2021/03/AFB.B.36.7Further-enhancing-CSO-engagements_final.pdf (accessed in February 2021).

35 https://unfccc.int/process-and-meetings/the-paris-agreement/nationallydetermined-contributions-ndcs (accessed in February 2021). 


\section{National Climate Change Coordination Bodies}

GCF Focal Point

\section{GEF Focal Point}

AF Focal Point

Figure 7. National level UNFCCC-led decision making

(Prepared by the author)

Nationally Determined Contributions are expected to be designed with the engagement of various stakeholders, as well as with a social, gender and human rights approach (World Resources Institute 2015). Inter-ministerial coordination through National Climate Change Coordination Bodies as well as public and private sector engagement have been identified as a good practice for the preparation of NDCs (Taibi and Konrad 2018).

All countries are required to submit National Communications (NCs) to the UNFCCC every four years (UNFCCC 2012b). National Communications provide a description of national and regional development priorities, objectives and circumstances that are relevant for addressing climate change mitigation and adaptation issues (UNFCCC 2002a). Annex I countries submit Biennial Reports (BRs) to the UNFCCC secretariat every two years, ${ }^{36}$ while nonAnnex I countries can submit Biannual Update Reports (BURs) based on their capacities and available support. ${ }^{37}$ National Communications, BRs and BURs are recommended to be inclusive and participatory with the engagement of civil society organisations (UNFCCC 2012b, 2003). As noted above, Annex I countries are required to provide financial resources to support low-carbon and climate resilient actions in non-Annex I countries. To identify specific areas of support, non-Annex I countries are invited to develop Nationally Appropriate Mitigation Actions (NAMAs) and Technology Needs Assessments (TNAs). Nationally Appropriate Mitigation Actions present opportunities for reducing GHG emissions within the context of sustainable development and in line

36 https://unfccc.int/BRs (accessed in February 2021).

37 https://unfccc.int/BURs (accessed in February 2021). with countries' national development goals. ${ }^{38}$ Technology Needs Assessments allow non-Annex I countries to understand technological options to support the implementation of their climate change ambitions. Technology Needs Assessments usually lead to the development of Technology Action Plans, which set specific actions for the development of needed climate change technologies.

At the national level, communication on UNFCCC related matters, including those involving climate finance, is taking place through assigned National Focal Points, who are in charge of liaising with relevant stakeholders at the national level and fulfilling UNFCCC reporting requirements (UNFCCC 1996) The UNFCCC Financial Mechanisms (GEF and GCF) and AF operate at the national level through a system of focal points and national designated authorities. In addition, UNFCCC Gender Focal Points were introduced (by the UNFCCC Decision 3/CP.25) to support the integration of a gender dimension in UNFCCC-led climate change decision making, implementation and monitoring.

\subsection{CONCLUSIONS}

This chapter has provided a historical overview of the integration of a gender perspective within UNFCCC policy narratives and the existing UNFCCC policy architecture. The chapter demonstrates the complexity of policy discourses and the architecture which can be challenging for those participating who are less familiar with its governance systems. Steering across various decision-making levels is one of the key characteristics of the UNFCCC. Three distinctive layers can be captured to describe UNFCCC-led decision making: (1) decision making at the international level conducted by UNFCCC parties (COP), i.e. countries which are signatories to the Convention; (2) decision making by the UNFCCC's Financial Instruments, which are institutions with independent management structures that are guided by the UNFCCC's decisions; and (3) UNFCCCguided decision making at the national level. This setup creates distinctive avenues to develop policy strategies and deploy institutional approaches to support the participation of women and women organisations.

Women have opportunities to be involved and participate in decision making by the key governing bodies, including the COP for the UNFCCC and associated Kyoto Protocol and the Paris Agreement, constituted bodies (or technica

${ }^{38} \mathrm{https} / / /$ unfccc.int/topics/mitigation/workstreams/nationally-appropriate-mitigation actions (accessed in February 2021). 
subsidiary bodies), country groups, and constituencies. Given the increase in attention to climate finance, the UNFCCC established the SCF and the GCF (as the main Financial Mechanism) in 2010. In addition, the GEF, including the SCCF and the LDCF, has served as one of the Financial Mechanisms since $1996 .{ }^{39}$

Under the UNFCCC's COP, there are also opportunities for women organisations who represent non-state (non-party) stakeholders to participate in decision-making processes as independent observer organisations or as part of constituencies. More specifically, the WGC represents the interest of civil society and non-governmental organisations which work on women's rights and gender justice issues. In addition, UNFCCC-guided climate funds offer opportunities for observer organisations to contribute to funds' decision making. Decision 8/CP.19 notes that the effectiveness of the Financial Mechanisms should be assessed based on the extent to which the financial mechanism is contributing to gender-sensitive approaches.

At the national level, there are a small number of functional roles and processes in place guided by the UNFCCC: NDCs, BURs, NAMAs and TNAs. Broader participation within the context of the UNFCCC is expected to resolve a lack of ambition and transparency of UNFCCC decision making. The importance of the participation of women and women organisations in UNFCCC-led decision making is acknowledged from both rights-based and instrumental perspectives. The UNFCCC policy narratives on the participation of women and women organisations have been evolving since 2001. These narratives are complex and some authors argue that the difficulty of understanding of UNFCCC's policy discourses disincentivises the participation of these actors (Villagrasa 2002). Therefore, discursive scrutiny is required to improve understanding on the existing policy strategies and their limitations that support the participation of women and women organisations.

In addition, participation has been challenged due to the complex architecture of the UNFCCC's governance, which does not always offer consistent participatory opportunities (Marquardt 2017; Bécault and Marx 2016). To improve meaningful participation within this complex set-up, there is a need to understand technical and organisational approaches implemented by the UNFCCC's bodies, Financial Mechanisms and organisations at the national level that enable the participation of women and women organisations in UNFCCC-led decision making.
The chapters below discuss both policy (discursive) and institutional (technical and organisational) strategies across multi-level UNFCCC-led governance, and provide analysis on the quality of these strategies to support meaningful participation of women and women organisations. However, prior to introducing the analysis of policy and institutional strategies in Chapters 4 to 7. Chapter 3 introduces the key definitions and concepts (used in relation to the participation of women and women organisations) that guide the empirical part of the thesis.

39 https://unfccc.int/resource/docs/cop2/15a01.pdf\#page $=55$. 


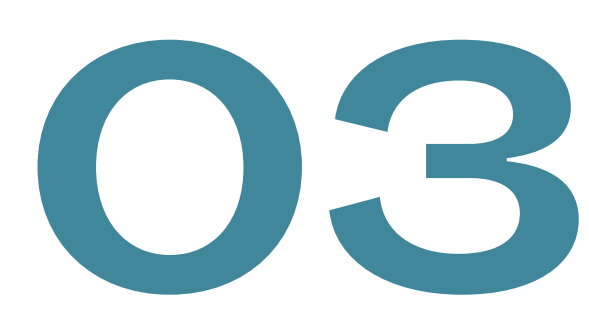

\section{CHAPTER 3:}

Theoretical

perspectives on

the participation

of women and

women organisations

in climate change

governance

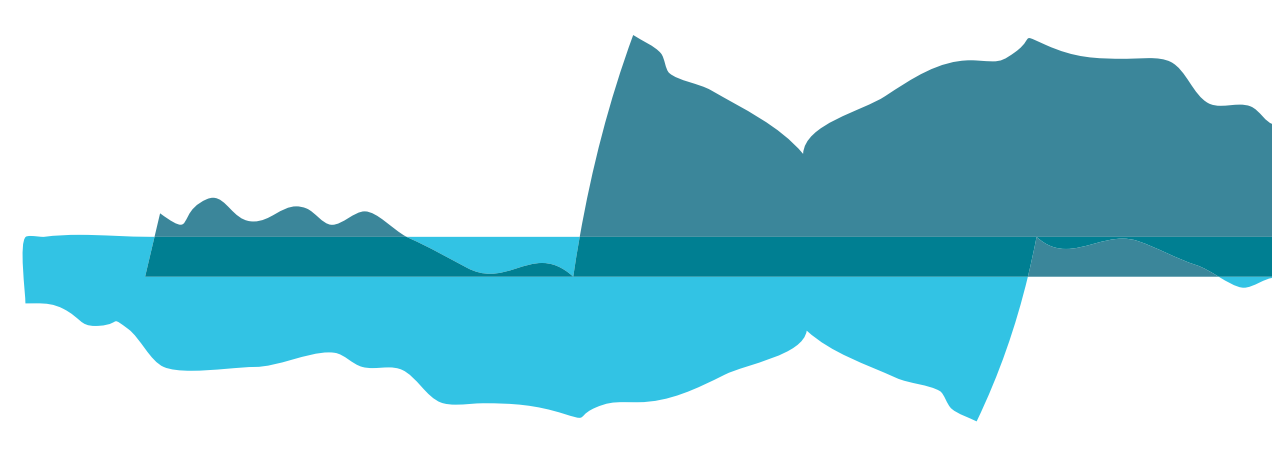

UNDERSTANDING POLICY AND INSTITUTIONAL

STRATEGIES TO SUPPORT THE PARTICIPATION

OF WOMEN AND WOMEN ORGANISATIONS WITHIN

UNFCCC-LED CLIMATE CHANGE GOVERNANCE 


\subsection{INTRODUCTION}

This chapter presents a review of the existing literature and lays the foundation for understanding the participation of women and women organisations within UNFCCC-led governance.

Section 3.2 of the chapter introduces the context, i.e. UNFCCC-led climate change governance, and describes how climate change governance is understood and studied in the academic literature with specific attention to UNFCCC-led decision making. Within broader climate change governance and more specifically within the UNFCCC context, participation and inclusion of various actors are necessary for addressing climate change problems at scale (L. Andonova, Betsil, and Bukeley 2009; Frank Biermann 2014).

While the need for the participation of women is hardly contested, there is a debate on what aspects of participation are important and how its quality and meaningfulness should be defined, i.e. the contribution of participation to problem solving or the fairness and inclusiveness of participatory processes. This is the topic of Section 3.3.

Women and women organisations appear to be mostly overlooked by climate change governance scholarship, however, feminist literature provides evidence on the comparative advantages of these actors and advocates for their involvement in climate change decision making. Section 3.4 demonstrates how the participation of women and women organisations in climate change governance is rationalised by scholars. However, participation is not a proxy for influence, and to enable better participation, specific policy and mobilisation strategies can be used to legitimise and empower women and women organisations. Such strategies are discussed in Section 3.5. Section 3.6 concludes with the key takeaways from the literature review and outlines the gaps in the literature that are further addressed in this thesis.

\subsection{THE UNFCCC AS A CLIMATE CHANGE GOVERNANCE FRAMEWORK}

In simple terms, climate change governance is defined as collaboration through regular interactions across scales when at least one actor is a nonstate agent who does not operate on behalf of a national government or an international organisation (L. Andonova, Betsil, and Bukeley 2009). A more nuanced understanding of climate governance is proposed through different concepts and theories, such as multilevel governance (Newig and Fritsch 2009), earth system governance (Biermann and Gupta 2011), polycentric governance
(Ostrom 2010; Dorsch and Flachsland 2017; Jordan, Forster, and Huitema 2018), and transnational governance (Abbott 2014; Bulkeley et al. 2014). Although none of these researchers take a gender perspective.

The UNFCCC remains one of the important climate change governance arenas and the inclusion and meaningful participation of various actors is essential in the delivery of policy outcomes across governance layers (M Di Gregorio 2019; Abbott 2014; Dorsch and Flachsland 2017; Betsill et al. 2015). Climate finance decision making is an integral part of UNFCCC-led governance, because transformation to low-carbon and climate resilient development requires an unprecedented scale of funding (Williams 2016). In the context of the UNFCCC climate finance is the key means of implementation (Williams 2016) and has an objective to assist developing countries to respond to climate change through the mobilisation of funds from developed countries (Bird 2015; Pickering et al. 2013). Although a large portion of climate finance has been channelled through institutions not associated with the UNFCCC, UNFCCC-led climate finance remains a central element of multilateral public sector climate finance (Bird, Watson, and Schalatek 2017).

Climate change governance is studied in the literature from two key perspectives, i.e. specific architecture, entry points and opportunities to participate and contribute to decision making (the "structure" perspective) (Lawrence, Suddaby, and Leca 2009; Beunen and Patterson 2019) and the abilities of actors to participate meaningfully and create policy changes (the "agency" perspective) (Capello and Harcourt, 2009; Dellas, Pattberg and Betsill, 2011; Cameron, Shine and Bevins, 2013; Colenbrander, Dodman and Mitlin, 2018; Gerlak et al., 2018; Burch et al., 2019). The issues of structure and agency are common analytical constructs that form a foundation for studying the participation and contribution of various actors to decision making.

In the literature, the UNFCCC structure is described as 'polycentric', as it accommodates multi-actor interactions at different levels and policy fields. These levels are decision making by the Conference of the Parties (COP) (Manga 2018; Morgan and Waskow 2014; Blaxekjær and Nielsen 2015; Brunnée and Streck 2013; Okereke and Coventry 2016), the financial mechanisms of the UNFCCC (Gomez-Echeverri and Muller 2010; Mizuno 2011; Antimiani et al. 2017; Harmeling et al 2013), and national level decision making (Stephenson et al. 2019; McKenzie 2021; Jernnäs et al. 2019). Scholars have been interested in understanding the role and agency of various stakeholders, for example, indigenous people (Belfer et al. 2019), youth (Thew, Middlemiss, and Paavola 2021), women (Allan 2021), and broader civil society (Phillips 2018) within these three UNFCCC layers. There is agreement that climate change governance requires responses across multiple scales and actors (Andonova, Betsil, and 
Bukeley 2009; Biermann 2014). Thus, understanding the quality of participation is crucial for enabling the development of effective climate change policies and solutions (Waylen 2007). This can be achieved inter alia through the analysis of participatory processes. More specifically, in relation to climate finance, which is an integral part of UNFCCC-led governance, there is a belief that the allocation of climate finance needs to be supported through genderresponsive and transparent participatory processes (Schalatek and Nakhooda 2014) to ensure the delivery of tangible solutions to communities that are most in need of climate finance (Bécault and Marx 2016; Terpstra, Carvalho, and Wilkinson 2013).

\subsection{PARTICIPATION IN CLIMATE CHANGE GOVERNANCE}

Participation has been a controversial topic, without consensus on how to measure its quality. Several positive qualitative descriptions of participation have been used in the literature, i.e. "meaningful", "effective" and "substantive". Meaningful participation is a term that refers to both aspects of participation, i.e. the quality of participatory processes and the outcomes of these participatory processes (Burns and Heywood 2004). Effective participation uses an outcome-oriented argument to explain the value of engaging various stakeholders (Kochskämper et al. 2018; Newig and Kvarda 2012). However, the use of the term "effective" in relation to participation is considered by some scholars as a strategic ploy so that the issue of participation is taken more seriously by decision-makers (Eyben and Napier-Moore 2009). Substantive participation is also an outcome-oriented definition, used specifically in relation to the participation of women. The idea of substantive participation is based on critical mass theory, which states that once a certain number of women are included in policymaking, they achieve "critical mass", which is necessary for achieving policy outcomes (Inglehart and Norris, 2003; Beckwith, 2007; Celis et al., 2008; Annesley and Gains, 2010).

On the other end of the spectrum, the term tokenism (Arnstein 1969) or "symbolic" has been used to refer to the type of participation that does not include shared decision making with those who traditionally have limited power (Goodman and Sanders Thompson 2017) or allow these stakeholders to influence decision-making processes (Aasgaard, Borg, and Karlsson 2012; Djou et al. 2017).

Despite the diversity in terms and outlooks, three scholarly approaches can be distinguished based on the distinctive arguments they use to explain the value of participation. The first approach is the so-called functionalist approach, which puts governance and policy needs at the centre. In this approach, participation is seen as an instrument to resolve climate change governance issues (Chan et al. 2015). The second approach is based on the rights-based perspective and sees participation as a fundamental right to access to decision making (Mohammad and Farjana 2018), which is linked with the right to non-discrimination and freedom of expression (McMurry 2019). While the functionalist approach is concerned with the achievement of policy goals and specific outcomes associated with participation, the rights-based approach is more focused on the quality of the participatory processes. The functionalist approach argues that participation is of good quality when it achieves policy outcomes. For example, in the case of climate change governance, such outcomes could include just and innovative climate change policies and fair climate finance (Birdsall and Nevers, 2012; Kronsell, 2013; Halimanjaya, Nakhooda and Barnard, 2014; Baatz, 2018; Van Oers, Boon and Moors, 2018). The rights-based approach to participation suggests that participation is of good quality when it is supported through inclusive, legitimate and accountable processes (Biermann and Gupta 2011; Abbott et al. 2015a; Nasiritousi 2017; Schalatek and Nakhooda 2014; Thornton et al. 2011; Terpstra, Carvalho, and Wilkinson 2013). For example, to make participation more meaningful, minor and vulnerable groups, whose interests are often marginalised, need to be included and their voices must be heard (Bäckstrand and Kuyper, 2017; Kirton and Larionova, 2017; Mees and Driessen, 2019; Doshi and Garschagen, 2020).

Both approaches have received criticism in the literature. Functionalists are criticised for an excessive focus on effectiveness and limited attention to the democratic credentials of governance practices (Nasiritousi, Hjerpe, and Bäckstrand 2016). The proponents of rights-based approaches are reminded that focus on processes only could be associated with challenges such as high short-term costs of participation (Coenen 2009) and exacerbated fragmentation of the climate-governance complex (Chan and Pauw 2014).

However, there is a third approach, which suggests that considering inclusiveness and transparency of participatory processes in isolation is not good practice within the context of polycentric climate change governance (or governance beyond the state) (Hogl et al. 2012). Participation needs to be both effective in problem solving, and inclusive and representative in identifying climate change solutions (Bäckstrand, Zelli, and Schleifer 2018). Thus, an integrated approach is required for the development of long-term governance benefits (Bäckstrand Zelli, and Schleifer 2018; Hogl et al. 2012) and some scientists have made efforts to synthesise functionalist and rights-based outlooks into one framework, i.e. the concept of input and output legitimacy. The concept suggests that, on the one hand, transparent, fair, inclusive and accountable participatory processes ensure the input legitimacy of climate change decision making. On the other 
hand, participation contributes to more substantive climate change policy decisions and solutions, which leads to output legitimacy (Bäckstrand, Zelli, and Schleifer 2018; Hogl et al. 2012)

\subsection{WOMEN AND WOMEN ORGANISATIONS AS CLIMATE CHANGE POLICY ACTORS}

As the previous section demonstrates, the issue of participation has been a contested and debated topic in the governance literature. Once attention is paid to the participation of women and women organisations, additional concerns arise, which are mainly studied in feminist literature. This section considers the feminist perspective on the climate change governance issues that have been discussed in the previous two sections.

Feminist literature studies structure and agency issues through a gender lens. In terms of the structure, feminist scholarship is focused on the gender dimension of governance structures, policies and decisions, which are inherently influenced by gender norms (Annesley and Gains 2010). The concept of agency in feminist literature is concerned with the quality of participation of women and women organisations and their abilities to contribute to climate change mitigation (Villagrasa 2002; True and Mintrom 2001). The feminist literature contains arguments that women and women organisations have the ability to support a better integration of gender perspective in climate change governance (Sharma 2010; Sweetman 2002).

The inclusion of a gender perspective is an aspect of gender mainstreaming, which is a tool for taking an integrated approach within policymaking that could address multiple inequalities and lead to better and more genderresponsive policies (Squires 2007; Krizsan, Skjeie, and Squires 2012). Gender mainstreaming, which was established by the Beijing Platform for Action as a key strategy to support gender equality (Cavaghan 2012), is necessary within the context of climate change governance, because climate change has a gender dimension since, it is argued, that different genders have different levels of vulnerability to climate change impacts (Nagel 2015; Chauhan and Vinaya Kumar 2016).40 Most major development organisations and many governments have embraced gender mainstreaming as a strategy for moving

40 While some scientists report that women are one of the most vulnerable groups (Williams 2016), others note that a gender differentiated impact exists under certain conditions and materialises on the intersection of gender equality and poverty, which are associated, but not identical constructs (Sweetman 2002; Clancy, Batchelor, and Skutsch 2003). towards gender equality (Inglehart and Norris 2003). Feminist scholars argue that gender mainstreaming requires the involvement of women and women organisations, since they are the owners of local knowledge on specific gender issues (Salehi et al. 2013) (True 2003; Markham 2013). Also, women and women organisations have a strategic interest in mainstreaming gender in climate policies to make sure that decisions reflect their gendered concerns and needs (Villagrasa 2002; Sweetman 2002).

Similarly to political scientists, feminist scholars apply functionalist and rights based narratives to study participation. The proponents of the functionalist approach draw attention to the advantages of the integration of traditional knowledge owned by women (Salehi et al. 2013) and women organisations (True and Mintrom 2001; Sharma 2010; Larson 2002). For example, in terms of the outcomes, scholars advocate that the participation of women and women organisations in climate change governance could deliver:

- Just and fairer distribution of climate finance that targets the poorest and most vulnerable communities and people (Terpstra, Carvalho, and Wilkinson 2013; Egli and Stünzi 2019; Baatz 2018; Bécault and Marx 2016; Van Oers, Boon, and Moors 2018; Kronsell 2013; Trujillo and Nakhooda 2013; Halimanjaya, Nakhooda, and Barnard 2014)

- Better integration of gender dimensions in climate change policies and climate finance, leading to women's empowerment and reduced gender inequalities (Krizsan, Skjeie, and Squires 2012; Schatalek and Nakhooda 2014; Sharma 2010). For instance, gender responsive climate finance projects can contribute positively to women's health and overall economic and socia development (Clancy et al., 2020; Sweetman, 2002), increase access of women to employment, education and services (Schalatek and Nakhooda 2014), and improve adaptive capacities (Page and Larsen, 2010; Newman and Stephenson, 2010).

- Development of innovative low-carbon and climate resilient policy solutions that are considerate of local knowledge (Sharma 2010; Alston 2013; Hebtezion 2013; Salehi et al. 2013)

The rights-based scholars concentrate on gender imbalances and women's rights and needs (Koczberski 1998; True 2003; Razavi and Miller 1995). They emphasise the engagement of women and women organisations in conjunction with traditionally limited access to resources, information and education among women (Sweetman 2002; Williams 2016; Dankelman 2012; Larson 2002 Godfrey 2012). While functionalist scholars suggest that women's participation needs to be effective to support climate change governance, rights-based scholars are concerned that utilising the argument of effectiveness could shift 
the attention from equality and justice of participatory processes to economic feasibility of participation (Annesley and Gains 2010).

To further understand the specific roles and participation of women and women organisations, the two need to be delineated, since they represent two distinctive types of governance actors. "Women" refers to informal groups and "women organisations" refers to institutionalised or semi-institutionalised entities. The participation of these two types of actors is studied using specific analytical lenses and theories in the literature. The next two sections discuss the literature on each of the groups.

\subsubsection{Women as climate change policy actors}

Women's participation in political processes has been in focus for almost 50 years, since the adoption of the Convention on the Elimination of All Forms of Discrimination against Women (CEDAW), which states that women should be able to engage in politics to address gender equality issues (Squires 2007). However, on some occasions, the focus of gender equality discussions on women only has been criticised, because gender equality or lack thereof affects all genders, not only women (UN Women 2015) and focusing on women in isolation means gender injustice issues are overlooked (Reeves and Baden 2000a). Moreover, some scholars have expressed reservations about presenting women as a homogeneous group of actors who are all able to advocate for women's interests (Annesley and Gains 2010) or want to (Childs and Krook 2009; O'Neil and Domingo 2016). On the other hand, a number of studies argue that women have distinctive qualities which should be harnessed for achieving better outcomes of climate change policies and enhancing the gender sensitivity of policy solutions (Schwerhoff and Konte 2020; Annesley and Gains 2010; Villagrasa 2002). It is believed that women as a group can enhance decision-making processes, particularly when they can draw on their strengths such as networking, interpersonal skills, and abilities to co-operate (Sweetman 2002). For instance, there is evidence that women display greater concern about and awareness of climate change in comparison to men (McCright 2010; Ergas and York 2012), and female leaders tend to more strongly support values that lead to ethical decisions (Adams and Funk 2012).

Despite the arguments supporting the comparative advantages of women as policy actors, the engagement of women does not imply that women's participation has an impact on policy decisions (Chattopadhyay and Duflo 2004), indeed there is a lack of empirical evidence to support these contestations (Annesley and Gains 2010). Nevertheless, some argue that the impact of women on policies could potentially materialise under certain conditions, which is further discussed in Section 3.5

\subsubsection{Women organisations as policy actors}

Feminist scholarship defines women organisations as institutions and arrangements that have three essential elements: associate themselves with women as a group, use explicitly gendered language, and ideas that are expressed by women representing women (McBride and Mazur, 2013). More practically, this can be observed in specific organisational mandates related to women's rights and gender equality and how organisations identify themselves (e.g. organisational names) (True and Mintrom 2001).

In the reviewed literature, women organisations are diverse actors who cannot be put squarely within one category of stakeholders. For example, there are women organisations that represent civil society organisations (Larson, 2002 Sharma, 2010; McBride and Mazur, 2013) and operate at the international, national and local levels (Sharma, 2010). International women's organisations, coalitions and transnational networks have been actively involved in mainstreaming a gender perspective in global public policy (True 2003) and empowering local grassroots organisations and national civil society (True and Mintrom 2001; Sharma 2010; Larson 2002). In addition to civil society women organisations, women's policy agencies are noted in the literature as state gender mainstreaming institutions assigned to promoting the rights, status, and condition of women and gender equality (Annesley and Gains 2010; McBride and Mazur 2013; Weldon 2002).

The extent to which women organisations are able to influence policy depends on a variety of factors, including for example capacity and institutional resources (Sharma 2010; Weldon 2002). Qualities such as clearly prioritised agendas and organisational cohesiveness are considered to increase the likelihood of achieving policy outcomes (Lovenduski 2005). Furthermore, relative power, acknowledged agency and strong policy positions of women organisations can also contribute to the delivery of desirable policy outcomes (Weldon 2002). Emerging from this literature is the argument that to support better engagement of women organisations, specific policy and mobilisation strategies could be applied to enable the contribution of women organisations. Such strategies are discussed in Section 3.5. 


\subsection{STRATEGIES TO IMPROVE THE PARTICIPATION OF WOMEN AND WOMEN ORGANISATIONS}

\subsubsection{Policy strategies to improve participation}

As noted earlier, the participation of women and women organisations is not a proxy for policy influence (Seckinelgin 2009; Annesley and Gains 2010). It is necessary to place governance actors in policy contexts (the structure) to gauge the extent of these actors abilities' to make policy changes, i.e. their agency (Annesley and Gains 2010; Seckinelgin 2009). Agency can be understood as actors' abilities to prescribe behaviour and define purposeful strategies to fulfil particular governance functions (Bulkeley et al. 2014). The development of agency is linked with gaining legitimacy and authority (Tallberg and Zürn 2019). There are a range of perspectives on how legitimacy can be gained.

In political science, agency is understood as normative and prescriptive order deriving from the rules and standards established by policies, while social scientists seek for empirical evidence of agency, based on the beliefs of policy actors about the existing rules and systems (Schmelzle 2012; Bäckstrand, Zelli, and Schleifer 2018; Ferreira and Coronel 2017). In both perspectives, agency is shaped through the perception of the rules as set by policies (social perspective) or actual compliance with the existing policies (political perspective) (Bäckstrand, Zelli, and Schleifer 2018). Feminists scientists analyse agency to understand the ways in which structural constraints affect the distribution of social rules, norms and resources and lead to social and gender inequalities (Kabeer 2021).

The use of specific policy strategies that are communicated through political discourse within institutional contexts can be critical for granting legitimacy to and the development of the agency of specific actors (Daviter 2011; Schmidt 2008). First of all, policies demonstrate how certain ideas are legitimised and how political interests and values are constructed (Schmidt 2008). Secondly, policy narratives are used to make certain issues and stakeholders more visible (Reyes 2011). Legitimation can be used as a policy approach to acknowledge specific actors and their participatory rights in policymaking and to make these actors more visible (Seckinelgin 2009; Bulkeley et al. 2014; Chase 2012). However, it is important to consider not only which actors are acknowledged by policies, but also how and why these actors are acknowledged (Schmidt 2008). Verloo (2016) considers that "why" and "how" are identified through policy framing. Policy framing is a form of legitimation, which is used as an approach to not only make certain actors more visible, but also to define specific problems and solutions in relation, for example, to the participation of these actors (Koon, Hawkins, and Mayhew 2016). Policy framing as a strategy allows policymakers to create policy narratives, for example in relation to the roles and functions of specific actors, and to intertwine these narratives with policy processes and outcomes (van Hulst and Yanow 2016). Policy framing is studied methodologically using critical policy frame analysis (Verloo 2016) which enables the unpacking of policy constructions that shape how specific policy issues are defined through political deliberations and what solution strategies they are matched with (Dekker 2017).

There is evidence that specific policy strategies have a direct impact on the implementation of policies (Daviter 2011; Schmidt 2008; Wahlström and Sundberg 2018). For example, it is recognised that the quality of engagement of civil society organisations that represent the interest of the most vulnerable groups is affected by the UNFCCC's policy constructs (Sharma 2010). More specifically, the complexity of the UNFCCC's policies has limited access to decision making among newcomers (e.g. women organisations) and women who traditionally have limited access to information (Villagrasa 2002; Eyben and Napier-Moore 2009). The same effect is observed within the context of the UNFCCC's Financial Mechanisms. For example, evidence suggests that civil society engagement has been limited in the GEF's decision making due to the existing policy context, which gives space to civil society to voice concerns, but does "very little to ensure that these concerns are acted upon" (Sharma, 2010:5).

\subsubsection{Institutional strategies to improve participation}

In addition to policy strategies, there are a range of institutional approaches that could be deployed to facilitate participatory processes and the delivery of policy outcomes. Two approaches for improving the policy influencing abilities of women have been identified in the literature:

1. Supporting the development of critical mass through gender quotas:

The critical mass theory implies that if at least $30 \%$ of decision-making bodies are women, this creates a critical mass that will allow women to achieve desirable policy outcomes (Celis et al. 2008; Annesley and Gains 2010; Beckwith 2007; Inglehart and Norris 2003; Dahlerup 2006; True and Mintrom 2001). In this regard, the introduction of gender quotas is suggested as an effective approach for achieving critical mass (Squires 2007). More specifically in relation to UNFCCC-led decision making, increasing the number of women in countries' delegations and their promotion to delegation heads is assumed to bring better policy and negotiation outcomes (Villagrasa 2002) However, the evidence supporting the critical mass argument is limited and mixed. For example, Mavisakalyan and Tarverdi's study (2019), which focused on women's participation in national parliaments in 70 countries, provides 
statistical evidence that increased participation of women leads to more stringent climate change policies. The study demonstrates that the change in female representation in national parliaments from $2 \%$ to $37 \%$ "could lead to a 6-fold increase in the stringency of the country's climate change policies" (Mavisakalyan and Tarverdi, 2019: 4). On the other hand, Chattopadhyay and Duflo (2004) question the reliability of cross-sectional comparison studies on women's participation and note that it is difficult to prove the contribution of women's participation on policy outcomes, since outcomes might be affected by other factors such as political preferences, education or religion.

\section{Gender mainstreaming to support women's empowerment:}

Gender mainstreaming could be a transformative tool to support women's empowerment (True 2003; Parpart 2014). Gender mainstreaming is an institutional approach that is embraced by many organisations as a strategy for ensuring gender equality (Inglehart and Norris 2003), while women's empowerment is a means to reduce existing inequalities (Eyben and NapierMoore 2009). Climate change issues cannot be effectively addressed if women are not empowered to participate in climate politics and climate finance implementation (Williams 2016; Page and Larsen 2010; Newman and Stephenson 2010). To enable a better contribution of women to the development of climate policies and solutions, the role of women needs to be shifted from their being passive beneficiaries to their being agents of change to support the effective policy development (Dankelman 2012; Reeves and Baden 2000a). The reviewed literature does not have a commonly accepted definition of women's empowerment, nor a consensus on how it can be measured (Raj 2017). According to the literature, women's empowerment could include such actions as promoting women's economic participation (Ajani, Onwubuya, and Mgbenka 2013), improving access to information and knowledge on climate change technologies (Khapung 2016), the provision of reproductive health services (Page and Larsen 2010), labour market participation and participation in political processes (Konte and Tirivayi 2020), or improving women's access to education and training and equipping them with the expertise to negotiate their interests (Sweetman 2002; True 2003; Reeves and Baden 2000b).

With regards to women organisations, the feminist literature identifies a few organisational strategies that can improve participatory processes and outcomes, e.g. the creation of strategic alliances between different groups of feminist organisations for a common aim, the development of extensive communication and advocacy networks (Vargas and Wieringa 1998; Larson 2002; Villagrasa 2002), and the development of strategies to overcome financial and time-investment barriers to participation in climate fora (Sweetman 2002). These strategies match the term "orchestration" which is applied by governance scholars for analysing the mobilisation of non-state actors in pursuit of policy goals (Abbott et al. 2016; Hale and Roger 2014). Orchestration is an overarching institutional strategy that can be used by intergovernmental organisations to improve the implementation of policy goals through engagement with non-state stakeholders in areas where intergovernmental organisations lack experience, contacts, or authority (Abbott et al. 2015). Orchestration can include such approaches as agenda setting, convening, financial and technical assistance, and coordination (Abbott et al. 2015).

More specifically, the UNFCCC is known for deploying orchestration in the form of soft methods of steering through partner organisations or intermediaries that possess experience and contacts that the UNFCCC does not have (Kuyper, Bäckstrand, and Schroeder 2017). Women organisations have unique expertise and qualities which could be beneficial for the development and implementation of the UNFCCC's policies. For example, women organisations' participation is linked with the integration of a gender perspective in global public policy (True 2003), as well as the promotion of the rights of women and gender equality (Annesley and Gains, 2010; McBride and Mazur, 2013). Also, women organisations can play an important role in fostering the implementation of inclusive policies (Larson 2002), while creating the space for grassroots organisations and empowering local and national civil society (True and Mintrom 2001; Sharma 2010; Larson 2002).

\subsection{CONCLUSIONS}

The section presents the key takeaways from the literature review, including limitations and gaps in the existing studies that require further attention. The literature on climate change governance pays considerable attention to UNFCCC-led governance, which remains one of the most important climate change governance arenas (Betsill et al. 2015; Dorsch and Flachsland 2017; Di Gregorio et al. 2019). However, knowledge about the polycentric architecture of the UNFCCC and interactions across its layers remains limited (Bécault and Marx 2016). The existing studies are mostly focused on fragments of the UNFCCC, e.g its Financial Mechanisms (Worlen, Altevvogt, and Keppler 2020; Hall, Granat, and Daniel 2019) or work of individual UNFCCC bodies (Schalatek and Nakhooda 2014) or national UNFCCC-led policy planning (Stephenson et al. 2019; Pauw and Klein 2020; Jernnäs et al. 2019). Furthermore, the studies on climate finance, which is the key means of implementation of the UNFCCC, are scarce and there is very limited knowledge on the UNFCCC-led climate finance architecture, key agents and their functions (Pickering et al. 2013; Clapp et al. 2012)

Within the context of climate change governance, there has been a recent focus on the participation of various actors and there is growing attention to 
'new agents', which have previously been understudied, including groups who are at risk of being disproportionately affected by climate change impacts (i.e. women and indigenous groups). The literature review demonstrates that while women and women organisations are studied in feminist literature, these types of actors are largely overlooked by climate change governance scholars.

Different analytical constructs (i.e. process oriented or outcome oriented) and terms (i.e. substantive, effective and meaningful) are used to study and describe participation. Within this academic discourse, there is no agreement on how the quality of participation needs to be measured, i.e. through problem-solving abilities or inclusiveness of participatory processes, and what the trade-offs between these two aspects of participation are. On the other hand, there is a consensus that it is difficult to substantiate the problem-solving ability of participation, and the existing evidence on the instrumental value of participatory processes is limited (Newig and Fritsch 2009; Speer 2012)

Gathering evidence on the impact of participation on policymaking processes is challenging (Coenen 2009; Speer 2012; Seckinelgin 2009). More specifically, the empirical evidence on the instrumental value derived from the participation of women and women organisations in climate change governance is mixed and extremely limited (Annesley and Gains 2010). However, it is believed that women and women organisations can contribute to more just climate policies, fair allocation of climate finance and better gender responsiveness of climate policies (Williams 2016; Larson 2002).

Thus, limited knowledge and evidence on instrumental participation are one of the key research gaps that have emerged from the literature review and require further attention. While there is a need to ensure inclusivity of participatory processes, enhancing the instrumental value of participation is of crucial importance for resolving climate dilemmas, which requires the effective contribution of various actors across scales (Andonova, Betsil, and Bukeley 2009; Biermann 2014). If participation does not adequately include relevant stakeholders and contribute to problem solving, it is frequently described as "symbolic" (Goodman and Sanders Thompson 2017; Aasgaard, Borg, and Karlsson 2012; Djou et al. 2017; Vandenbeld 2015).

The evidence suggests that to improve the instrumental participation of women and women organisations, there is a need to develop their agency. Political and governance scholarship suggests that agency could be developed through specific policy strategies that legitimise particular actors, values and ideas (Schmidt 2008). Discursive policy analysis methods have been gaining popularity within political scholarship. The use of such approaches enables an opportunity for studying policy strategies that legitimise the engagement of women and women organisations in UNFCCC-led climate change governance, and, in doing so, presents a rich discursive field that has not been well studied previously.

In addition to policy strategies, specific institutional approaches can be used to facilitate the instrumental participation of women and women organisations. To increase the policy influencing abilities of women, the development of a critical mass of women in decision-making bodies and women's empowerment approaches have been proposed by some scholars (Mavisakalyan and Tarverd 2019; Williams 2016; Page and Larsen 2010; Newman and Stephenson 2010). The evidence collected so far on the impact of critical mass has been criticised for its lack of robustness (Chattopadhyay and Duflo 2004). Supporting the empowerment of women through dedicated technical and financial assistance, on the other hand, is a promising approach. However, this approach lacks conceptualisation and empirical knowledge within the context of climate change governance.

With regards to women organisations, feminist scholars have proposed a few institutional strategies that are applicable to broader global policy contexts, such as financial support (Sweetman 2002; Jahan 1995), institutional strengthening (Terpstra, Carvalho, and Wilkinson 2013), and the creation of partnerships and strategic alliances (Vargas and Wieringa 1998; Larson 2002 Villagrasa 2002). Climate governance scholars use the concept of orchestration to study the mobilisation of non-state actors. However, women organisations as non-state actors are largely overlooked by climate governance scholars. Thus, the concept of orchestration provides an opportunity for studying the mobilisation of women organisations specifically within the UNFCCC context.

The next four substantive chapters describe and analyse the quality of select institutional and policy strategies that are used to support the participation of women and women organisations in the UNFCCC-led governance. More specifically these strategies include:

- Policy framing - a policy strategy that defines "why" and "how" women and women organisations are acknowledged by UNFCCC's policies (discussed in Chapter 4).

- Legitimation - a policy strategy that is used to make women and women organisations more visible in UNFCCC's policy texts (discussed in Chapter 5).

- Orchestration - an institutional strategy that is used by the UNFCCC to engage with women organisations on climate finance issues (discussed in Chapter 6).

- Integration of women empowerment issues within climate finance allocation as an institutional practice of the GCF guided by its Gender Policy (discussed in Chapter 7). 
CHAPTER 4:

Analysis of COP/

CMP / CMA policy

strategies supporting

the participation of

women and women

organisations in

the UNFCCC ${ }^{41}$

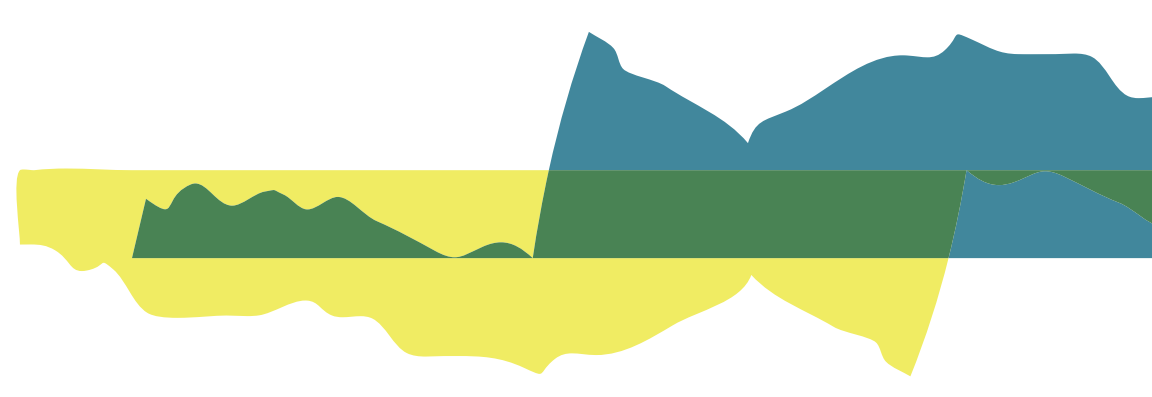

UNDERSTANDING POLICY AND INSTITUTIONAL

STRATEGIES TO SUPPORT THE PARTICIPATION

OF WOMEN AND WOMEN ORGANISATIONS WITHIN

${ }^{41}$ The chapter has been submitted as an article to Climate Policy journal and is

UNFCCC-LED CLIMATE CHANGE GOVERNANCE 


\subsection{INTRODUCTION}

Climate change is a complex problem that requires global efforts to address the issues, including not only the actions of governments but also those of non-state actors such as civil society organisations, local communities, indigenous people, and women groups. The Paris Agreement acknowledges that wider participation is needed for equality and fairness in climate change governance (Bach and Davidson 2016). More specifically, from the perspective of gender equality, the participation of women and women organisations is seen as necessary for engendering policy agendas and solutions to climate change (Larson, 2002; Wong, 2016; Hall, Granat, and Daniel, 2019; Mavisakalyan and Tarverdi, 2019).

Several studies have acknowledged the role of women in providing technical expertise and facilitating the implementation of more ambitious and inclusive climate change policies (Larson, 2002; Wong, 2016; Hall, Granat, and Daniel, 2019). There is empirical evidence supporting this notion (Mavisakalyan and Tarverdi, 2019). Women organisations ${ }^{42}$ are also noted as important actors who can facilitate the integration of gender perspectives in global policies (True and Mintrom 2001; True 2003).

As shown in Chapter 2, policy attention to women and women organisations has been on the rise. Already before the adoption of the Paris Agreement, the importance of the engagement of women in climate change actions was acknowledged in the Cancun Agreement (Decision 1/CP.16) (UNFCCC 2011) and Decision 23/CP.18 (UNFCCC 2013) on promoting gender balance and improving the participation of women in UNFCCC negotiations.

While the participation of women and women organisations in UNFCCC-led decision making is of policy interest, there is little understanding of how the participation of these specific actors is framed in the policy texts and what policy strategies are used to engage them. The lack of understanding of policy strategies that support the participation of women and women organisations and their limitations poses challenges to the development of robust climate solutions and the implementation of UNFCCC's policies.

The objective of this chapter is to analyse whether the existing policy strategies that support the participation of women and women organisations are complete and consistent. The critical policy frame analysis applied in the study allows for untangling the logic of complex UNFCCC decisions. I define

${ }^{42}$ Women organisations are institutions that are described with explicitly gendered language, e.g. their naming and mandates refer to women or gender (McBride and Mazur 2013) policy strategies as specific policy positions and narratives that discursively link and explain women and women organisations' functional responsibilities, roles, entry points for their engagement, and anticipated policy outcomes that these actors are expected to bring to decision making.

This chapter has methodological and policy relevance. Methodologically, it offers insights on how critical policy frame analysis can be adapted to climate change policymaking. More specifically, I show how this method can be applied for contextualising the engagement of various stakeholder groups within UNFCCC-led policymaking. On a policy level, the findings of the study assist policymakers in designing better policy strategies, which can enhance the implementation of UNFCCC policy ambitions with regards to the engagement of women and women organisations.

\subsection{PROBLEM STATEMENT AND RESEARCH QUESTIONS}

The meaningful participation and contribution of women and women organisations to policy processes could be affected by the institutional contexts and policy environments (Sharma 2010). For instance, there is a notion that the complexity of the UNFCCC's decision-making processes has increased considerably over the years and that this has limited women's participation (Villagrasa 2002). It is recommended that in order to support meaningful participation of women and women organisations, the development of specific strategies that encourage women's empowerment, capacity building, and access to decision making and leadership is required (Williams 2016; Page and Larsen 2010; Newman and Stephenson 2010). Therefore, if women and women organisations are to participate in deliberations and make meaningful contributions to climate change policies and solutions, there is a need to understand the UNFCCC's policy strategies that guide and support their participation to ensure that those aspirations are reached.

The UNFCCC's decisions have been described as "an eclectic mixture of old and new clichés, assembled through a complex process of political negotiations, compromises and strategizing" (Eyben and Napier-Moore 2009:6). I refer to differences in how roles, entry points and anticipated outcomes are defined as policy controversies. Complex policy texts are frequently associated with policy controversies, which could be detrimental to establishing clear policy strategies (Dekker 2017). I argue that the lack of policy strategies that establish the specific roles, responsibilities, entry points, and anticipated outcomes for women and women organisations could limit their meaningful participation and contribution to policymaking. 
So far, the analysis of UNFCCC policy narratives and their quality with regards to the participation of women and women organisation has been extremely limited. For example, the Gender and Climate Tracker ${ }^{43}$ (GCT) analyses the UNFCCC's decisions adopted at the international level and provides a count of references to women as a vulnerable group, gender balance, and gender equality. However, the GCT does not track references in relation to women's varied roles, activities, and the outcomes of their engagement and does not provide contextualisation of these references within broader UNFCCC-led climate change governance contexts. Also, the GCT does not include women organisations in its analysis.

Overall, there is very little research and clarity on how women and women organisations' participation is understood within the UNFCCC's policies and what is expected from their engagement. Improving knowledge of policy strategies that support the participation of women and women organisations within UNFCCC-led climate change governance should enhance the meaningful participation of these actors in the development of climate change policies and solutions, and support the implementation of the UNFCCC's policy goals.

The objective of this chapter is to analyse policy strategies that define women and women organisations' functional responsibilities, roles, anticipated outcomes, and entry points for their engagement. If the description of roles, entry points, functions and outcomes is not complete (i.e. these categories are not fully defined for women and women organisations) or inconsistent (e.g. there are mismatches between the anticipated roles, entry points, functions and outcomes), then the policy strategies include so-called policy controversies. I consider the presence of policy controversies is the key criterion for understanding the quality of policy strategies.

The research question is: what is the quality of the UNFCCC policy strategies that define the participation of women and women organisations?

The sub-questions are:

- How is the participation of women and women organisations defined in the UNFCCC's policy texts, including the anticipated roles, entry points, functions, and participatory outcomes?

- Are there any policy controversies in how the participation of women and women organisations is defined?

\subsection{METHODOLOGY}

This chapter uses a methodology which:

- Identifies policy strategies that shape the participation of women and women organisations, by mapping various definitions of women and women organisations that are used in these texts and identifying anticipated functions, roles, outcomes, and entry points for their engagement;

- Assesses the quality of policy strategies based on the presence of potential controversies in policy strategies, which could hamper meaningful engagement of women and women organisations in UNFCCC policies.

The first objective is achieved through policy frame analysis, which is used to map specific actors that could be identified as women and women organisations and to identify processes for their engagement, roles, and outcomes as defined by the UNFCCC policies.

The policy frame analysis conducted in this study covers a set of UNFCCC decisions that have been adopted between 2001 (since, according to the GCT, this is the first reference to women's participation in the decision-making process) and 2019. These policy documents were retrieved from the UNFCCC website: https://unfccc.int/decisions (accessed in February 2021). In total, there were 575 decisions by three governing bodies, the COP, the CMA, and the CMP. These supreme governing bodies are comprised of the representative of all country signatories to the UNFCCC, Paris Agreement, and Kyoto protocol. Within these 575 UNFCCC decisions, there are 374 decisions by the COP (covering 18 meetings from the eighth to the 25th meeting, i.e. COP8 to COP25), 30 decisions by the CMA (covering the first and the second meeting of the CMA, i.e. CMA1 and CMA2), and 171 decisions by the CMP (covering 15 meetings from the first to the 15th meeting of the CMP, CMP1 to CMP15).

The analysis has been conducted using the ATLAS.ti software, in two tracks:

1. Policy strategies for the engagement of women; and

2. Policy strategies for the engagement of women organisations.

${ }^{43}$ https://genderclimatetracker.org. 
I establish five frames to analyse UNFCCC's policy texts. The term 'frame' is used to describe sets of various ideas and arguments that shape policy strategies with regard to the participation of women and women organisations. The five frames are:

- Functions, which describes policy positions that refer to the implementation of specific tasks or activities within climate change policymaking, climate finance, or broader climate actions.

- Processes, which refers to either qualitative descriptions of participatory processes that are envisaged, or specific entry points and opportunities to engage in decision making.

- Outcomes, which includes texts that describe anticipated results of women and women organisations' engagement.

- Roles, which denotes references to women and women organisations' positions and interests.

- Actors, which describes different stakeholders who are mentioned in the policy texts in relation to gendered policy outcomes and/or have gender and women issues embedded in their description.

For the analysis of the policy strategies for the engagement of women, I used "women" and/or "female/s" as a search term and analysed the fragments of texts associated with the use of this term in line with the policy frames described above. For the analysis of the policy strategies for the engagement of women organisations, I adapted the screening criteria for identifying women organisations that have been proposed by McBride and Mazur (2012), i.e. only organisations that explicitly define themselves using gendered language were included in the research (McBride and Mazur 2012). Thus, I searched for references to women and/or gender in the names and descriptions of institutionalised or semi-institutionalised actors.

The second objective is achieved through the interpretation of the findings of the policy frame analysis, which allows for identifying potential controversies and conflicts in policy strategies (Koon, Hawkins, and Mayhew, 2016). I introduce and analyse two types of policy controversies, which are defined in the following way:

- Incomplete framing: This reflects missing definitions of the roles, functions, or outcomes associated with the engagement of identified types of women and women organisations. For example, in relation to certain actors, the policy text could identify specific functional responsibilities but not indicate processes for their engagement or vice versa.
- Inconsistent framing, which is identified through a mismatch between the scope of roles, functions, participatory processes, and outcomes.

\subsection{RESULTS}

\subsubsection{Policy strategies for the participation of women and women} organisations

In total, 20 decisions that refer to women as policy actors have been identified in the reviewed CMP/CMA/COP documents. Additionally, CMP/CMA/COP documents recognise indigenous women and grassroots women as independent categories of policy actors. Indigenous women are described as leaders and solution holders and grassroots women as owners of traditional knowledge. The key roles of these actors, as well as their functional responsibilities, entry points and policy outcomes, are presented in Annex 1.

The policy frame mapping of UNFCCC decisions reveals that women have been increasingly recognised as leaders and are expected to play active roles in chairing and facilitating negotiations. Additionally, they are expected to contribute to more technical processes related to the preparation of national communications, the formulation of climate change efforts, and the design and implementation of climate finance strategies. This requires the development of technical capacities and education, which is also acknowledged in COP and CMA decisions (Decision 15/CP.25; Decision 17/CMA.1; Decision 15/ CP.21; Decision 15/CP.18). In terms of entry points, women are expected to participate in the UNFCCC constituted bodies, national delegations, and climate change decision making at the national, regional, and local levels. As a result of these efforts, women's participation is expected to contribute to gender-responsive climate change policy. Based on the analysis presented in Annex 1 , indigenous and grass-root women are not sufficiently conceptualised in UNFCCC decisions. This is also reflected in the low number of decisions (Decision 3/CP.25 and Decision 21/CP.22) acknowledging their roles and the lack of policy positions reflecting anticipated outcomes from their participation (Annex 1).

I have identified three groups of actors as women organisations (Annex 2):

- Grassroots women organisations

- Women groups

- National women and gender institutions 
There is only one decision that acknowledges women organisations' role, that is Decision 3/CP.25, as part of the Enhanced Lima work programme on gender and its gender plan. This decision notes the role of grassroots women organisations as recipients of climate finance. The roles of women groups and national women and gender institutions are not explicitly recognised in the analysed UNFCCC policy texts. In terms of the anticipated functions, women organisations are expected to integrate gender issues within climate change policies, plans, and strategies. Thus, gender-responsive implementation of climate change policies and strategies, including providing the means of implementation (i.e. climate finance), could be achieved as a result of women organisations' engagement.

In addition, the analysis identified four groups of actors that are involved in the implementation of activities and outcomes that have gender dimension (Annex 3):

- CSOs in conjunction with their role in gender-responsive budgeting (Decision 3/CP.23)

- NGOs in conjunction with their role to support the participation of women and gender-responsive budgeting

- Indigenous people and communities in conjunction with their role in gendersensitive adaptation planning

- Local communities in conjunction with their role in supporting the integration of gender integration into climate policies, plans, and strategies

These actors have not been explicitly identified as women organisations and they can represent various organisations, which are not necessarily mandated to work with gender equality issues. On the other hand, their relevance from the perspective of the delivery of gendered outcomes should not be overlooked. As the literature shows, some NGOs and CSOs are women organisations (Larson, 2002; Sharma, 2010; McBride and Mazur, 2013). These findings point to challenges with the identification of women organisations, who may not have a clear identity in the UNFCCC's policy texts. Inability to identify women organisations in policy texts may lead to deficient policy strategies and symbolic engagement of these actors. Implications of the existing policy strategies and associated controversies are discussed in the next section.

\subsubsection{Analysis of policy controversies}

Two policy controversies have been identified in line with the data analysis presented in Annexes 1 and 2:

- Incomplete framing in relation to women organisations (including grassroots women organisations, women groups and national women and gender institutions) and the participation of indigenous and grassroots women:

Entry points for women are explicitly defined across UNFCCC governance processes as well as at the national, regional and local levels. However, the participation of indigenous women and grassroots women does not have a similar set of entry points. In terms of the outcomes, while the participation of grassroots women is associated with gender-responsive climate action, no references to the contribution of indigenous women to gendered policy outcomes were found in the UNFCCC policy texts.

Organisations that can be directly identified as women organisations do not appear to have prominent positions in UNFCCC governance. Policy frames describing the participation of such organisations are mostly incomplete. For instance, there are no references to entry points for grassroots women organisations. Also, the roles of women groups and national gender institutions are not adequately acknowledged. There is only one brief sentence in the Enhanced Lima work programme on gender and its gender action plan (UNFCCC 2019a:13) which touches on the contribution of women groups to gender-responsive implementation and means of implementation: "Engage women's groups and national women and gender institutions in the process of developing, implementing and updating climate policies, plans, strategies and action, as appropriate, at all levels."

\section{- Inconsistent policy framing in relation to women and women organisations:}

On the one hand, women are expected to participate in the design, development and implementation of climate finance strategies. On the other hand, the UNFCCC's policies do not acknowledge any policy outcomes of women's engagement in climate finance, nor note women as recipients of climate finance. In other words, while the UNFCCC's policies offer opportunities for women to participate in climate-finance decision making, the policy language does not have the ambition to ensure that the participation of women is organised in a meaningful way and delivers climate finance policy outcomes, e.g. genderresponsive climate finance. This inconsistency in policy framing may lead to the symbolic participation of women in climate finance decision making. 
In terms of the participatory processes, a number of important entry points for women have been identified within the UNFCCC's policy texts: UNFCCC subsidiary bodies, UNFCCC constituted bodies, national delegations, and regional, national, and local levels. However, this variety of entry points is not made available for women organisations, whose role is mostly acknowledged at the national level. This inconsistency in policy framing could limit the contribution of these actors to UNFCCC governance and outcomes. For instance, participation in decision making at the international level via national delegations offers a unique opportunity to integrate decision making across different levels by linking local knowledge with international decisions. Formal inclusion of non-state stakeholders such as CSOs (who can be represented by women organisations) in national delegations that participate in international policy forums is associated with greater opportunities for these actors to influence governmental decision making at both national and international level (Seckinelgin 2009; Steffek and Nanz 2008; Thomann 2008).

\subsection{DISCUSSION}

The policy frame mapping of UNFCCC decisions shows how the participation of women and women organisations is conceptualised within policy texts. The conducted policy frame mapping indicates specific policy strategies that acknowledge women and women organisations' roles, particular functions, and participatory outcomes, as well as processes through which women and women organisations are invited to participate in the UNFCCC's governance.

The policy frame mapping on the participation of women and women organisations in the UNFCCC shows the utilisation of a various types of language and terms, which are not well defined or agreed upon in the policy texts or academic literature. For instance, in relation to gendered outcomes, the following terms are used: "gender-responsive climate policy", "genderresponsive climate action", "gender-sensitive adaptation", "gender-responsive budgeting", and "gender-responsive means of implementation". Frequently, these terms are used interchangeably without acknowledging the difference in associated technical approaches. These terms have a general usage, but this usage is not precise enough. For example, "gender-sensitive" is used for an approach where gender norms and roles are considered, although appropriate actions may not necessarily have been taken. "Gender-responsive" may imply that gender norms and inequalities are not only taken into consideration but also are actively addressed (Germain 2009). In addition, there is no agreement on what the application of these two distinctive approaches would mean in relation to climate action and policies, budgeting, and means of implementation.
The problem of vague policy strategies with regards to the engagement of women and women organisations is not unique to the UNFCCC, and the conceptualisation of participation within broader policy frameworks is often highly ambiguous (Cornwall 2008; Moynihan 2003). However, utilising vague terms and policy positions with regards to participatory roles and outcomes on the assumption that there is an agreement on what these positions mean often leads to diluting the meaning of policies and downplaying policy goals (Verloo 2016).

The difficulty with positioning women organisations in the UNFCCC processes could also be linked with the ambiguity of the policy framing in relation to their identity. There is a possibility that women organisations are disguised under different identities, such as CSOs or NGOs. For instance, in January 2014, there were more than $1,600 \mathrm{NGOs}$ admitted as observers to UNFCCC. ${ }^{44}$ However, there is no data in terms of how many of these NGOs had gender equality mandates and positions, which makes it difficult to trace the actual participation of women organisations and their contribution to policymaking processes.

The purpose of the study was to map different categories of women and women organisations that are present in policy texts and to offer initial insights on how the participation of these actors is framed in policy texts. As findings point, UNFCCC mostly recognizes women as a broader group of stakeholders with limited references to indigenous and grass-women. However, the study acknowledges that treating women as a homogeneous group for the purposes of policy development could be a problematic approach. Therefore, from the perspective of an additional area of research, it would be important to consider how the intersectional understanding of gender could be integrated in policy decisions.

${ }^{44}$ https://unfccc.int/files/parties_and_observers/ngo/application/pdf/constituencies_ and_you.pdf (accessed in February 2021). 


\subsection{CONCLUSIONS}

In this chapter, I have analysed policy strategies that support the participation of women and women organisations.

How is the participation of women and women organisations defined in the UNFCCC's policy texts, including the anticipated roles, entry points, functions, and participatory outcomes?

The participation of women and women organisations appears to be associated with an eclectic mixture of policy positions describing their functions, roles, entry points, and governance outcomes which is in agreement with the definition by $\mathrm{E}$ and $\mathrm{N}-\mathrm{M}$ cited in section 4.2. Women as governance stakeholders are well recognised in UNFCCC decisions. The entry points for women's participation are explicitly defined across UNFCCC governance processes, as well as at the national, regional, and local levels. Women have been recognised as vulnerable groups. Also, women are recognised as leaders and recipients of capacity building and education. In addition to women as a broader category of stakeholders, the UNFCCC's decisions recognise the role of grassroots and indigenous women, who are acknowledged as owners of traditional knowledge and solution holders

Women organisations have been defined in UNFCCC decisions as three types of organisations: women groups, national women and gender institutions, and grassroots women organisations. Based on the policy frame analysis, I conclude that the women organisations have limited recognition in the UNFCCC's decisions. Most notably, among 575 analysed decisions, only one decision (Decision 3/ CP.25) explicitly acknowledges women organisations' contribution and roles within UNFCCC-led climate change governance. Indigenous women appear to be presented as independent categories of actors with unique identities and roles, however the outcomes from their participation are not defined.

Are there any policy controversies in how the participation of women and women organisations is defined, i.e. the description of anticipated roles, entry points, functions and outcomes is not complete or/and consistent?

The findings suggest that the quality of policy strategies is limited, because the analysis has identified policy controversies that are associated with inconsistent and incomplete policy framings in relation to women's engagement in climate finance. While women are expected to participate in the development of climate finance strategies, their role as recipients of climate finance is not recognised. The incomplete policy framing is also observed in relation to indigenous women, whose participation does not appear to be linked with any policy outcomes in the policy texts. The participation of grassroots women organisations does not have a description of specific entry points and processes for engagement.

Further research is required to understand the impact of inconsistent and incomplete policy framing on the engagement of women and women organisations across various entry points, including those associated with climate finance. This research needs to be complemented by data collection on the representation of women organisations in national delegations and in UNFCCC-led decision making at various levels, including national, regional, and local. Also, an additional area of research could include the analysis of UNFCCC's policies from the perspective of intersectional gender considerations. 


\section{CHAPTER 5:}

Legitimising the engagement of women and women organisations in UNFCCC led climate change governance: The example of Georgia ${ }^{45}$

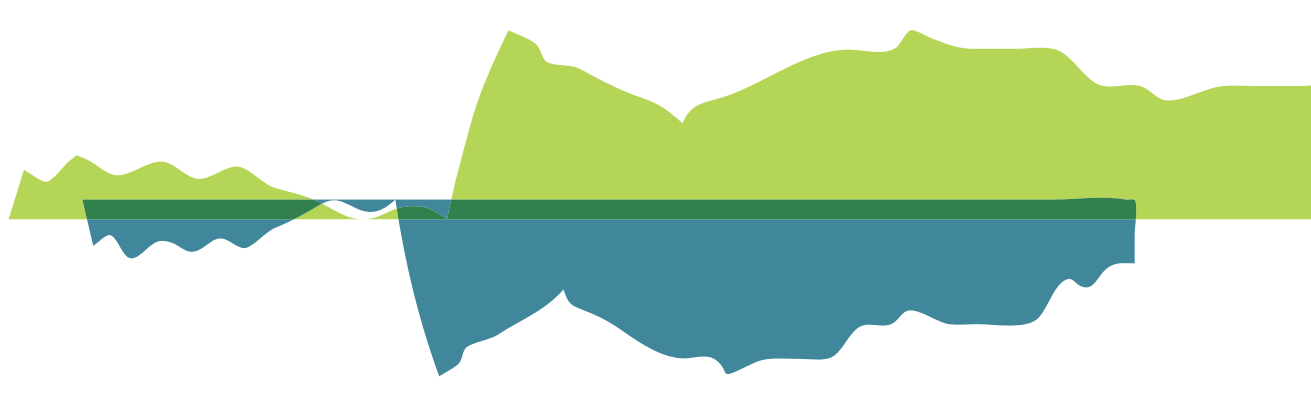

UNDERSTANDING POLICY AND INSTITUTIONAL STRATEGIES TO SUPPORT THE PARTICIPATION OF WOMEN AND WOMEN ORGANISATIONS WITHIN UNFCCC-LED CLIMATE CHANGE GOVERNANCE
${ }^{45}$ The chapter is under review in the World Journal: https://www.mdpi.com/journal/world 


\subsection{INTRODUCTION}

As demonstrated in Chapter 2, the UNFCCC is one of the key climate change governance frameworks, which is characterised by a high degree of regulation, including concerning the engagement of women (UNFCCC 2018a, 2019a; UN WOMEN 2016). The previous chapter analyses the key policy framings related to the participation of women and women organisations in the UNFCCC policies that have been adopted by the COP, the CMP, and the CMA. According to the UNFCCC's policy framing, women and women organisations are anticipated to influence climate change and climate change decisions at the national level. This chapter presents an extension of the analysis in Chapter 4 and looks specifically at how policy strategies constructed by the UNFCCC's parties at the international level, including the COP and Financial Mechanisms' decisions, are interpreted and being materialised at the national level.

Legitimation as a policy strategy allows policymakers to draw the attention to certain actors and make these actors more visible. The main argument of this chapter is that if women and women organisations are legitimised adequately and consistently within the UNFCCC-led multi-level governance system, they should be able to participate meaningfully and contribute to UNFCCCled decision making, including at the national level (as anticipated in the UNFCCC's policies). As described in Chapter 2, UNFCCC-led climate change governance regulates the engagement of women and women organisations through a number of policy processes at the international and national levels, which offer opportunities for acknowledging the role of women and women organisations in the UNFCCC-led multi-level governance system. Thus, I define these processes as legitimation channels (Figure 8).

\section{International legitimation channels}

UNFCCC's Governing bodies
COP Policies CMA Policies

CMP Policies

UNFCCC's Financial instruments

GEF GCF

AF

\section{National legitimation channels}

NDC BUR NAMA

\section{NC TNA and TAP}

Project documents
Figure 8. UNFCCC-guided legitimation channels (Prepared by the author)

At the international level, the engagement of women and women organisations has been regulated within two legitimation channels - the UNFCCC's decisions (adopted by the COP, the CMP, and the CMA) and the UNFCCC's Financial
Mechanisms. Based on the analysis presented in the previous chapter (which covered 575 COP, CMA, and CMP decisions), 20 decisions were adopted between 2001-2019 with references to the participatory roles of women. Only one decision, Decision 3/CP.25, was adopted with a reference to women organisations. As shown in Chapter 4, the participation of women and women organisations is anticipated to be instrumental in delivering specific policy outcomes. For example, in line with UNFCCC Decision 1/CP.21 $1^{46}$ and Decision 23/CP.18, ${ }^{47}$ the participation of women at the international level is linked with the development of gender-responsive climate policy at the national level. The participation of women organisations at the national level is expected to contribute to gender-responsive climate finance (as a means of implementation) (Decision 3/CP.25)

In addition to COP/CMA/CMP decision-making processes at the international level, there are two Financial Mechanisms (the Green Climate Fund (GCF), the Global Environmental Facility (GEF)) and the Adaptation Fund (AF), whose operations are guided by the UNFCCC. These funds also present specific international decision-making channels where the legitimation of women and women organisations takes place (UN WOMEN, 2016; Hall, Granat, and Daniel, 2019).

At the national level (Figure 8), there are a few UNFCCC-guided decisionmaking processes that present opportunities for legitimising the roles of women and women organisations, e.g:

- National Determined Contributions (NDC): The Paris Agreement requires each country signatory to prepare, communicate and maintain NDCs to reduce national emissions and adapt to the impacts of climate change. Parties are required to update NDCs at least every five years starting from 2020 (UNFCCC / Technology Executive Committee 2017). There is very limited guidance on the preparation of NDCs, which has led to individual interpretations of the scope of NDCs and considerable variations in formulation of mitigation and adaptation ambitions (Taibi and Konrad 2018) and the integration of gender equality issues (Murray 2019; Huyer 2016).

${ }^{46} \mathrm{https}: / /$ unfccc.int/process-and-meetings/conferences/past-conferences/parisclimate-change-conference-november-2015/cop-21/cop-21-decisions (accessed in March 2021).

47 https://unfccc.int/sites/default/files/cop18_gender_balance.pdf (accessed in March 2021). 
- National Communications (NC): Non-Annex I Parties are required to submit their NCs every four years. National Communications need to describe countries' national and regional development priorities, objectives, and circumstances, based on which they will address climate change and its adverse impacts (UNFCCC 2002a).

- Nationally Appropriate Mitigation Actions (NAMA): Nationally Appropriate Mitigation Actions are a formal submission by countries indicating key actions that are required for reducing GHG emissions, including technology, finance, and capacity needs.

- Technology Needs Assessments (TNA) and Technology Action Plans (TAP): Technology Needs Assessments are planning documents to improve countries' vision on technology needs, so they can develop plans to address these needs and receive support for implementing specific climate investments. Technology Needs Assessments and TAPs are instrumental for planning climate finance under the UNFCCC process. A TAP is a medium/long-term plan for increasing the uptake of identified technologies. The plan outlines actions to be undertaken to enhance this uptake, which is further elaborated in project concept notes (UNFCCC / Technology Executive Committee 2017).

- Biennial Update Reports (BUR): UNFCCC BURs contribute to tracking progress made towards the implementation of NDCs.

- Project documents of climate investments supported by UNFCCC's financial instruments. On the one hand, project proposals demonstrate national priorities and the alignment with the key national strategies. On the other hand, they are technical documents, which show how institutional policies, e.g. gender policies related to climate funds, are interpreted into specific actions.

Within these diverse UNFCCC-led policy processes that exist at the international and national level, the quality of legitimation is important to ensure meaningful participation of women and women organisations, which should be based on consistent and inclusive participation of women and women organisations across multi-level decision-making processes and enable their contribution to the development of climate change solutions that are considerate of gender inequalities.

The research in this chapter has a dual purpose: (1) to summarise and describe the existing approaches to the legitimation of women and women organisations in the international and national UNFCCC-led multi-level governance system using Georgia as an example and (2) to provide insights on the quality ${ }^{48}$ of the existing legitimation approaches.

A single-case study approach is taken as a starting point for exploring the methodology on the assessment of the quality of legitimation across the three levels of UNFCCC-led governance, i.e. from COP decisions to the national level. Georgia is chosen as a case due to its relatively developed UNFCCCled climate finance governance landscape, which presents various avenues for the involvement of women and women organisations in UNFCCC-led climate change policy processes. Such an approach also delivers insights for understanding the impact of international UNFCCC-led policy discourse at the national level in Georgia.

The chapter concludes with reflections on the quality of the existing policies developed by the UNFCCC that legitimise the engagement of women and women organisations in multi-level UNFCCC-led climate change governance and provides recommendations for further research and policy development.

\subsection{PROBLEM STATEMENT AND RESEARCH QUESTIONS}

The legitimation approaches to support the engagement of women and women organisations in the multi-level UNFCCC-led governance system have received little attention from researchers, hence these approaches are not well understood. No systemic analysis has been conducted into the legitimation approaches across various UNFCCC's governance levels. However, the concept of legitimation within multi-level governance frameworks has been studied in other contexts (for example, in relation to biodiversity). There is emerging evidence that legitimation within the context of multi-level governance could be challenging to implement and, if carried out inconsistently, could further limit the implementation of policies (Suškevičs 2012).

In this chapter, I argue that the quality of legitimation of women and women organisations across UNFCCC-led decision-making levels could affect the quality of participation of these actors (which is one of the UNFCCC's policy goals) and their contribution to UNFCCC-led decision making. As demonstrated

${ }^{48}$ I defined the quality of legitimation based on the three criteria (1) visibility of women and women organisation at the national level, (2) their involvement in the UNFCCC-led climate finance decision-making at the national level and (3) consistency of UNFCCC guided policy definitions that are used in relation to women and women organisations at the international and national levels. 
in Chapter 4, COP decisions imply that women and women organisations should take part in national-level policymaking and improve climate change decisions, for example through a better integration of the gender dimension (Decision 15/CP.18, ${ }^{49}$ Decision 3/CP.1750 and Decision 3/CP.25). ${ }^{51}$ Thus, the quality of policy strategies could be gauged through evidence on whether UNFCCC policies adopted at the international level that target women and women organisations lead to participation of women and women organisations at the national level in climate change decision making, and whether women and women organisations contribute to UNFCCC-led decision making at the national level. If such evidence exists, it would imply that the policy strategies adopted at the international level are successful.

As noted previously, women and women organisations are considered as two distinct categories of actors (institutional and non-institutional) who can lobby for gender equality issues and achieve policy changes (Annesley and Gains 2010; True and Mintrom 2001; Celis et al. 2008; Beckwith 2007; Inglehart and Norris 2003), therefore it is important to present data for these two groups of actors.

In this chapter, based on the problem statement in the previous section, I answer the following two research questions:

-What are the existing legitimation approaches to support the engagement of women and women organisations in international and national UNFCCC-led climate change governance (using the example of Georgia)?

-What is the quality of legitimation of the participation of women and women organisations in Georgia?

The approaches to legitimation are analysed using the following sub-questions:

-What are the sources of legitimation within multi-level UNFCCC-led governance, including the national level, in Georgia?

- How have women and women organisations been recognised across these sources, including patterns in the attention to women and women organisations and variations in definitions that are used in relation to these actors?

49 https://unfccc.int/process-and-meetings/conferences/past-conferences/dohaclimate-change-conference-november-2012/cop-18/cop-18-decisions (accessed in March 2021).

50 https://unfccc.int/resource/docs/2011/cop17/eng/09a01.pdf (accessed in March 2021).

51 https://unfccc.int/sites/default/files/resource/cp2019_L03E.pdf (accessed in March 2021).
The quality of legitimation in Georgia is analysed through the following subquestions:

- Are the existing definitions (that are applied in relation to women and women organisations in Georgia) consistent with the definitions applied at the international UNFCCC-led governance?

- Do the UNFCCC's policy provisions that target women and women organisations lead to the participation of women and women organisations at the national level in Georgia?

- Are women and women organisations visible actors in the UNFCCC-led governance in Georgia, i.e. is their participation linked with a policy contribution at the national level in Georgia?

\subsection{METHODOLOGY}

This chapter uses a methodology which:

1. Describes the existing approaches to the legitimation of women and women organisations within multi-level UNFCCC-led climate change governance channels using the example of Georgia;

2. Provides insights into the quality of the existing approaches to the legitimation of women and women organisations.

Methodologically, the analysis of legitimation in the context of political science is applied in relation to institutional actors and international organisations (Tallberg and Zürn 2019). However, in the social sciences, legitimation is analysed in relation to how broader concepts, including specific groups, areas of knowledge, and cultural phenomena, are acknowledged in policy texts (Ferreira and Coronel 2017). The latter approach is used for this study, given that women do not present institutional actors.

Georgia is chosen as the case for this study, since it has the key UNFCCC led climate change policy frameworks (including NDCs, three NCs, two BURs, two TNAs, and two TAPs), an established UNFCCC Gender Focal Point, and investments by the GEF, GCF, and AF. Additionally, Georgia has made considerable efforts in fostering gender equality through policy reforms (e.g. Gender Equality Law and National Action Plan) and adopted a number of sectoral policies that support women's participation (UNDP 2018). Georgia signed CEDAW in 1994 and has made efforts to encourage the participation of women in all economic sectors (WECF 2015). 


\subsubsection{Describing the existing approaches to legitimation}

Language represents an "instrument of control" for making certain issues and stakeholders more visible and legitimate (Reyes 2011). Thus, content analysis is an important tool for describing the approaches to legitimation across various UNFCCC-led policy channels. The content analysis has been conducted using ATLAS.ti software across three legitimation channels, the UNFCCC (COP, CMA, and CMP), the UNFCCC's Financial Instruments (the GCF, GEF and AF), and the national level (as per Figure 8).

The first step in describing the approaches is the identification of the sources of legitimation. Chapter 4 presents the initial analysis of 575 UNFCCC decisions, which resulted in the identification of 20 COP, CMA, and CMP decisions (with 19 adopted in 2009-2020) with references to women and one decision with a reference to women organisations. These decisions are the sources of legitimation of the UNFCCC's Governing Bodies.

The analysis of the UNFCCC's financial instruments was based on a review of the participatory policies and guidelines of UNFCCC-guided climate finance funds (the GEF, GCF, and AF). In total, $30 \mathrm{GEF}, 5286 \mathrm{GCF}^{53}$ and $28 \mathrm{AF}^{54}$ policies and guidelines were retrieved from the funds' websites and analysed.

At the national level, national policies and frameworks associated with the implementation of UNFCCC objectives were screened to identify sources of legitimation: NDCs, BURs, TNAs and TAPs, NCs, and documents of projects funded by the GCF, GEF, and AF. ${ }^{55}$ In total, 27 documents were analysed, including proposals for 11 climate change projects approved by the GEF in Georgia, ${ }^{56}$ one proposal approved by the $\mathrm{GCF}^{57}$ and two proposals approved

52 https://www.thegef.org/documents/policies-guidelines (accessed in March 2021).

${ }^{53}$ https://www.greenclimate.fund/about/policies (accessed in March 2021).

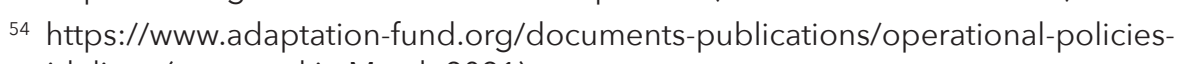
guidelines (accessed in March 2021).

55 It is worth noting that as of December 2020, Georgia was working on key climate finance related policies, whose drafts have not been made publicly available yet, e.g. National Adaptation Plan, Climate Action Plan and Long Term Low Emission Development Strategy, updating NDCs. While these national climate change policies could serve as important legitimation sources, these policy texts have not yet been adopted and they were therefore excluded from the analysis presented here.

56 https://www.thegef.org/projects-faceted?f[]=field_country:66\&f] ]=field_p_ focalareas:2207 (accessed in March 2021).

57 https://www.greenclimate.fund/countries/georgia (accessed in March 2021). by the $A F^{58}$ (adopted in 2020). The identified sources of legitimation were screened for variations in the definitions of women and women organisations.

The second step included a quantitative analysis of the legitimation approaches in 2009-2020, which covers the most active years of UNCCC decision making (see Chapter 4). The total number of decisions with references to women and women organisations was considered as a key criteria showing the dynamics in the attention to women and women organisations in 2009-2020. A combo chart is used to show the potential relationship and influence between legitimation channels to support further research.

\subsubsection{Analysing the quality of legitimation}

The analysis of quality is based on three criteria:

a. Consistency of definitions that are applied across the three levels of UNFCCC-led governance in relation to women and women organisations;

b. Visibility of women and women organisations based on the experts perception of women and women organisations' contribution to UNFCCCled decision making in Georgia; and

c. Involvement of women and women organisations (based on experts' opinion, i.e. anecdotal evidence).

The analysis of the consistency of definitions is derived from the description of legitimation approaches (as explained in Section 5.3.1). The perception of the abilities of women and women organisations to influence decision making and anecdotal evidence on the involvement of women and women organisations were derived using semi-structured interviews with Georgian national UNFCCC experts.

The visibility of women and women organisations' was gauged through the interviews with Georgian national experts and experts' perception of specific roles of women and women organisations (actual and potential) and policy outcomes from women and women organisations' participation in UNFCCCled decision making at the national level in Georgia. Interviews with experts have been used to triangulate the analysis of quality of legitimation with additional data.

58 https://www.adaptation-fund.org/projects-programmes/project-information/ projects-map-view/ (accessed in March 2021). 
With regards to the involvement of women and women organisations, it is worth noting that it is difficult to verify the level of participation of women and women organisations in UNFCCC-led climate change decision making, since lists of participants are rarely available. Hence, anecdotal evidence, based on the opinion of experts who are directly involved in UNFCCC-led decision making, has been used to understand the extent of women and women organisations' participation and contribution.

The interviews were conducted in April 2020 and consisted of one-hour sessions with four ${ }^{59}$ national experts, namely two experts from national womenled NGOs, who have been involved in the UNFCCC processes at the national level, the UNFCCC Gender Focal Point, and a representative of the Ministry of Environmental Protection and Agriculture (which serves as the UNFCCC Focal Point and also represents the GEF, AF and GCF focal points).

\subsection{FINDINGS}

\subsubsection{Description of legitimation}

\section{a. Legitimation sources for the participation of women}

Table 2 presents sources of legitimation for the engagement of women identified through the content analysis. At the international level, as shown in Chapter 4, there are 19 sources of legitimation with references to women in decisions adopted between 2009-2020 by the COP/CMP/CMA. There are 37 sources of legitimation with references to participatory roles and rights of women in decisions adopted by the GEF, GCF and AF. At the national level, there are 11 sources of legitimation.
Table 2. Sources of legitimation for women (in UNFCCC decisions and project documents adopted in 2009-2020) (Prepared by the author)

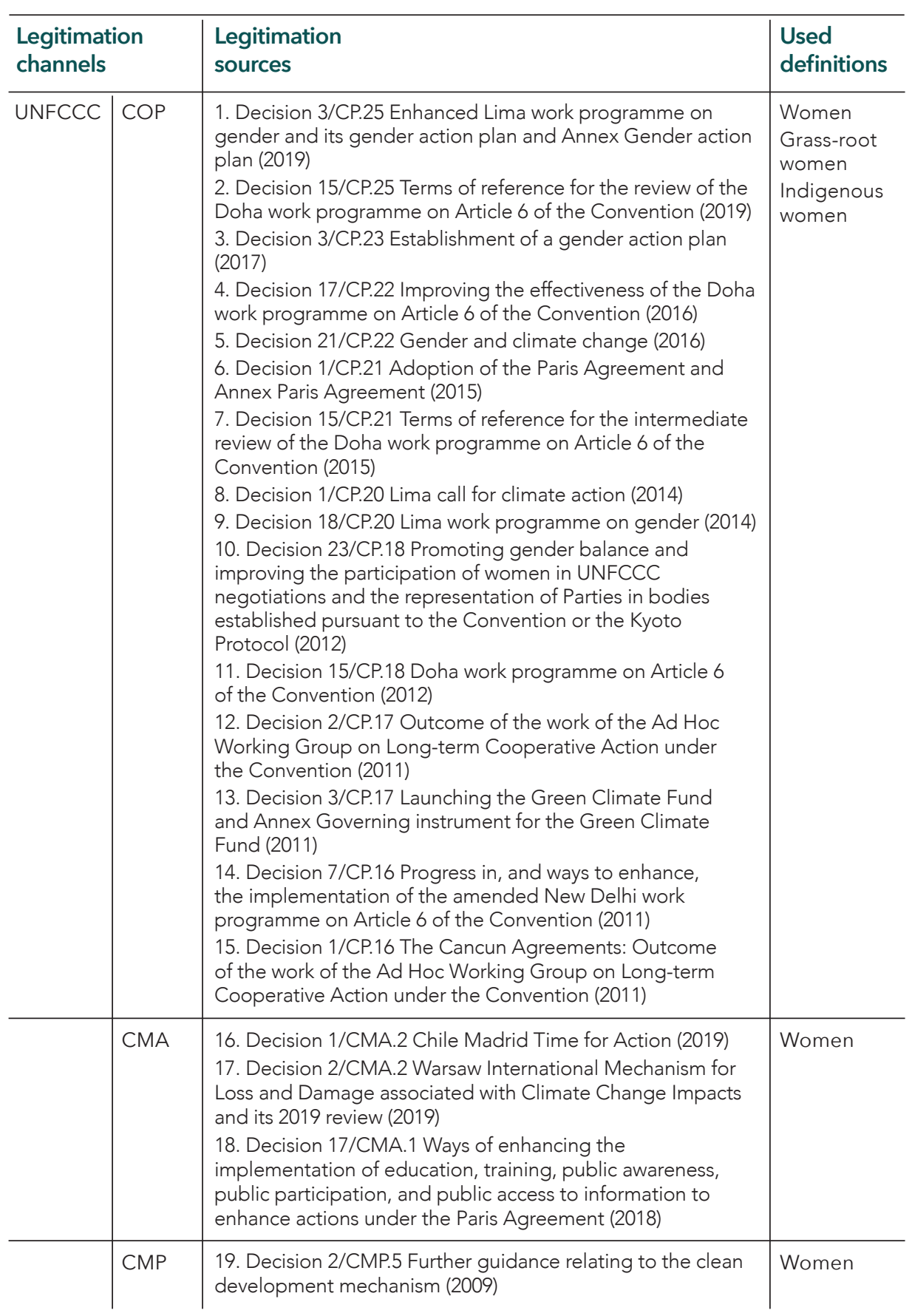

59 Given the novelty of the climate finance governance, experts with the knowledge of UNFCCC-led governance processes are extremely limited. The involved experts appeared to be the key known experts working in the UNFCCC-led climate finance governance in Georgia. 


\begin{tabular}{|c|c|c|c|}
\hline \multicolumn{2}{|c|}{$\begin{array}{l}\text { Legitimation } \\
\text { channels }\end{array}$} & \multirow[b]{2}{*}{$\begin{array}{l}\text { Legitimation } \\
\text { sources } \\
\text { 20. GCF Programming Manual: An introduction to the Green } \\
\text { Climate Fund project cycle and project development tools } \\
\text { for full-size projects (2020) } \\
\text { 21. Guidance note on designing and ensuring meaningful } \\
\text { stakeholder engagement in GCF-financed projects (2019) } \\
\text { 22. Investment criteria indicators (2019) } \\
\text { 23. Policy on the Prevention of and Protection from Sexual } \\
\text { Exploitation, Sexual Abuse, and Sexual Harassment (2019) } \\
\text { 24. Gender Policy and Gender Action Plan 2020-2023 (2019) } \\
\text { 25. GCF readiness support guideline (2018) } \\
\text { 26. Indigenous People Policy (2018) } \\
\text { 27. Environmental and Social Policy (2018) } \\
\text { 28. Initial Investment framework: Activity-specific sub-criteria } \\
\text { and indicative assessment factors } \\
\text { 29. Governing instrument (2015) } \\
\text { 30. Monitoring and accountability framework for accredited } \\
\text { entities (2015) } \\
\text { 31. Gender policy (2015) } \\
\text { 32. Governing instrument (2011) }\end{array}$} & \multirow{2}{*}{\begin{tabular}{|l|} 
Used \\
definitions
\end{tabular}} \\
\hline $\begin{array}{l}\text { Financial } \\
\text { instruments }\end{array}$ & GCF & & \\
\hline & $A F$ & $\begin{array}{l}\text { 33. Medium-Term Strategy of the Adaptation Fund for the } \\
\text { years 2018-2022 (2018) } \\
\text { 34. Guidance document for Implementing Entities in } \\
\text { compliance with the Adaptation Fund Gender Policy (2017) } \\
\text { 35. Gender Policy and Action Plan of the Adaptation Fund (2016) } \\
\text { 36. Entities on compliance with the Adaptation Fund } \\
\text { Environmental and Social Policy (2016) } \\
\text { 37. Guidance on Accreditation Standards (2016) } \\
\text { 38. Gender Policy and Action Plan of the Adaptation Fund } \\
\text { (amended in March 2021) } \\
\text { 39. Environmental and Social Policy (Amended in March 2016, } \\
\text { approved in November 2013) } \\
\text { 40. Results Framework and Baseline Guidance - Project level } \\
\text { (2011) } \\
\text { 41. Guidelines for Project/Programme Final Evaluations (2011) }\end{array}$ & $\begin{array}{l}\text { Women } \\
\text { Indigenous } \\
\text { women } \\
\text { Rural } \\
\text { women }\end{array}$ \\
\hline & GEF & $\begin{array}{l}\text { 42. Guideline on Mainstreaming Gender in GEF Project Cycle } \\
\text { (2020) } \\
\text { 43. GEF Gender Implementation Strategy (2018) } \\
\text { 44. Guidelines on Core Indicators and Sub-Indicators (2018) } \\
\text { 45. Guidelines on the Project and Program Cycle Policy (2018) } \\
\text { 46. Policy on Gender Equality (2018) } \\
\text { 47. Guidelines on Gender Equality (2018) } \\
\text { 48. Policy on Environmental and Social Safeguards (2018) } \\
\text { 49. Guidelines on GEF Policy on Environmental and Social } \\
\text { Safeguards (2018) } \\
\text { 50. Guidelines on Environmental and Social Safeguards (2018) } \\
\text { 51. Stakeholder Engagement Policy (2017) } \\
\text { 52. Guidelines on the Implementation of the Policy } \\
\text { on Stakeholder Engagement (2017) } \\
\text { 53. GEF Gender Equality Action Plan (2015) } \\
\text { 54. GEF Public Involvement Policy (2012) } \\
\text { 55. GEF Gender Mainstreaming Policy (2012) } \\
\text { 56. Policy on Gender Equality (2017) }\end{array}$ & Women \\
\hline
\end{tabular}

\begin{tabular}{l|l|l|l}
\hline $\begin{array}{l}\text { Legitimation } \\
\text { channels }\end{array}$ & $\begin{array}{l}\text { Legitimation } \\
\text { sources }\end{array}$ & $\begin{array}{l}\text { Used } \\
\text { definitions }\end{array}$ \\
\hline $\begin{array}{l}\text { National } \\
\text { level in } \\
\text { Georgia }\end{array}$ & $\begin{array}{l}\text { UNFCCC } \\
\text { guided } \\
\text { projects }\end{array}$ & $\begin{array}{l}\text { 57. Second BUR (2019) } \\
\text { 58. First NDCs (2017) } \\
\text { 59. Gender-sensitive NAMA for sustainable energy } \\
\text { in rural areas (2015) }\end{array}$ & Women \\
& $\begin{array}{l}\text { National } \\
\text { projects }\end{array}$ & $\begin{array}{l}\text { 60. Enabling Implementation of Forest Sector Reform } \\
\text { in Georgia to Reduce GHG Emissions from Forest } \\
\text { Degradation (GCF) (2020) } \\
\text { 61. Dairy Modernization and Market Access: Adaptation } \\
\text { Component (DiMMAdapt) (AF) (2019) } \\
\text { 62. Scaling up Multi-Hazard Early Warning System and } \\
\text { the Use of Climate Information in Georgia (GCF) (2018) } \\
\text { 63. Development of Georgia's Fourth National } \\
\text { Communication and Second Biennial Update Report } \\
\text { to the UNFCCC (GEF) (2017) } \\
\text { 64. Georgia's First Biennial Update Report (GEF) (2014) } \\
\text { 65. Green Cities: Integrated Sustainable Transport in the } \\
\text { City of Batumi and the Achara Region (GEF) (2014) } \\
\text { 66. Enhancing Resilience of the Agricultural Sector } \\
\text { in Georgia (ERASIG) (GEF) (2013) } \\
\text { 67. Developing Climate Resilient Flood and Flash } \\
\text { Flood Management Practices to the Protect Vulnerable } \\
\text { Communities of Georgia (AF) (2011) }\end{array}$ & \\
Comen \\
\end{tabular}

Figure 9 shows the changes in the attention to the participation of women across three legitimation channels. Since 2015, the participation of women has received relatively sustained attention in the UNFCCC. Within policies of the UNFCCC's climate finance funds, attention to women has been increasing since 2015 with a peak in 2018. At the national level in Georgia, attention to women's issues has not been systemic over the last 10 years. Overall, it appears to follow the increase in attention in the UNFCCC and its Financial Mechanisms' policies (Figure 8).

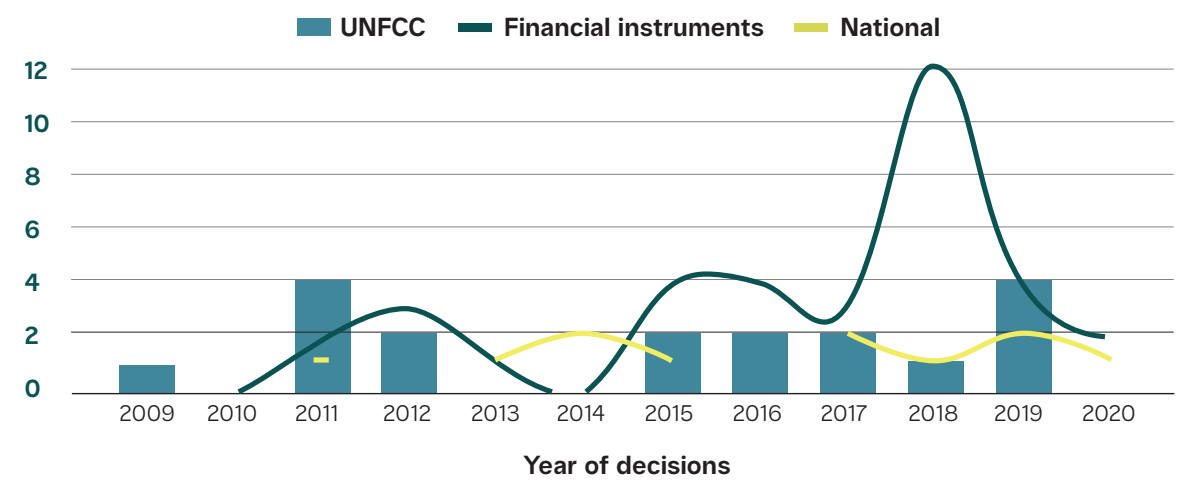

Figure 9. Dynamics in the attention to women's participation across legitimation channels 2009-2020 (combo chart)

(Prepared by the author) 


\section{b. Legitimation sources for the participation of women organisations}

With regards to the legitimation of women organisations, policy attention to these actors only started to emerge in 2017 and has remained inconsistent. At the international level, as shown in Chapter 4, there is one source of legitimation with references to women organisations adopted between 2009-2020 by the COP (Decision 3/CP.25) and four sources of legitimation in decisions adopted by the GEF, GCF and AF. At the national level, there are also two sources of legitimation which are presented by GCF and AF projects (Table 3).

No graphs have been developed for the legitimation of women organisations, since the share of documents with references to women organisations within the total number of adopted documents in each legitimation channel is negligible. It is also not feasible to demonstrate the dynamics given how little attention has been paid to women organisations in the policy documents.

Table 3. Sources of legitimation for women organisations (in UNFCCC decisions and project documents adopted in 2009-2020)

(Prepared by the author)

\begin{tabular}{|c|c|c|c|}
\hline \multicolumn{2}{|c|}{$\begin{array}{l}\text { Legitimation } \\
\text { channels }\end{array}$} & \multirow{2}{*}{\begin{tabular}{|l|} 
Legitimation \\
sources
\end{tabular}} & \multirow{2}{*}{\begin{tabular}{|l|} 
Used \\
definitions \\
Grass-roots women organisations \\
National women and gender \\
institutions \\
Women groups \\
\end{tabular}} \\
\hline UNFCCC & COP & & \\
\hline & CMA & No references to women organisations & N/A \\
\hline & CMP & No references to women organisations & N/A \\
\hline \multirow{3}{*}{$\begin{array}{l}\text { Financial } \\
\text { instruments }\end{array}$} & GCF & 2. GCF readiness support guideline (2018) & Women-led groups \\
\hline & $A F$ & $\begin{array}{l}\text { 3. Guidance document for } \\
\text { Implementing Entities in compliance } \\
\text { with the Adaptation Fund Gender Policy } \\
\text { (2017) }\end{array}$ & $\begin{array}{l}\text { National women's machineries } \\
\text { and institutions } \\
\text { Women's cooperatives and } \\
\text { community-based organisations, } \\
\text { which are often run by women } \\
\text { and target services to women } \\
\text { and their families }\end{array}$ \\
\hline & GEF & 4. Guidelines on Gender Equality (2018) & $\begin{array}{l}\text { Non-government } \\
\text { organisations focused on } \\
\text { promoting gender equality, } \\
\text { women's rights, or the } \\
\text { empowerment of women }\end{array}$ \\
\hline
\end{tabular}

\begin{tabular}{l|l|l|l}
\hline $\begin{array}{l}\text { Legitimation } \\
\text { channels }\end{array}$ & $\begin{array}{l}\text { Legitimation } \\
\text { sources }\end{array}$ & $\begin{array}{l}\text { Used } \\
\text { definitions }\end{array}$ \\
\hline $\begin{array}{l}\text { National } \\
\text { level in } \\
\text { Georgia }\end{array}$ & $\begin{array}{l}\text { UNFCCC } \\
\text { guided } \\
\text { policies }\end{array}$ & N/A & N/A \\
\cline { 2 - 3 } & $\begin{array}{l}\text { National } \\
\text { projects }\end{array}$ & $\begin{array}{l}\text { 5. Dairy Modernization and Market } \\
\text { Access (2019) (AF) }\end{array}$ & $\begin{array}{l}\text { Women initiative groups } \\
\text { Women's groups and private- } \\
\text { sector-led women organisations }\end{array}$ \\
\cline { 2 - 4 } & $\begin{array}{l}\text { 6. Enabling the Implementation of } \\
\text { Forest Sector Reform in Georgia to } \\
\text { Reduce GHG Emissions from Forest } \\
\text { Degradation (2019) (GCF) }\end{array}$ & $\begin{array}{l}\text { Private-sector-led women } \\
\text { organisations }\end{array}$ \\
\hline
\end{tabular}

\subsubsection{Analysis of the quality of legitimation}

This section reflects on the success of legitimation using three criteria: (1) consistency of definitions in relation to women and women organisations; (2) experts' perception of women and women organisations' contribution; and (3) experts' perception (or anecdotal evidence) on the involvement of women and women organisations. The data was collected through semi-structured interviews with four experts who participate in UNFCCC-led decision making in Georgia.

\section{Consistency of definitions that are applied across the three levels of the} UNFCCC-led governance in relation to women and women organisations

The qualitative analysis presented in Tables 2 and 3 shows discrepancies in how women and women organisations are defined and a lack of a common approach. With regards to women, aside from references to women as a broader category, the analysed legitimation sources refer to grass-root women, indigenous women and rural women. Also, there is no universal definition of women organisations that has been used across various legitimation channels (see Table 3). For example, the national women and gender institutions are recognised by the AF and UNFCCC COP's decisions only. References to private-sector-led women organisations are found only in the projects funded by the AF and the GCF.

\section{Participation of women and women organisations (based on experts'} perception)

Generally, the expert interviewees demonstrated awareness of and provided anecdotal evidence on the participation of women in national climate change decision making. Project development for accessing funds from the UNFCCC's Financial Mechanisms is one of the areas that has been linked with the better 
perception of women's involvement by experts. Interviewees linked this success to climate finance funds' gender policies, which require project level consultations to be conducted in a gender-balanced way.

According to the experts, the actual engagement of institutional actors, such as national women institutions, women organisations, and women-led organisations, is low. For example, according to the interviewees, only a small number of women-led NGOs has been involved in climate finance decision making (two of these NGOs were interviewed for this study). Moreover, the engagement of national women institutions with specific mandates to support gender equality and women's empowerment is, according to the interviewees, non-existent. These types of organisations engage on human rights issues, but they do not appear to have knowledge of climate change. According to the interviewees, the lack of national guidelines and participatory standards that explicitly recognise these stakeholders and processes for their engagement results in limited participation and a lack of interest to participate.

With regards to the participation of national women's institutions, interviewees had difficulty identifying the public sector institution in charge of women's rights and gender equality issues. According to the interviewees, gender and women's issues are a cross-sectoral topic, which is administered to various degrees by different ministries. The National Action Plan of 2014-2016 for the Implementation of the Gender Equality Policy in Georgia triggered the creation of the Inter-Agency Commission on Gender Equality, which is chaired by the Ministry of Justice. The Commission consists of representatives of several ministries, including the Ministry of Environmental Protection and Agriculture (MEPA). Despite the integration of the MEPA in gender equality discussions, the interviewees did not confirm the participation of the Ministry of Justice in climate finance decision making. However, according to the interviewees, the Ministry of Justice does have gender equality mandates.

With regards to the involvement of women organisations from the nongovernmental sector, the interviewees confirmed that typically, working groups are established to support the engagement with civil society for the development of national climate decisions, strategies and action plans. The working groups present a possibility for the inclusion of a variety of experts from civil society organisations, including the private sector, R\&D, and potentially women organisations. However, this possibility appears not to have been fully utilised yet.

According to the interviewees, for the update of the NDCs, which took place between 2018 and 2020, MEPA supported focus group discussions and bilateral meetings with a number of national gender experts to support the development of the gender chapter in the NDCs. The experts were associated with local NGOs, of which a very small number were represented by organisations that have gender and women's rights mandates. According to the expert representing the UNFCCC Gender Focal Point, who was directly involved in the organisation of these consultations, only two or three organisations (out of 12) were women organisations, and these had a limited understanding of climate change topics and expressed concerns over this.

As previously noted, project development was linked by the interviewees with better involvement rates of women. However, the interviewees note that the engagement of women organisations in project design is not tracked and they were unable to provide anecdotal evidence for their engagement.

\section{Visibility of women and women organisations in the UNFCCC-led climate} finance decision making in Georgia (based on experts' perception)

To analyse visibility, experts were asked to identify policy outcomes (actual or potential) that could be associated with the engagement of women and women organisations in the UNFCCC-led climate finance governance in Georgia. The interviewees had difficulty identifying actual outcomes of the participation of women and women organisations, including the integration of a gender dimension in policies. While there is evidence of ex-ante engagement of women in climate change projects in project documents, the interviewees questioned whether these engagements within project implementation have led to any concrete outcomes. Experts noted that gender mainstreaming through the integration of gender-disaggregated data in project design could drive the engagement of women. However, this approach is perceived by the interviewed experts as a symbolic practice that does not guarantee the delivery of climate finance governance outcomes related to, for instance, gender equality or women's empowerment.

With regards to the engagement of women-led organisations, according to the interviewees, this has not increased the integration of gender issues in climate finance planning policies. For instance, one of the most actively involved women-led NGOs, which was interviewed, has a dedicated gender policy However, according to the interviewee from this organisation, the organisation does not position itself as a gender advocate and is not mandated to actively pursue gender equality and women's empowerment agendas in its work unless this is explicitly requested by donor policies or in project proposals that the organisation implements.

Despite the lack of actual evidence on the engagement of women organisations, interviewees perceive women organisations' potential role in climate finance decision making as positive. There is a belief that such organisations could bring 
different perspectives and engender climate change agendas. Interviewees attribute the lack of engagement of women organisations, on the one hand, as linked with these organisations' limited knowledge of climate change and climate finance issues. On the other hand, the lack of national guidelines and participatory standards that would explicitly recognise these stakeholder groups and processes for their engagement in Georgia also plays a role.

\subsection{DISCUSSION}

The quantitative analysis undertaken in this chapter (Figure 9) shows a gradual increase in the number of policies and strategies acknowledging women's participatory rights and roles. The attention to women organisations has also increased, but, so far, this has been very inconsistent and limited.

The qualitative analysis shows inconsistent legitimation of women and women organisations in Georgia. The interviews with experts in Georgia show that the quality of narratives with regards to the participation of women organisations across various climate change governance channels could be an underlying reason for the limited role of women and women organisations. In addition to the analysis of consistency of legitimation, additional insights need to be developed through a more nuanced qualitative analysis of legitimation strategies. For example, two distinctive approaches to legitimation could be considered (Tallberg and Zürn 2019):

- A behavioural approach, which aims at strengthening legitimacy through the establishment of participatory norms and standards, and

- A discursive approach, which acknowledges the role of specific actors in official documents and statements.

The concept of legitimation is critical for gaining insights into how policies grant political authority to certain actors (such as women and women organisations) and enable their contribution to policymaking (Tallberg and Zürn 2019). Thus, assessing the presence of discursive and behavioural legitimation approaches and their impact on the legitimation of women and women organisations could be the next step for increasing the understanding of the agency of women and women organisations.

The experts' perception shows that the involvement and contribution of both women and women organisations in Georgia are low. While initial legitimation efforts have been made in Georgia and the attention of policies to women and women organisations appears to be growing, the existing approach to legitimising the participation of women and women organisations does not appear to contribute to the development of women and women organisations agency (or their abilities to influence policy processes). Using perception fo analysing the quality of participation of women and women organisations is hindered by the novelty of the topic, which could explain the interviewees perception of the limited roles and contributions of women and women organisations. Generally, there is agreement among interviewees that women and women organisations' engagement as a policy theme has started emerging only recently. The findings of the interviews also point to a limited awareness of the concept of women's organisations by national experts.

Based on the experts' feedback, there are a number of issues that could be limiting the participation and contribution of women and women organisations to national climate change governance in Georgia, for example, a shortage of data on the specific gendered impacts of climate change and women's vulnerabilities, women's limited capacities and knowledge on climate change and climate finance. Thus, there is a need to collect evidence on the contribution of women and women organisations at the national level (as anticipated in the UNFCCC decisions).

It has been recognised by scholars that it is challenging to establish a cause-effect relationship between specific policy outcomes and legitimation strategies targeting the participation of women in order to analyse policy outcomes. The methodological challenges in attributing policy outcomes to participation have been recognised and could be addressed through experimentally controlled studies that create a counterfactual setting (Coenen 2009; Speer 2012; Seckinelgin 2009). This approach is likely to be inaccessible within the context of the UNFCCC-led governance system. Therefore, the development of innovative methods to measure the outcomes of women and women organisations' participation within the UNFCCC's contexts is required.

The findings of the current study allude to the possibility of influence across legitimation channels within UNFCCC-led climate change governance (see Figure 9 above). Moreover, the interviewed experts perceive some of the legitimation channels as more impactful than others in the case of Georgia. For example, climate funds' policies have been noted as the most important source of legitimation to support women's engagement. This calls for further research on how the existing legitimation strategies could be optimised to enhance the participation of women and women organisation and their impact on policy processes. 


\subsection{CONCLUSIONS}

This chapter describes the existing approaches to the legitimation of women and women organisations within the UNFCCC-led multi-level governance and provides insights on their success using mixed methods. Certainly legitimation approaches to engaging women and women organisations into this context have been increasing in the last 10 years, which is demonstrated by the attention to the participation of women in climate change mitigation in the analysed policy documents.

This chapter sets out to explore legitimation approaches to engaging women and women organisation at the national level in the specific context of Georgia by answering two research questions.

What are the existing legitimation approaches to support the engagement of women and women organisations in international and national UNFCCC-led climate change governance (using the example of Georgia)?

Sixty-seven sources of legitimation from between 2009-2020 have been identified across analysed legitimation channels (Table 2). These sources not only acknowledge the importance of women as a broader group of actors in UNFCCC-led climate change decision making, but also recognise rural, indigenous, and grass-root women as relevant actors. Despite growing attention to women's participation at the international level, at the national level in Georgia, the attention to women's issues has not been systemic since 2009. That being said, the findings imply that the attention to women's participation at the national level in Georgia appears to follow the increase in attention in the UNFCCC and its financial instrument policies.

With regards to the legitimation of women organisations, policy attention to these actors only emerged in 2017 (at the international level) and has remained inconsistent. In total, seven sources of legitimation have been identified (Table 3).

What is the quality of legitimation of the participation of women and women organisations?

The quality of legitimation is limited based on Georgia's case. First of all, there is low consistency in definitions that are applied in relation to women and women organisations across the three studied UNFCCC legitimation channels. Second, while there is anecdotal evidence that women engage in UNFCCC-led national level policymaking, according to experts' opinions, their engagement has not led to policy outcomes. With regards to women organisations' participation in Georgia, the interviewed experts provided limited anecdotal evidence on their participation. Visibility of women and women organisations in Georgia is also limited, i.e. interviewed experts could not link the engagement of women organisations with policy outcomes. However, the potential roles and contribution of women and women organisations are perceived positively by the interviewees.

Based on the experts' feedback, in Georgia, the participation and contribution of women and women organisations to UNFCCC-led policy processes at the national level is limited by several factors: the quality of policy narratives, a lack of data on the specific gendered impacts of climate change and women's vulnerabilities, and limited capacities and knowledge on climate change and climate finance.

The findings from the Georgia's case study point to a few actions that could enhance the participation and contribution of women and women organisations at the national level in Georgia:

- Explore possibilities for enhancing synergies across narratives of various UNFCCC-led legitimation channels with regards to the participation of women and women organisations;

- Create consistent definitions of women and women organisations and acknowledge different gendered actors and their specific roles; and

- Invest in upgrading the technical knowledge and skills of women and women organisations to ensure their substantive participation in climate change governance.

In this chapter, I proposed and tested a methodology for analysing the quality of legitimation of women and women organisations in multi-level UNFCCC led governance. Georgia is the first case where the methodology has been tested. Further fine-tuning and application to different national settings will be necessary to advance understanding on the role of gendered actors in supporting UNFCCC-led mandates and policy implementation.

In addition, to aid policy development, there is a need to expand methods of qualitative analysis of legitimation and consider discursive and behavioural legitimation. Also, considering limited access to data on participation and difficulties with creating controlled experiments within the UNFCCC's settings, there is a need to develop innovative methods for understanding the causeeffect relationship between legitimation strategies, participation rates and policy outcomes. 


\section{CHAPTER 6:}

Orchestrating the participation of women organisations in UNFCCC-led climate finance decision making ${ }^{60}$

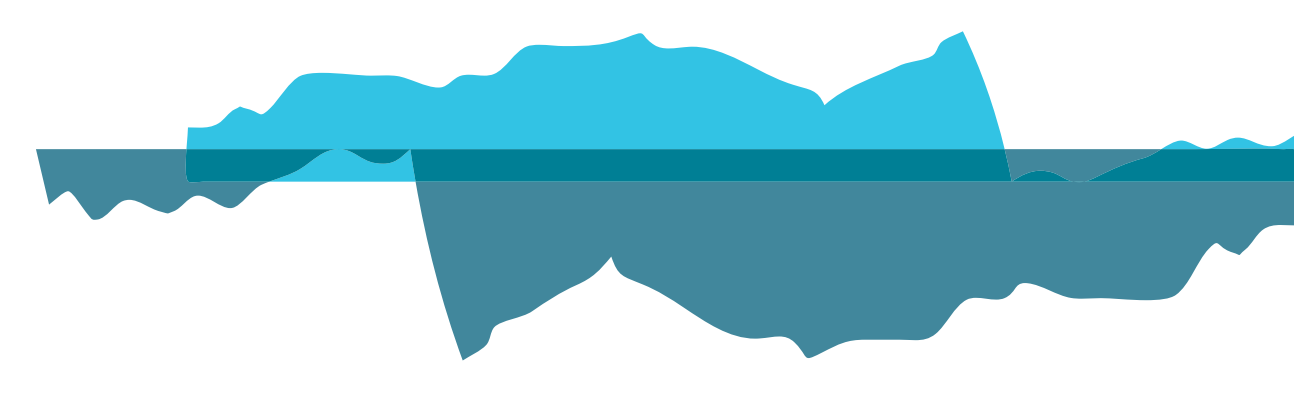

UNDERSTANDING POLICY AND INSTITUTIONAL STRATEGIES TO SUPPORT THE PARTICIPATION 


\subsection{INTRODUCTION}

The UNFCCC encourages the participation of non-state actors as stakeholders in climate change policymaking (Nasiritousi and Linnér 2016). Non-state actor participation is considered increasingly important in the post-Paris Agreement era (Kuyper, Linnér, and Schroeder 2018). It is argued that such stakeholders can influence high-level policy dialogue while bringing two particular benefits. First, non-state actors provide direct access to local information and knowledge, which is generally unavailable to international organisations and nation states (Manara 2012; Abbott et al. 2015a; True 2003). Second, the involvement of non-state actors increases the range of societal groups contributing to policy formulation as a more inclusive process.

Women organisations are a unique type of stakeholder whose participation is linked with the integration of a gender perspective in global public policy (True 2003), as well as with the promotion of the rights of women and gender equality (Annesley and Gains, 2010; McBride and Mazur, 2013). Women organisations can play an important role in fostering the implementation of inclusive policies (Larson 2002), while creating space for grassroots organisations and empowering local and national civil society (True and Mintrom 2001; Sharma 2010; Larson 2002). One approach for making the engagement of non-state actors more meaningful is for the UNFCCC to coordinate or orchestrate their participation. Orchestration is a mode of governance that uses indirect and soft methods of steering through partner organisations or intermediaries that possess experience and contacts that the UNFCCC does not have. In this way, orchestration helps the UNFCCC to more readily reach its objectives. Research shows that the UNFCCC is the central orchestrator of non-state actors within global climate governance (Hale and Roger 2014; Bäckstrand and Kuyper 2017). Indeed, the UNFCCC's method of operation can be seen as acting as an orchestrator and mobilising intermediaries (like constituencies ${ }^{61}$ ) to bring their additional knowledge and capacities into the policy formulation process. This is done by engaging with non-state actors with relevant expertise (target actors) in an attempt to facilitate the implementation of policy goals (Abbott et al. 2015b).

The UNFCCC recognises women organisations as important non-state actors in relation to climate finance, which is a mechanism for the implementation of the UNFCCC's policies. A clear statement of the UNFCCC's recognition of the

${ }^{61}$ Within the context of the UNFCCC, Constituencies are groups of actors, for example NGOs, that are voluntarily formed on the basis of shared interests and beliefs: https://unfccc.int/files/parties_and_observers/ngo/application/pdf/ constituencies_and_you.pdf (accessed in June 2021). role of women organisations comes in UNFCCC Decision 3/CP.2562, in which the role of women grassroots organisations and women groups is acknowledged as important for improving the gender responsiveness of climate finance.

This chapter explores the existing orchestration practices used by the UNFCCC in relation to women organisations and analyses the quality of this orchestration in implementing UNFCCC policy objectives (explained in section 6.2), e.g. improving participation of women organisations and achieving gende responsiveness of climate finance. The concept of orchestration is described in the next section. Section 6.3 sets out the problem statement and Section 6.4 describes the methodology. Results and findings that describe the existing orchestration approaches and analyse the quality of these approaches are discussed in Section 6.5. The chapter concludes with a discussion on how to interpret the findings and makes some research and policy recommendations for the mobilisation of women organisations within UNFCCC-led climate finance governance.

\subsection{ORCHESTRATION: THE PARTICIPATION OF NON-STATE ACTORS IN MULTI-LAYERED GOVERNANCE FRAMEWORKS}

The orchestration concept has been widely recognised in political science scholarship as a tool to study participation and interactions between state and non-state actors within multi-layered governance frameworks (Abbott et al. 2015b), and more specifically within the UNFCCC (Hale and Roger 2014 Abbott et al. 2015b; Bäckstrand and Kuyper 2017; Chan and Amling 2019; Thew, Middlemiss, and Paavola 2021). Orchestration is seen as arrangements that do not rely on legal enforcement but on voluntary coordination among state and non-state actors to improve the achievement of policy goals (Bendlin 2020; Frank Biermann and Kim 2020). The key feature of the orchestration concept is a model which describes the various roles in the process of orchestrating, i.e. Orchestrator - Intermediary - Target (Abbott et al. 2015b). Within this model, orchestrators, in the pursuit of policy goals, mobilise intermediaries (including the private sector, civil society, and transnational networks) to reach out to targets (for example, grassroot women organisations). Intermediaries are considered a necessary element in orchestration, because they possess local information technical expertise, enforcement capacity, material resources, legitimacy, and direct access to targets, which the orchestrator lacks (Abbott et al. 2015a). In

62 https://unfccc.int/sites/default/files/resource/cp2019_L03E.pdf (accessed in June 2021) 
addition, meta-intermediaries (i.e. institutional mechanisms) can be utilised to provide additional steering of intermediaries on certain issues (Bäckstrand and Kuyper 2017). Orchestration is expected to improve the implementation of policy goals by engaging with various types of expertise and improving the capabilities of the orchestrator in areas where it lacks experience, contacts, or authority (Abbott et al. 2015a). Abbott et al (2015) have produced a typology of orchestration approaches:

- Convening: providing opportunities to deliver policy messages through contact with influential actors, using participation in the meetings or a variety of other mechanisms (e.g. side events);

- Agenda setting: providing guidance on policy solutions;

- Assistance: providing material (e.g. travel funds) and capacity support;

- Endorsement: acknowledging and empowering intermediaries as competent and legitimate actors; and

- Coordination: ensuring the alignment of the orchestrator's activities with those of intermediaries.

The orchestration concept relies on a functionalist approach to participation, implying that non-state actors can contribute to filling governance deficits in knowledge, information and implementation (Chan and Amling 2019). Thus, the quality of orchestration could have an impact on the achievement of policy goals. In previous studies, the quality of orchestration has been linked with

- Meaningful recognition of intermediaries of orchestration (Moynihan 2003);

- Explicit policy mandates that specify what the participation is intended to achieve (Moynihan 2003); and

- Availability of resources and strategies to overcome barriers to participation (Belfer et al. 2019; Sweetman 2002).

While the concept of orchestration suggests that it is intended to enhance governance practices, in reality it may be used for symbolic purposes ${ }^{63}$ without having a significant impact on policies.

${ }^{63}$ Symbolic participation implies here that it does not involve shared decision making with women organisations nor allow them to influence decision-making processes.

\subsection{PROBLEM STATEMENT AND RESEARCH QUESTIONS}

There are two intermediaries in the UNFCCC system that can play an important part in enabling women organisations' meaningful participation in climate finance: The Standing Committee on Finance (SCF) and The Women and Gender Constituency (WGC).

The SCF is a constituted body ${ }^{64}$ with limited membership (consisting of governmental actors drawn from signatories to the UNFCCC) that provides technical support to the UNFCCC on climate finance issues, including the mobilisation, measurement, reporting, and verification of funds. The WGC is one of nine official observer groups of the UNFCCC. ${ }^{65}$ The WGC's goal is to "formalise the voice of the women's and gender civil society organisations". 66

The UNFCCC can utilise these two intermediaries to engage with women organisations by using the mandate of the SCF to engage and steer nongovernmental actors, including the WGC. The WGC, in turn, directly coordinates with women organisations (Figure 10). In other words, the UNFCCC is the orchestrator of a meta-intermediary (SCF), which orchestrates an intermediary (WGC) to engage with the target (women organisations).

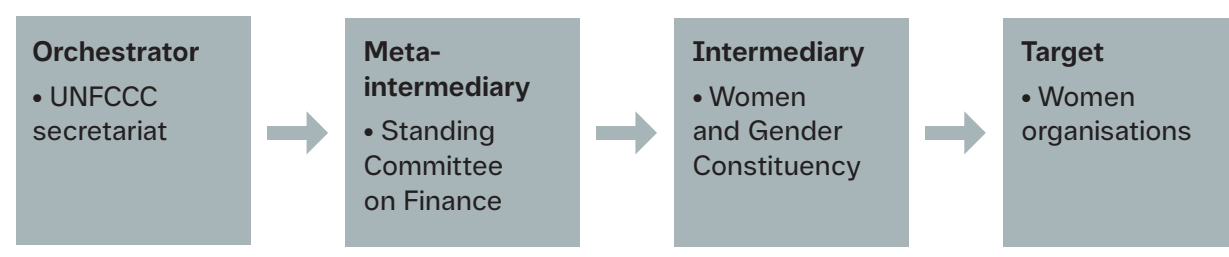

Figure 10. Orchestrating the engagement of women organisations in UNFCCC-led climate finance decision making

(Prepared by the author)

${ }^{64}$ Constituted bodies are institutional arrangements with limited membership that provide technical advice to the Convention, the Kyoto Protocol and the Paris Agreement.

${ }^{65}$ The WGC is one of the constituencies operating within the UNFCCC system. Participation is voluntary but confined to civil society organisations and networks that are recognised as an observer to the Conference of the Parties. Members must be actively engaged in gender equality and women's rights at the national, regional or global level. https://womengenderclimate.org/about-us/ (accessed in June 2021)

$66 \mathrm{https}$ ///womengenderclimate.org/about-us/ (accessed in June 2021). 
For both the UNFCCC and women organisations, orchestration efforts to mobilise women organisations to contribute to climate finance decisions should be of sufficient quality to allow them to reach their policy objectives. However, without adequate policy framing of orchestration and an understanding of the existing barriers to the meaningful participation of women organisations, the outcome could be that women organisations fail to reach their full potential to influence the outcomes of climate policy, which would also be detrimental to the UNFCCC. It is therefore timely to assess the existing orchestration approaches to support the engagement of women organisations in UNFCCC-led climate finance decision making and to evaluate the quality of orchestration efforts to involve women organisations. To make this assessment, I answer the following two questions:

1. What are the existing orchestration approaches to support the engagement of women organisations in UNFCCC-led climate finance decision making?

2. What is the quality of orchestration efforts to involve women organisations?

The main objectives of this chapter are first to provide early evidence on the existing orchestration approaches to engage women organisations in UNFCCC-led climate finance governance and, second, to reflect on the quality of the orchestration efforts which enable the UNFCCC to achieve its objectives and which ensure that women organisations, as non-state actors, are able to participate meaningfully. A third objective is, if necessary, to develop policy recommendations for enhancing the orchestration of women organisations in UNFCCC-led climate finance decision making.

In addition, the study contributes to the multilevel governance theory through an innovative look that uses the concept of orchestration and explores governance processes at the intersection of climate finance and gender equality.

\subsection{METHODOLOGY}

The chapter utilises mixed methods, i.e. document review and interviews with key informants. The documents reviewed were:

- 214 substantive SCF documents including annual reports, background papers, guidance to financial mechanisms, and records on the outcomes of the meetings. The documents were accessed at https://unfccc.int/scf/scfmeetings-and-documents in March 2021;

- 31 official submissions of the WGC and their members tracked through the UNFCCC's website: https://unfccc.int/process-and-meetings/parties- non-party-stakeholders/non-party-stakeholders/submissions/submissionsfrom-non-party-stakeholders (before 2018) and https://www4.unfccc.int/ sites/submissionsstaging/Pages/Home.aspx (after 2018) (both accessed in March 2021)

- 120 records of WGC interventions made at the UNFCCC's meetings, which are available on the WGC's website: https://womengenderclimate.org/ resource/ (accessed in March 2021)

These documents were analysed using ATLAS.tj software. The texts of SCF documents were scanned using the search terms "women", "female" and "gender". The fragments of texts associated with the use of these terms were scrutinised to identify references to organisations and institutional actors who are described using the above-mentioned terms. The texts of the WGC's submissions were analysed using the search term "finance" to identify specific narratives related to the role of women organisations in climate finance.

Semi-structured interviews were conducted with four experts. These experts were selected to cover each of the four groups of actors in the orchestration process as shown in Figure 10:

- Interviewee A (Representative of the UNFCCC Secretariat: the Orchestrator)

- Interviewee B (SCF expert: the Meta-intermediary)

- Interviewee C (WGC Focal point to SCF: the Intermediary)

- Interviewee D (WGC member: the Target)

In line with the University of Twente's ethical policy, the interviewees are not identified by name but by a code. Each interview lasted approximately one hour and each was recorded with the interviewees' consent, which is in keeping with the university's ethical guidelines.

The interviews covered the following topics:

1. The UNFCCC's existing participatory processes and management of participation, specifically in relation to women organisations, including challenges and barriers to the participation of women organisations;

2. Approaches utilised by women organisations for influencing policy outcomes and the interviewees' perception of limitations and opportunities associated with these approaches; and

3. Awareness on the influence of women organisations on climate finance policymaking, including specific language being integrated and/or enhanced, norms or targets being adopted, commitments increased, etc. 
The data generated was used to answer the two research questions using different frameworks. The first question is answered using the framework proposed by Abbott et al. (2015b), described above. The specific approaches that exist within the orchestration model are described using an analysis of the UNFCCC's guidelines and documents on participation and the interviews with experts. The second question is answered using document review and semistructured expert interviews. The following criteria were used to assess the quality of orchestration:

- The extent of the engagement of the WGC (intermediary) in the SCF's meetings, based on a review of the list of participants;

- The extent of the mobilisation of women organisations (the targets) by the WGC, based on an analysis of its membership;

- Consistency across the policy framings, which are used by the orchestrator and intermediaries, in relation to the definition of women organisations and the purposes specified for mobilising women organisations (assessed through document review via ATLAS Software); and

- The presence of challenges and barriers to the participation of women organisations based on expert interviews.

\subsection{RESULTS}

\subsubsection{Existing orchestration approaches}

In this section, I provide an answer to the first research question by describing the existing approaches to orchestrate women organisations' engagement in climate finance decision making under the UNFCCC. I use the typology identified by Abbot et al. (2015b): convening, agenda setting, assistance and endorsement. The summary of the analysis is presented in Figure 11.

\section{Convening} - Bilateral meetings between WGC's Focal Point and SCF's members - Briefings between SCF's Chairs and observers before the SCF meetings

Agenda setting

Assistance

- Intervention opportunities provided by the SCF's Chairs

- Written submissions by the WGC

Women Delegates Fund (WDF)

WGC's donors

Women for Results Initiative (MCWR)

Gender Just Climate Solutions Awards
Convening: Constituencies, which include women organisations, are invited to hold bilateral meetings with SCF members to share position papers and submissions and advocate for policy perspectives. The constituencies engage with constituted bodies through the constituency's focal point, who convey joint constituency statements. In addition, non-party stakeholders can advocate through the organisation of press conferences, side events, and exhibits Another opportunity to convey messages is at workshops and meetings of the constituted bodies, which are seen as platforms for retrieving experts' advice and input.

Interviewee A explained that, in 2018, the SCF opened up participation in its meetings to a broader range of stakeholders. The SCF was one of the first constituted bodies within the UNFCCC offering constituencies this engagement modality. If the time allows, observers from the constituencies are given the floor to provide input on agenda items. Before 2018, if constituencies came to the meetings, their participation was only as observers, although they could discuss policy matters informally before or after meetings and during breaks. In 2018, a more formal orchestration process was instituted, which includes regular briefings with observers before the SCF meetings. These briefings have been attended by the WGC Focal Point. The WGC's Focal Point is allowed to attend the break-out group discussions, which focus on technical matters.

The WGC has been offered an opportunity to hold informal dialogues with SCF members, for instance during coffee breaks. Interviewee $\mathrm{C}$ stated that the WGC has mostly delivered policy messages through these informal bilateral meetings.

Agenda setting: Constituencies can contribute to agenda setting by responding to calls for information, developing position papers, and making formal submissions. In addition, there is a possibility to make interventions during the plenaries and meetings of constituted bodies. Intervention opportunities are provided by the chairs of the respective bodies. The WGC has been providing written submissions, ${ }^{67}$ for example on climate finance, as a key means for the implementation of gender-responsive climate actions. The opportunities to submit inputs are provided by co-chairs of the SCF and are available on the SCF's website.

Assistance: There have been initiatives to provide travel funds to support women's engagement in national delegations and the participation of grassroots local and indigenous peoples' communities in the UNFCCC. For instance, the 
Women Delegates Fund (WDF) was established in 2009 through the support of several donors ${ }^{68}$ to support the participation of women from grassroots, local and indigenous communities. The WDF falls under the jurisdiction of the WGC, which, at the time of writing, is administered by the Women's Environment and Development Organisation (WEDO) as the acting administrator of the WGC. The WDF covers travelling costs only for delegates who are part of the official government delegation and are nominated by the UNFCCC Focal Points. In some cases, the WDF nominates candidates as UNFCCC Focal Points. Since 2017, the WDF has supported over 63 trips by female experts, however, it is not evident how many of these women represented women organisations.

Financial assistance for participation in SCF meetings is somewhat limited. According to Interviewee C the WGC's donors see little value in prioritising participation by women organisations in the SCF's deliberations, which has led to low prioritisation of travel for attending the meetings, resulting in mostly virtual participation by the WGC in the SCF's events.

Endorsement: Some initiatives acknowledge the key role of women organisations in addressing broader climate change. For instance:

- The UNFCCC's Momentum for Change: Women for Results Initiative (MCWR) (launched in 2012) ${ }^{69}$ showcases women-led initiatives, as well as initiatives implemented by organisations with gender equality mandates that support climate action.

- Gender Just Climate Solutions Awards, organised by the WGC as side events held during the UNFCCC's meetings, to recognise the activities of women and women organisations in the implementation of transformative climate change policies and climate finance solutions. ${ }^{70}$

\subsubsection{The quality of orchestration}

In this section, I describe the quality of orchestration using four criteria: (1) the extent of mobilisation of women organisations (targets) by the WGC (the intermediary), (2) the extent of the engagement between the WGC and the SCF (intermediary and meta-intermediary), (3) the presence of barriers and

${ }^{68}$ Including the governments of Australia, Canada, France, Iceland, the Netherlands, Scotland, Sweden, and Switzerland, https://wedo.org/what-we-do/our-programs/ women-delegates-fund/ (accessed in March, 2021)

$69 \mathrm{https}: / /$ unfccc.int/climate-action/momentum-for-change/women-for-results (accessed in March, 2021).

$70 \mathrm{https}$ ///unfccc.int/playground-20/level-2/level-3/women-and-gender-constituencyand-the-climate-technology-center-and-network (accessed in March, 2021). challenges to the participation of women organisations, and (4) consistency across the policy framings that are used by the orchestrator and intermediaries on how women organisations and the purposes of orchestration are defined by the UNFCCC.

\section{Mobilisation of women organisations by the WGC}

The WGC, established in 2009, consists, at the time of writing, of 33 women and environmental civil society organisations (Figure 12). Within these broader categories, WGC members identify themselves as national, international, and regional NGOs, grassroots organisations, and networks. The WGC mobilises women organisations through a range of mechanisms. For example, organisations which are accredited as an observer organisation to the UNFCCC and work in alignment with the WGC's goals and priorities can become members of the WGC.71 In addition, the WGC mobilises a broader range of organisations, which are not accredited by the UNFCCC, through the WGC Advocacy List and the Women's Caucus. The WGC Advocacy List includes about 500 representatives of civil society who are engaged in developing climate policy positions and are contacted for information and sharing key advocacy positions. The Women's Caucus is a mailing list for all types of stakeholders interested in the WGC's work for sharing information and collective advocacy.

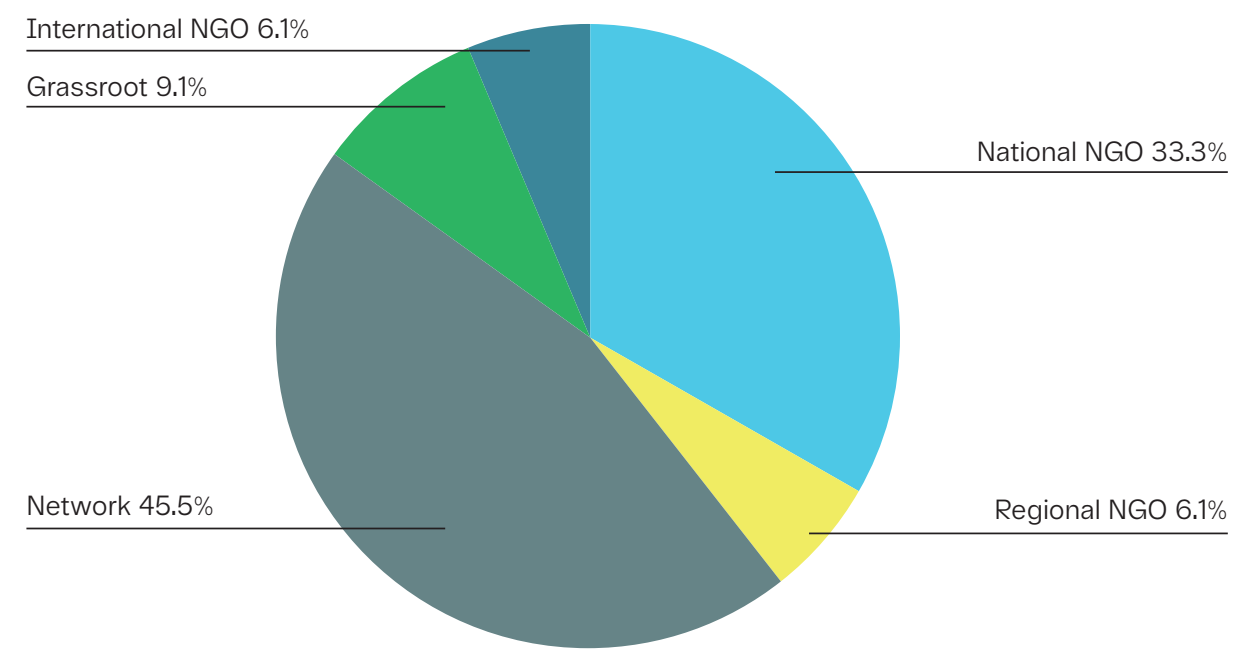

Figure 12. The composition of the WGC (as of 2021) (Based on https://womengenderclimate.org/member/)

71 https://womengenderclimate.org/how-to-join/ (accessed in March 2021). 
According to the interviewee representing the WGC, expanding membership is not an ambition or an indication of effective mobilisation. Enhancing the representation of women organisations at UNFCCC meetings or building knowledge of these organisations on the UNFCCC's decision making is not seen as an appropriate orchestration approach. Interviewee $C$ stated: "It is not critical for local knowledge to be at the negotiations, but it is critical to have an organising structure to mobilise and share knowledge between negotiations

.. so the strategies can be built to connect international policies with locallevel experiences".

\section{Engagement between the SCF and the WGC}

Since its establishment in 2012, the SCF has organised 23 meetings (as of March 2021). ${ }^{72}$ Based on the analysis of the list of participants, the WGC participated in three SCF meetings. The participatory evidence correlates well with the information provided during the expert interviews. According to the four interviewees, the track record of WGC participation in meetings, in terms of both physical attendance and making interventions, on climate finance issues under the UNFCCC is limited. The interviewees unanimously agreed that the SCF has not been able to mobilise the WGC substantively, nor has the WGC, so far, been able to make much impact on climate finance.

\section{Orchestration challenges}

The interviewees, in attempting to explain the existing participatory challenges for women organisations, identified a number of issues which I group into three categories:

- Challenges that are related to general UNFCCC practices and rules, which define the constrained roles of civil society actors. These types of challenges are well captured in the literature and are inherent in the political setup of the UNFCCC decision-making processes (Derman 2014; Sharma 2010).

- Challenges that are related to limitations on how the participation, at the intersection of climate finance and gender equality, is organised by the SCF and is taking place.

- Challenges that are related to specific WGC capacity issues to mobilise and influence climate finance decision making.

Given the objectives set out in Section 6.3, I further reflect here on orchestration challenges that are specific to climate finance decision making. For example, the limited opportunities for engaging in agenda setting are linked with the

72 https://unfccc.int/scf/scf-meetings-and-documents (accessed in March 2021). political setup of the UNFCCC and its constituted bodies. According to the interviewees, meeting agendas are set in line with the COP's decisions and cannot be adjusted even by SCF members. However, Interviewee A noted that there are other opportunities to contribute indirectly to setting agendas, for instance, the provision of substantive inputs within the development of flagship reports, such as the Biannual assessment of climate finance. ${ }^{73}$ These opportunities have not yet been fully utilised by the WGC.

Interviewees A, C, and D report that opportunities for enhancing non-state actors' roles (and more specifically those of Civil Society Organisations (CSOs)) require better awareness and recognition of their instrumental roles. In the opinion of the interviewees, there is a need to convey and demonstrate the utility of CSOs' participation in strengthening policy outcomes. There is anecdotal evidence that in some cases the instrumental value of CSOs is acknowledged. According to the interviewees, some Parties ${ }^{74}$ value CSOs participation, because CSOs frequently share points that help Parties to prepare texts and talking points which help create stronger positions in negotiations about climate finance.

In terms of the management of participation at the SCF, Interviewee $\mathrm{C}$ noted that following the decision-making processes at the SCF has been challenging. Transparency is limited with regards to how the policy documents are drafted and finalised. In theory, the WGC's assigned focal points could work (between meetings) on untangling the logic of the decision-making process, but the capacities of the WGC to follow up on each decision are limited.

In addition, the interviewees agreed that knowledge on the intersection of gender equality and climate finance is new and limited. According to Interviewees A and C, it appears that for SCF members, the newness of gender equality as a topic results in limited integration and attention to these issues within the SCF's agendas and hampers the mobilisation of women organisations. The SCF experts are knowledgeable about climate finance but have little understanding of gender equality issues. On the other hand, all four interviewees perceive women organisations' technical knowledge of climate finance as limited. Interviewee $C$ noted that the content of the issues discussed at the SCF is extremely difficult to grasp and comprehend, particularly for anyone without an understanding of finance.

${ }^{73}$ In line with the guidance from the COP, the SCF has to assess the geographical and thematic distribution of climate finance flows, including but not limited to climate finance from the UNFCCC's Financial instruments.

74 Parties are countries which are signatories to UNFCCC. 
Generally, all four interviewees are in agreement about the lack of capacity of the WGC to deliver systemic contributions to climate finance decision making. These capacities are related to nascent organisational structure and limited availability of resources.

In interviewee C's opinion, the WGC does not appear to have specific mandates related to climate finance. The funding that has been raised to support the work of the WGC has been geared towards mainstreaming gender issues in policy texts. It is the interviewee's opinion that this is not necessarily an indication of a lack of attention to these issues, but rather one of a nascent level of organising and low level of resources. The perception of donors on how WGC's activities need to be prioritised has a not insignificant impact on the WGC's participation in SCF meetings. Interviewee C noted that the WGC has had difficulties with convincing donors about the importance of travel for attending SCF meetings, which has led to mostly virtual participation in SCF events. As a consequence, the opportunities for informal meetings are not possible, resulting in lost possibilities for influencing policies and outcomes.

\section{Consistency of policy framings}

The study analysed the consistency of the policy framings that are used by the Orchestrator, Meta-intermediary and Intermediary in relation to the definition of women organisations and the purposes of their mobilisation. The findings of the analysis are presented below.

The Orchestrator framing: The earlier analysis of the UNFCCC documents shows that the participation of women organisations is considered as key for ensuring that climate finance is gender responsive. The UNFCCC has clearly indicated, as shown by Decision 3/CP.25, that it expects women groups, grassroots women organisations, and national gender institutions to play an important role in ensuring the integration of gender issues in climate policies, plans, and strategies. In addition, grassroots women organisations are noted as recipients of climate finance. In line with this framing, the purpose of orchestrating women organisations could be presented as improving access to and ensuring the gender responsiveness of climate finance.

The Meta-intermediary framing: The analysis of the SCF documents revealed that the SCF appears to have gender mandates, which include inter alia reporting on progress towards integrating a gender perspective into SCF processes and providing capacity building to committee chairs and members on how to integrate gender considerations. ${ }^{75}$ However, within these documents, there

75 Background document on the 2019 workplan of the SCF Mandated activities https://unfccc.int/sites/default/files/resource/BN3_2019WP.pdf (accessed in April 2021). is no recognition of the role of women organisations in the implementation of these mandates. On the other hand, the guidance provided by the SCF to the UNFCCC Financial Instruments states that the participation of "womenled organisations" is linked with the development of inclusive strategies and strengthening gender-related actions of climate finance. ${ }^{76}$ In addition, the role of the WGC is noted (in the analysed SCF policy texts) in relation to achieving gender balance in the UNFCCC process and gender-sensitive climate policy. ${ }^{77}$ In line with this framing, the purpose of the orchestration via the WGC may be seen as increasing both the participation of women in the policy process and the gender sensitivity of climate policies.

The Intermediary framing: Based on the analysis of women organisations submissions to the UNFCCC, they are interested in and aim to contribute to the following aspects of climate finance:

- Gender responsiveness: One of the key claims of women organisations is that $100 \%$ of climate finance needs to be gender responsive.

- Equity: Women organisations claim that climate finance is key to achieving just and equitable solutions to the climate crisis. In addition, women organisations advocate for better integration of gender equality considerations in climate finance policies, procedures, and approaches.

- Accessibility: Women organisations convey that access to climate finance needs to be ensured for the world's farmers and direct access entities (DAEs) (i.e. sub-national, national or regional organisations from developing countries that could access climate finance directly from the GCF).

- Adequate volume and predictability: Women organisations request increased contributions of the public sector to support the mobilisation of US $\$ 100$ billion per year by 2020, enhanced contributions to limit temperature growth under $1.5^{\circ} \mathrm{C}$, and increased adaptation finance.

- Transparency and accountability: Women organisations demand that climate finance accounting be transparent and available to track climate finance in the long term.

- Additionality: Women organisations appear to have strong positions in relation to the additionality of climate finance to support loss and damage.

76 The Seventh Report of the Green Climate Fund to the Conference of the Parties to the United Nations Framework Convention on Climate Change https://unfccc.int/ sites/default/files/resource/Seventh\%20Report\%20of\%20the\%20GCF\%20to\%20 UNFCCC\%20COP_UNFCCC\%20submission.pdf (accessed in April 2021).

77 Compendium of past guidance provided to the Green Climate Fund: COP 16 - COP 20 https://unfccc.int/files/cooperation_and_support/financial_mechanism/ standing_committee/application/pdf/compendium_gcf.pdf (accessed in April 2021). 
In line with the information presented above, there are two inconsistencies in policy framings:

- Inconsistent definition of women organisations: While the UNFCCC's decisions acknowledge three types of women organisations, the references to women organisations in the SCF's policy texts are not aligned with the terms used by the UNFCCC. Women-led organisations are a category of organisations targeted by the SCF. However, this type of organisation may not qualify as an entity with gender equality mandates or have specific knowledge on gender equality issues. As was stated above, grassroots women organisations appear to be one of the important stakeholders of climate finance (as per UNFCCC decisions), but these types of organisations are not recognised in the SCF texts, nor do they appear to represent a significant portion of the WGC membership organisations. As shown in Figure 12, grassroots organisations represent $9 \%$ of constituency members.

- Inconsistent purposes of orchestration: Ambiguous policy mandates, that lack specificity on what the participation is intended to achieve, have been identified as one of the key barriers to orchestration (Moynihan 2003). The orchestration of the participation of women organisations in the UNFCCC generally, and more specifically in climate finance decision making, appears to be in line with this finding. The UNFCCC's text defines the purpose of mobilising women organisations as improving the gender responsiveness of climate finance. The SCF's texts refer to the purpose of improving the gender sensitivity of climate policies through the engagement of womenled organisations. While the terms "gender responsive" and "gender sensitive" can be used interchangeably in policy texts, development professionals delineate the terms. Gender sensitivity usually refers to the acknowledgment of roles and inequalities. Gender responsiveness implies the development of appropriate actions to respond to the existing issues and inequalities (WHO 2009). While the WGC aims to increase the gender responsiveness of climate finance and climate policies, there are other key policy messages that the women organisations have been conveying through the WGC in relation to climate finance, i.e. equity, additionality, transparency, accountability, accessibility, and predictability, which face similar problems in gaining recognition. Interviewees $\mathrm{C}$ and $\mathrm{D}$ report that the integration of a gender perspective in climate finance is a priority, however the overarching purpose of mobilisation is to "create better systems for climate and gender justice". Indeed, gender responsiveness is noted as one of the key demands. However, based on experts' statements, other demands, e.g. transparency, accessibility, predictability, and additionality, are conveyed by emphasising the implicit linkages of these demands with gender equality. This being said, it appears that explicitly linking various demands by WGC members related to gender and climate justice is challenging within the UNFCCC processes.

\subsection{DISCUSSION}

The results show that the quality of existing orchestration approaches that support the mobilisation of women organisations has been limited in conjunction with four criteria introduced earlier: (1) the extent of engagement of the relevant intermediaries in climate finance meetings, (2) the extent of the mobilisation of women organisations by the intermediary, (3) consistency across the policy framings used by the orchestrator and intermediaries in relation to women organisations, (4) presence of challenges and barriers to the involvement of women organisations in UNFCCC-led climate finance decision making (based on experts' opinion).

The concept of orchestration is useful for studying the mobilisation of non-state actors within multi-layered governance, however the orchestration concept has mostly been used to understand the role of the orchestrator and its abilities to steer participation. While the perspective of the orchestrator is crucial because it shapes the approach to participation, the meta-intermediaries and intermediaries play key roles in the management and organisation of the participation. As my analysis shows, in complex polycentric governance systems (such as the UNFCCC), meta-intermediaries and intermediaries have their own interpretations of the goals of the orchestration. In addition, the targets' capacities may be crucial for ensuring their effective mobilisation.

The quality of orchestration could be affected by a mismatch in the framing of orchestration efforts, which could further lead to sub-optimal orchestration outcomes. Based on the analysis of over 365 documents, this appears to be the case in relation to the orchestration of women organisations' participation in UNFCCC led climate finance decision making. My analysis has identified two types of inconsistencies: first in how women organisations (as targets of orchestrations) are defined and, second, in how the purpose of their mobilisation is seen by the UNFCCC (the Orchestrator); the SCF (the Metaintermediary) and the WGC (the Intermediary). While integrating a gender perspective in climate finance appears to be a common purpose for mobilising women organisations, the WGC acknowledges other policy demands of women organisations, including equity, additionality, transparency, accountability, accessibility, and predictability of climate finance. These findings imply that women organisations' identity and their policy contributions are not well captured within UNFCCC climate finance decision-making processes.

Aside from discrepancies in framing, there are some process and capacityrelated challenges that limit the success of the orchestration efforts. These challenges, to a large extent, are defined by the inherently limited roles of CSOs, including women organisations, within UNFCCC climate finance 
decision-making processes and by a lack of understanding of the utility of their engagement. In addition, the study has found that women organisations' technical knowledge on climate finance issues has been limited. Within the context of the UNFCCC negotiations, which have now become more complex, the lack of understanding of technical issues has been known to disincentivise the engagement of newcomers and actors who are less familiar with technical topics (Villagrasa 2002). Thus, capacity building is required to improve access to climate finance training for women organisations.

Within the context of the UNFCCC, the application of top-down engagement models with women organisations (i.e. based on initiatives from the top) has been linked with limited participatory outcomes (Sharma 2010). A bottom-up engagement approach, which is based on the creation of adequately funded and accountable national networks of women organisations, should lead to better outcomes (Sharma 2010a). However, as the current study shows, funding assistance to support the engagement of women organisations in climate finance decision making has been scarce.

Similar capacity issues have been recognised in other arenas such as holding national governments to account for budgetary allocations (Balmori 2003). There are tools available, such as gender audits, that can enable orchestration actors to engage more effectively, and in an inclusive manner, in climate finance decision making (Clancy and Mohlakoana 2020).

Based on the interviewees' statements, providing evidence to policymakers on the positive contribution of women organisations to climate finance could address these orchestration challenges. However, providing this evidence is challenging, since the instrumental narratives around the participation of women organisations are difficult to substantiate. First of all, the ambiguity of framing in relation to women organisations hampers the development of adequate participation indicators (e.g. policy outcomes), which could demonstrate and assess the instrumental value of women organisations' participation. Second, even if the policy outcomes are defined, proving the attribution of women organisations to the delivery of these outcomes would require the consideration of counterfactual scenarios, i.e. what would happen without the engagement of women organisations. The development of such scenarios within UNFCCC-led orchestration efforts on climate finance may not be attainable.

\subsection{CONCLUSIONS}

This chapter set out to answer two questions: (1) what are the existing orchestration approaches to support the engagement of women organisations in UNFCCC-led climate finance decision making and (2) what is the quality of orchestration efforts?

With regards to the first question, my research has identified some orchestration approaches existing within the UNFCCC-led climate finance decision making processes. However, while these approaches are recognised, actual opportunities to participate are limited. For example:

- The WGC's convening of policy messages is organised mostly through informal bilateral meetings. However, the capacities of the WGC to deliver systemic contributions on behalf of women organisations to climate finance decision making are considered limited due to a lack of technical expertise on climate finance issues.

-While agenda-setting opportunities exist and invitations to submit inputs are provided by the SCF's co-chairs, these opportunities are extremely limited since the agendas are guided by the COP's decisions and cannot be adjusted even by SCF members.

- Some forms of financial assistance for participation exist, but they are limited as donors see little value in prioritising the WGC's participation in the SCF's deliberations.

- Endorsement takes place through a number of initiatives, e.g. the UNFCCC's Momentum for Change and Gender Just Climate Solutions Awards, which acknowledges the key role of women organisations in addressing broader climate change.

With regards to the second question, I show that the quality of orchestration of women organisations in UNFCCC-led climate finance governance has been low. There is a number of challenges within the orchestration process that, if they were to remain unaddressed, are likely to result in only a symbolic mobilisation of women organisations. In line with the triangulation of document analysis and expert evidence, the following key issues that limit the quality of orchestration have been identified:

- Lack of policy convergence between the purposes of orchestration, including limited correlation between how women organisations are defined as targets of orchestration and what the participation of women organisations is intended to achieve. 


\section{CHAPTER 6}

- Newness and complexity of the issues on the intersection of climate finance and gender.

- Lack in the WGC's capacity, including technical knowledge of climate finance issues, and consistent prioritisation of climate finance issues in its mandates to aim for and deliver systemic contributions to climate finance decision making

One of the key findings of my research is that orchestration at the intersection of climate finance and gender equality is very limited and is associated with a number of orchestration challenges stemming from the newness of the practice. While orchestration as a concept has been useful for studying the mobilisation of non-state actors within one issue (or focal) area, there is a need to expand orchestration concepts with knowledge about the intersection of two focal areas, such as climate finance and gender equality.

I have shown that the UNFCCC's existing orchestration approaches are inherently limited. The orchestration of women organisations in UNFCCCled climate finance governance may be used for symbolic purposes without a significant impact on policies. To make the engagement with women organisations more meaningful, the following measures could be considered by policymakers:

- Exploring possibilities for experimenting and diversifying the existing orchestration practices, including those related to funding assistance. Generally, willingness to innovate and entrepreneurial efforts of orchestrators are considered as one of the factors defining the success of orchestration (Abbott et al. 2015b)

- Improving policy framing and reducing the divergence of the purposes of orchestration and roles of meta-intermediaries, intermediaries, and targets. The convergence of goals and their correlation is linked with the better success of orchestration (Abbott et al. 2015b). 


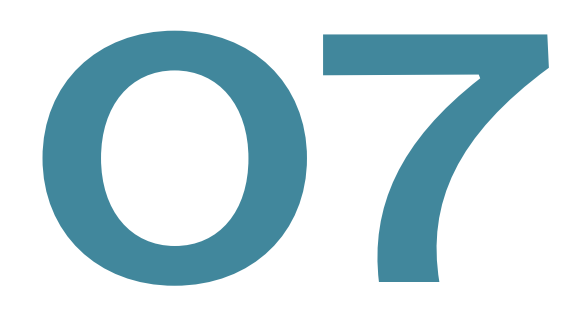

\section{CHAPTER 7:}

Climate finance allocation practices to support women's empowerment: GCF case-study ${ }^{78}$

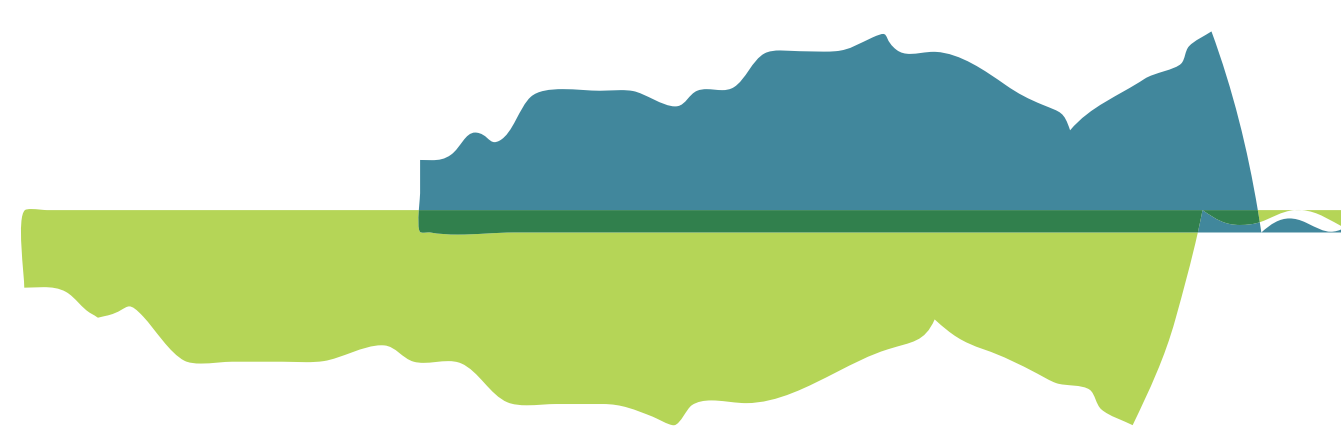

UNDERSTANDING POLICY AND INSTITUTIONAL STRATEGIES TO SUPPORT THE PARTICIPATION OF WOMEN AND WOMEN ORGANISATIONS WITHIN UNFCCC-LED CLIMATE CHANGE GOVERNANCE

78 The Chapter is based on the article published in Clancy J., Özerol G., Mohlakoana

N., Feenstra M., Sol Cueva L. (eds) Engendering the Energy Transition. Palgrave

Macmillan, Cham. https://doi.org/10.1007/978-3-030-43513-4_9 


\subsection{INTRODUCTION}

Over the last 15 years, the international climate finance institutions have been undergoing transformations to address the need for scaled-up and effective investments (Gomez-Echeverri 2013). In parallel to this, policymakers, development organisations, civil society, women's groups, and scientists have argued that climate investments made with consideration of gender equality and women's empowerment issues enhance development impacts and facilitate transformation to sustainable development (European Institute for Gender Equality 2016; Kronsell 2013; Tanaka \& Bhandari 2016; UN WOMEN 2016; Raney et al. 2011).

The GCF is the largest multilateral climate finance fund, which is the Financial Mechanism created under the UNFCCC to support transformational projects aimed at low-emission and climate-resilient development that deliver beyond business-asusual approaches in developing countries. The Governing Instrument of the GCF states that the Fund will aim at maximising impact of its funding including inter alia by taking a gender sensitive approach. This statement is also in line with UNFCCC Decision 8/CP.19 (2014) that the extent of gender-sensitive approaches defines the effectiveness of the funds disbursed by climate finance funds.

The inclusion of women and overall integration of gender issues into the GCF's projects and programmes is guided by the existing Gender Policy (introduced in 2015), which highlights the importance of pursuing low carbon and climate-resilient development based on the principles of gender equality. The Gender Policy specifies that resource allocation for adaptation and mitigation projects and programmes has to contribute to gender equality and women's empowerment (GCF/B.09/23:88, 2009). Furthermore, the proposal for the updated GCF Gender Policy ${ }^{79}$ states that climate change initiatives are more sustainable and effective if women's empowerment considerations are integrated into the design and implementation of projects (GCF/B.20/07 2020).

While there is clear recognition of the importance of the integration of women's empowerment issues within climate finance disbursed by the GCF, there is little knowledge about whether this ambition materialises in practice. In this

79 The updated policy has been undergoing a number of thorough revisions which have been presented to the Board on several occasions. During the Board meeting held in July 2019, a procedurat decision was adopted to con assessment for the implementation of the Gender Policy and to present a revised Gender Action Plan together with the Gender Policy at B.24 to the Board Meeting to be held in November 2019 chapter I analyse climate finance allocation practices to assess whether they support the delivery of women's empowerment outcomes using the example of the GCF energy generation and access portfolio, which presents the largest investment portfolio of the GCF, both in terms of the total number of projects and in terms of volume of investments. 80

In this chapter I analyse how women's empowerment considerations are included and vary across different types of energy investment categories. Based on this analysis, the chapter identifies and discusses factors that could influence the integration of women's empowerment issues in GCF's climate finance. The findings provide insights for the climate finance community (including policymakers, project developers and beneficiaries of climate finance) on any gaps in the existing institutional strategies that support gender responsive energy transitions with recommendations on how these gaps to be closed to provide more meaningful engagement of women in climate finance projects and programmes.

\subsection{PROBLEM STATEMENT AND RESEARCH OUESTIONS}

Women have been recognised as important actors within climate finance governance (Figueres, Tovar-Restrepo and Eddy 2013) and there are a number of studies linking the engagement of women with good climate governance (Wakefield 2017), more inclusive decision making that considers diverse vulnerabilities and needs (Kronsell 2013), and effectiveness and efficiency of climate finance (UNDP 2013; Adams et al. 2014; Wong 2016; Schalatek 2018), as well as the involvement of women in specific sectoral interventions to support climate change mitigation and adaptation (Marshall, Ockwell, and Byme 2017 Siulemba and Moodley 2014; Mcleod et al. 2018; Jerneck 2018; Mishra and Pede 2017). The GCF is the largest climate finance fund and the UNFCCC's main Financial Mechanism with an overall initial pledged capital of over USD 10 billion. Women are recognised as a key stakeholder by the Governing Instrument of the GCF, which was approved by the COP. ${ }^{81}$ Furthermore, the initial GCF Gender Policy explicitly notes that climate finance disbursed by the GCF needs to contribute to gender equality and women's empowerment (GCF/B.09/23 2015).

80 As of February, 2019, the energy and access portfolio covered $40 \%$ of total GCF funding (equivalent of USD 2 bln) (GCF/B.23/Inf.1 2019).

81 https://www.greenclimate.fund/documents/20182/1246728/Governing_ Instrument.pdf/caa6ce45-cd54-4ab0-9e37-fb637a9c6235 (Accessed 27 October 2019) 
The initial GCF Gender Policy prescribes that:

- All climate investments should be screened for gender sensitivity at the various stages of the project preparation, appraisal, approval, and monitoring by the relevant bodies, e.g. NDAs, Accredited Entities (AEs), and the Secretariat.

- All climate investments should include a mandatory initial socioeconomic and gender assessment.

- Accredited entities should conduct gender equitable stakeholder consultations for the design and implementation of investments. And women and men should be provided with equitable opportunities to be included in decision making.

- All climate investments should include a gender perspective in the application of the mandatory project/programme social and environmental safeguards.

Furthermore, in the GCF Gender Mainstreaming Guidelines (GCF 2017), there is a recognition that the GCF's resource allocation practices need to be guided by the potential to deliver women's empowerment outcomes. There is however little evidence on how this ambition is reflected in the investment framework, which lacks references to specific women's empowerment results.

There is an increasing need to understand how women are mobilised through climate finance and what institutional, technology and implementation factors affect the integration of women's empowerment issues in climate finance investments. This knowledge is necessary to improve institutional policies to support more meaningful engagement of women in the development of climate solutions.

Therefore, the objectives of this chapter are:

- to analyse the existing climate finance allocation practices from the perspective of the integration of women's empowerment issues within the context of the GCF energy generation and access portfolio; and

- to compare different energy categories to identify factors that could affect the integration of women's empowerment issues within climate investments.

These objectives lead to the formulation of two research questions:

-What is the quality of climate finance allocation practices in terms of the integration of women's empowerment issues within the GCF energy portfolio?

- What institutional, technology and implementation factors may affect the extent of the integration of women's empowerment issues within the GCF energy portfolio?

\subsection{METHODOLOGY}

This chapter uses a methodology which:

- Analyses the quality of climate finance allocation from the perspective of the integration of women's empowerment issues across specific categories of the GCF's energy investments that are guided by the scale of energy technology, sectoral orientation (mitigation vs. adaptation), and type of implementing partners, public vs. private sector institutions.

- Identifies factors that could affect the extent of the integration of women's empowerment issues through the comparison of the different categories of the GCF energy investments.

\subsubsection{The quality of the integration of women's empowerment issues}

To analyse the quality of the integration of women's empowerment issues within climate finance, the concept of women's empowerment and its assessment criteria need to be defined. While there is no consensus on how women's empowerment can be measured (Raj 2017), some women's empowerment indicators have been developed and applied by development organisations, including the UN and international aid agencies (Malhotra, Schuler and Boender 2002; Chung et al. 2013; Sundström et al. 2017). To carry out the analysis I have adapted the assessment criteria developed by Chung et al. (2013) and I developed a framework that is tailored for analysing the GCF energy investments (Table 4). The framework describes women's empowerment outcomes across five result areas, i.e. economic, education, governance, health, and information. 
Table 4. Women's empowerment results areas in climate investments (Adapted from Chung et al., 2013)

\begin{tabular}{l|l}
\hline Result area & Description \\
\hline Economy & $\begin{array}{l}\text { The investment project creates specific opportunities for women's access } \\
\text { to energy services and provides access to financial and development } \\
\text { opportunities associated with clean energy markets. }\end{array}$ \\
\hline Education & $\begin{array}{l}\text { The investment project provides educational opportunities for women in } \\
\text { the clean energy sector. }\end{array}$ \\
\hline Governance & $\begin{array}{l}\text { The investment project creates opportunities for women's involvement in the } \\
\text { decision-making processes for the implementation of project and broader } \\
\text { climate finance decisions at the national, regional, and local levels. }\end{array}$ \\
\hline Health & $\begin{array}{l}\text { The investment project creates health or wellbeing related outcomes } \\
\text { and benefits. }\end{array}$ \\
\hline Information & $\begin{array}{l}\text { Women are involved in consultations related to the implementation of projects } \\
\text { and climate investments. }\end{array}$
\end{tabular}

The framework is used in the context of the GCF energy access portfolio, which includes 32 projects (as of June, 2019). For each project, publicly available information, specifically, approved funding proposals, gender assessments, and gender action plans (GAPs) were screened using content and thematic analysis methods. To analyse the quality of the integration of women's empowerment, the study identifies the share of projects in the GCF energy portfolio with specific references and targets referring to women's empowerment in accordance with five impact areas (as per Table 4). The project proposals were analysed in their entirety for the presence of references to women's empowerment, while the presence of targets is specifically checked in projects' results frameworks and gender action plans

Making a distinction between targets and references is important from the perspective of accountability and the likelihood that women's empowerment outcomes will materialise. Targets demonstrate the presence of specific commitments to support women's empowerment, while references point to general acknowledgment of an opportunity to create women's empowerment outcomes.

For the analysis of references, the texts of full funding proposals, gender action plans, and gender assessments were screened for the presence of the words "women" and/or "female". These fragments of texts were then analysed to understand the relationship between them and specific impact areas highlighted in Table 4.
For the analysis of targets, the projects' results frameworks, including those in projects' gender action plans, were analysed for the presence of the words "women" and/or "female". Similarly to the analysis of references, identified targets referring to women were further analysed to identify the relationship of these targets to the women's empowerment results areas.

\subsubsection{Variations in the integration of women's empowerment issues} within the GCF's energy investments

The GCF's energy investments have been grouped into the three key categories to help understand factors that could affect the integration of women's empowerment issues across different types of investments and projects.

\section{Sectoral approach: mitigation vs. cross-cutting}

The distinction between mitigation and cross-cutting projects is important from the perspective of acknowledging differences in narratives and possibilities for women's empowerment outcomes (Morgan and Waskow 2014; Williams 2016; Wong 2016; Ebi 2009; Roberts 2009; Marshall, Ockwell and Byme 2017). As per the Governing Instrument of the GCF ${ }^{22}$, the Fund has thematic funding windows for adaptation and applies an integrated approach for cross-cutting projects that deliver both climate change mitigation and adaptation impact. The GCF's Results Management Framework provides a mechanism for labelling projects as mitigation, adaptation and/or cross-cutting (see Annex 4). While all energy generation projects contribute to the mitigation results areas, some energy investments are presented as cross-cutting interventions, which deliver certain resilience benefits beside $\mathrm{GHG}$ s reductions. ${ }^{83}$

\section{Technology scale: small scale vs. utility scale}

Utility-scale projects refer to energy generated by a project being fed into the grid. However, there is no agreement on the size of a project that can be regarded as utility scale. The categorisation proposed for this study is based on the definition given by the United States Department of Energy ${ }^{84}$ and PearlMartinez (2014), which refer to projects with developments larger than $10 \mathrm{MW}$ as utility-scale projects. Generally, small-scale projects (below $10 \mathrm{MW}$ ) have a greater role to play in ensuring the sustainability of rural livelihoods and remote communities (Byrne et al. 2007; Cherni and Hill 2009).

82 https://www.greenclimate.fund/document/governing-instrument (Accessed 25 November 2021).

83 https://www.greenclimate.fund/what-we-do/projects-programmes (Accessed 25 October 2019).

84 https://www.energy.gov/eere/slsc/renewable-energy-utility-scale-policiesand-programs (Accessed 25 October 2019). 
3. Implementing entities: (a) direct access vs. international access and (b) public vs. private

The GCF's Governing Instrument distinguishes between two types of accredited organisations, international and direct access entities (DAEs), and highlights specific opportunities for the private sector. Countries can access climate finance through a range of international organisations (including Multilateral Development Banks, UN agencies or international private companies) which often operate across a number of countries and regions. DAEs are represented by national or regional organisations from the public and private sector, who are nominated by National Designated Authorities. The role of DAEs is to enhance country ownership and to ensure better alignment of climate investments with national climate change needs.

\subsection{FINDINGS OF ENERGY PORTFOLIO ANALYSIS}

As of February, 2019, the GCF has supported 32 projects which target energy access and generation. Figure 13 shows an overview of different categories of investments in the GCF energy portfolio.
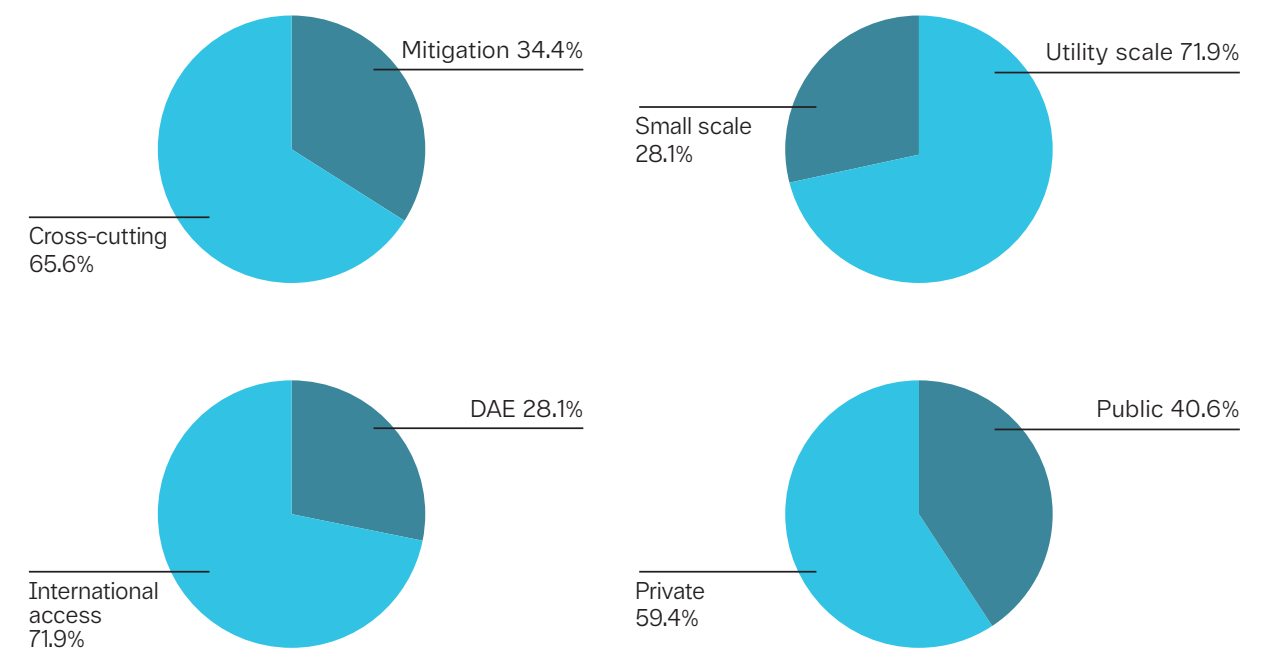

Figure 13. Overview of the GCF energy generation and access portfolio (Prepared by the author)
All projects in the GCF energy portfolio contribute to reduced emissions through increased low-emission energy access and power generation, however, 65.5\% of projects also deliver climate change adaptation results related to increased resilience of livelihoods and communities. The majority of the current energy portfolio supports utility-scale technologies, which are implemented mostly by international entities (71.9\% of projects).

\subsubsection{The quality of the integration of women's empowerment issues} within the GCF's energy investments

Based on the results of the analysis of project documents, the quality of the integration of women's empowerment issues within the GCF's energy investments is limited - at least half of the GCF's energy projects do not include women's empowerment targets (Figure 14).

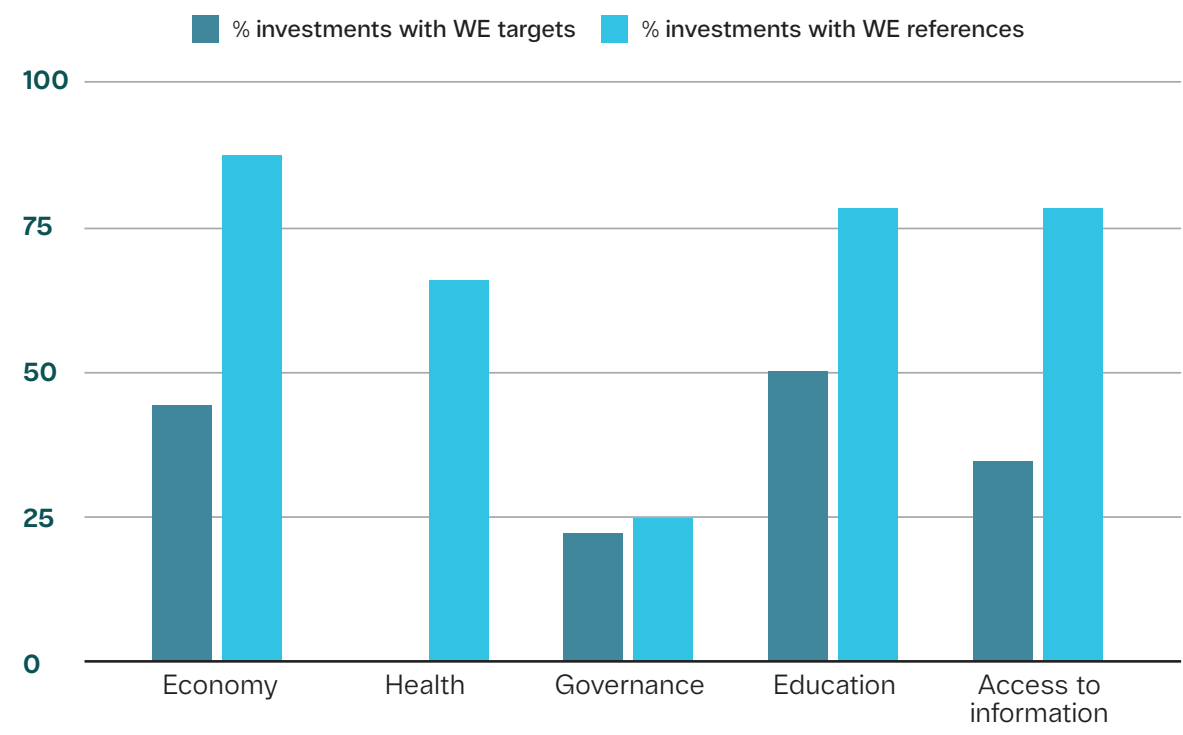

Figure 14. Analysis of the GCF energy portfolio from the perspective of women's empowerment (WE)

(Prepared by the author)

Women's empowerment through education appears to be the most popular results area, with $50 \%$ of GCF energy projects committing resources and setting targets to support the development of skills and knowledge among women. Economy is the second area with a relatively high level of commitments to support women's empowerment through lending, creation of employment opportunities, and development of women-led businesses. None of the studied 
projects commit to women's empowerment targets through improved health and wellbeing. However, about $65 \%$ of the GCF's energy projects provide clear references to health benefits associated with improved air quality and, in some cases, improved access to health services in conjunction with improved infrastructure, e.g. the construction of roads associated with the development of low-carbon energy infrastructure can improve access to health care.

The inclusion of references to women's empowerment issues is more frequent in the project documents. For example, economic opportunities for women are well referenced in the design of energy projects $-87 \%$ of projects referred to economic opportunities for women as a result of investment. Education and access to information are also popular areas where energy projects supported by the GCF intend to create opportunities for women's empowerment; around $75 \%$ of projects refer to educational opportunities for women. Women's empowerment in governance areas is rarely targeted or referenced. Frequently, inclusion in decision making is used interchangeably with the involvement of women in consultations. However, it is not clear whether projects are committed to engaging women in the steering processes and in shaping key decisions associated with a project.

\subsubsection{Comparison of small- and utility-scale energy investments from} the perspective of the integration of women's empowerment

Both utility-scale investments and small-scale investments acknowledge empowerment outcomes across five impact areas. Based on the content analysis (Annex 4), the design of small-scale investments is more oriented towards less served beneficiaries, including small enterprises, women, individuals in remote areas, and more vulnerable communities.

For instance, in the case of economic empowerment, utility-scale projects promote gender equality activities in the workplace and gender balanced employment practices and provide equal access to services such as energy, water, and housing, in some cases with specific attention to female-headed households. In terms of access to energy, most utility scale investments use gender disaggregated targets to comply with the GCF's gender policy, for instance $50 \%$ of men and $50 \%$ of women benefitting from the generation of clean energy. However, these targets are reflective of the demographics of consumers benefitting from dispatched clean energy through the grid. Such approach to setting gender disaggregated targets for access to clean energy does not imply that an investment will undertake specific measures to support the needs of women.
Based on the analysis of the GCF's energy portfolio (Annex 4), small-scale investments also provide employment opportunities for women. However, they propose more focused activities, in comparison to utility-scale investments, supporting the development of women-led businesses and entrepreneurs and reducing energy poverty in remote areas not connected to the grid. The ability of small-scale energy investments to provide the most remote regions with energy creates a wide array of co-benefits related to improved wellbeing and health (for instance through access to medical facilities).

Where empowerment of women through education is concerned, both utilityscale and small-scale projects aim at increasing awareness on gender equality and providing training to support the development of technical knowledge and skills among women.

Overall, small-scale projects refer to and target women's empowerment including through education, economic opportunities, health benefits, and governance approaches more frequently than utility-scale projects (Figure 15) The only result area where utility-scale energy projects are better than smallscale projects at integrating women's empowerment outcomes is in access to information. The largescale utility projects are frequently associated with higher environmental and social risk categories and therefore have stricter regulations concerning the disclosure of information and the engagement of local stakeholders (GCF 2018a). This situation can explain the higher sensitivity in this area of utility-scale investments in comparison to small-scale investments. 
Utility scale _ Small scale
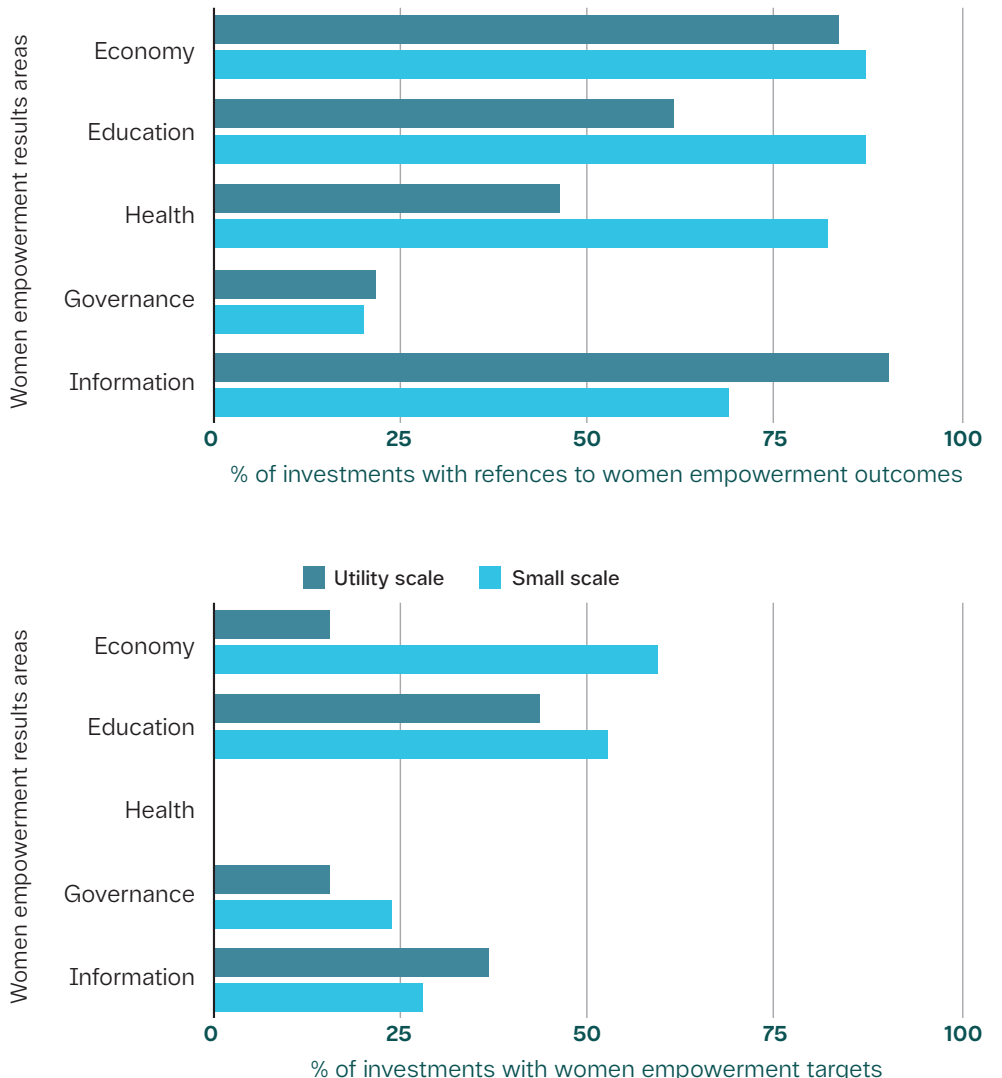

Figure 15. The integration of women's empowerment issues in energy generation projects implemented at utility and small scales

(Prepared by the author)
7.4.3 Comparison of GCF energy investments implemented by different types of accredited entities from the perspective of the integration of women's empowerment

Besides a clear distinction in the reach of operations (national/regional vs. international), accredited entities can be represented by private or public organisations and be different in terms of the value of the projects for which they are accredited by the GCF. Based on the analysis of the GCF's entity portfolio, ${ }^{85}$ DAEs are accredited to implement projects under USD 50 million, which are considered predominantly lower risk investments, categories $C$ and $\mathrm{B}^{86}$ (Annex 4). International access entities implement investments over USD 50 million, which are considered considerably greater risk than those in the portfolio of DAEs, categories A and B (Annex 4). According to the analysis of the energy generation and access portfolio, almost $60 \%$ of projects are implemented by private sector entities.

As noted by the $\mathrm{GCF}^{87}$ DAEs frequently have less developed capacities and experience with climate finance. To address capacity gaps, the GCF provides technical assistance and resources to support DAEs including to meet the requirements of the GCF gender policy as well as to increase the DAEs knowledge about gender mainstreaming.

Within the GCF energy portfolio, nine projects out of 32 are implemented by direct access entities, of which only two projects target large scale technologies. The majority, eight out of nine, of direct access modalities within the energy access and generation portfolio are implemented by private sector organisations.

${ }^{85}$ As of October 2019, the GCF website refers to 88 accredited entities, of which 51 are direct access: https://www.greenclimate.fund/how-we-work/tools/entity-directory (Accessed in October 2019).

${ }^{86}$ Based on the GCF Guidance note for screening and categorizing GCF-financed activities: Category A - projects with significant adverse environmental and/or social risks and impacts; Category B - projects with limited adverse environmental and/ or social risks and impacts that; Category $\mathrm{C}$ - projects with minimal or no adverse environmental and/or social risks. Source: https://www.greenclimate.fund/sites/ default/files/document/sustainability-guidance-note-screening-andcategorizing-gcffinanced-activities.pdf (Accessed in October 2019).

87 https://www.greenclimate.fund/documents/20182/194568/GCF_in_Brief_Direct_ Access.pdf/8112c210-54a6-44bc-a084-ef25e71dc965 (Accessed in October 2019). 

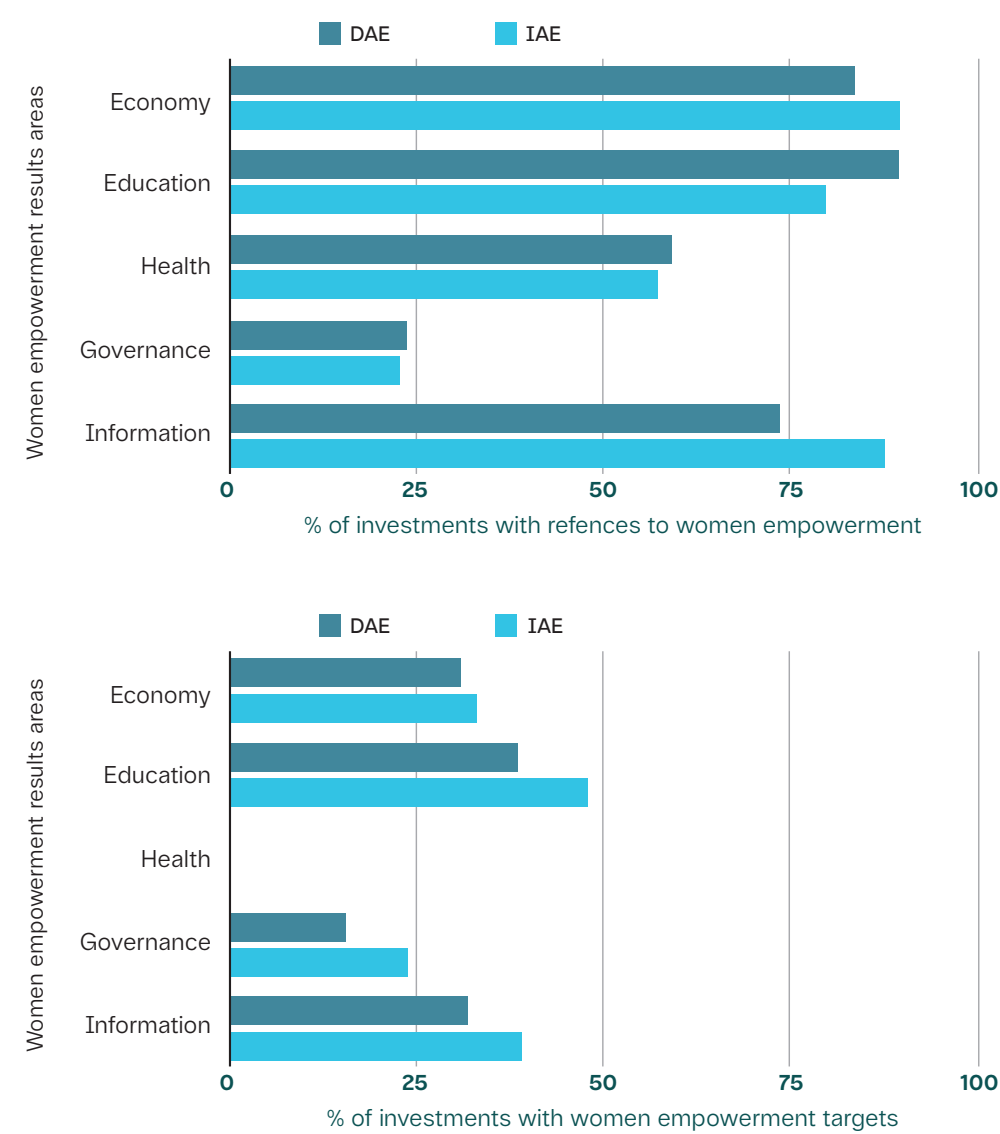

Figure 16. Variations in the integration of women's empowerment issues in energy generation projects implemented by international and direct access entities (Prepared by the author)

More frequently than international access entities, DAEs appear to consider women's empowerment issues through education (Figure 16). However, international access entities have targets for the delivery of educational outcomes more frequently than DAEs. Direct access entities, in comparison to international access entities, fare slightly better in acknowledging the impact of investments on women's health and wellbeing. On the other hand, international access entities target women's empowerment outcomes in governance, economic development, and access to information more frequently than DAEs.
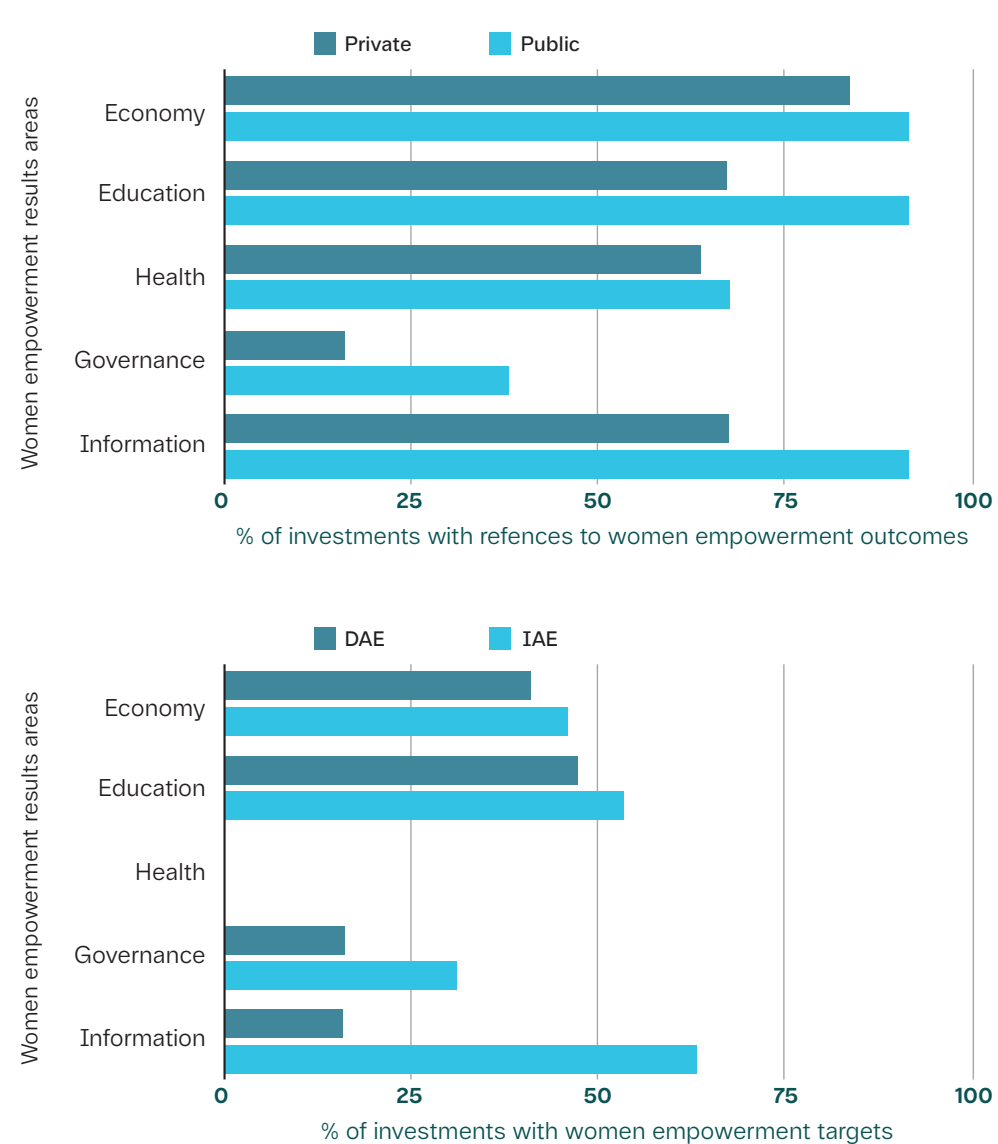

Figure 17. Variations in the integration of women's empowerment issues in public vs. private energy generation projects (Prepared by the author)

The analysis of projects that are implemented by private and public entities clearly shows that public sector projects recognise women's empowerment issues better in project design (Figure 17). A large percentage of public sector projects include references to and targets of women's empowerment across the five results areas, while the most striking differences with international access entities are in education, governance and access to information.

\subsubsection{Comparison of climate investments implemented in dedicated} mitigation energy projects vs. cross-cutting energy projects

In contrast to dedicated mitigation types of projects, cross-cutting projects address climate vulnerability and increase the resilience of infrastructure and built environment, livelihoods of people and communities and improve health food and water security. Only 11 projects in the current GCF energy portfolio aim 
at providing access to energy and delivering additional resilience outcomes. Out of these 11 projects, only four projects target utility-scale energy technologies.

As shown in Figure 18, the design of energy investments which are labelled as dedicated mitigation appears to be more committed to women's empowerment through the development of specific targets for the provision of educational and economic opportunities. These types of energy investments also have better acknowledgment of women's empowerment issues than investments classified as cross-cutting, which is evident through the presence of specific references to potential economic, education and health benefits, as well as improved access to information.

In terms of health, projects with additional resilience benefits refer more frequently to health benefits for women associated with climate investments. Furthermore, cross-cutting energy projects more frequently include targets for and references to women's empowerment through governance approaches and access to information.
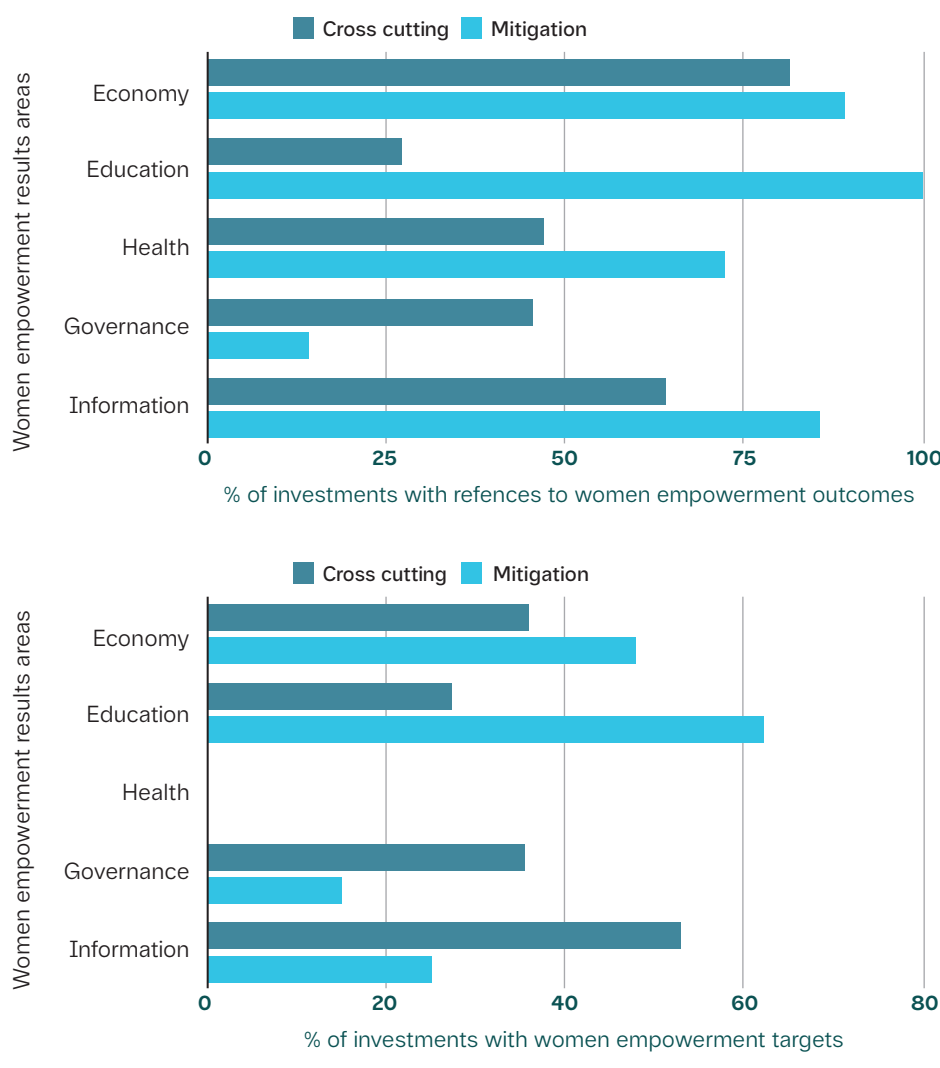

Figure 18. Variations in the integration of women's empowerment issues in crosscutting vs. dedicated mitigation energy generation projects (Prepared by the author)

\subsection{DISCUSSION}

The findings show that the quality of the integration of women's empowerment issues within the GCF's energy portfolio (in terms of the presence of specific references and targets to women empowerment issues) is limited. However the importance of women empowerment is acknowledged through references in reviewed proposals (on average $63.4 \%$ of projects have references to women empowerment), with only a very small share of energy projects (on average 23.3\% are committed to specific and measurable targets to support the achievement of women's empowerment outcomes.

Sixty percent of GCF energy projects failed to present targets for the economic empowerment of women, $80 \%$ of projects do not include targets for women's empowerment in the governance area, $50 \%$ have no targets for women's empowerment through education, and $75 \%$ have no measurable commitments for women's access to information, and none of studied projects target women empowerment through health improvements.

Based on the analysis of project documents of the GCF's energy portfolio, there are considerable variations in how women's empowerment issues across economic, education, health, governance and access to information areas are integrated within the design of energy projects. The consideration of women's empowerment issues varies by type of entity and scale of energy technologies. Small-scale investments appear to be more considerate of women's empowerment outcomes compared to utility-scale investments. On average projects developed by international entities appear to be more frequently committed to women's empowerment targets in comparison to DAEs. However, DAEs appear better than international entities at acknowledging women's empowerment outcomes in education and health.

Another key observation is that public sector entities have a better rate of commitments and references to women's empowerment results in comparison to private sector entities. This suggests that a more in-depth exploratory study is necessary to understand capacities, strengths and weaknesses of public and private sector entities to support gender mainstreaming and the integration of women's empowerment issues within project design.

The interpretation and use of the findings of this study needs to consider the following limitations:

1. The study is based on the assumption that activities proposed within project design will materialise and deliver women's empowerment outcomes. It is possible that project activities could be re-shaped during implementation 
in light of changing circumstances and result in lesser or greater women's empowerment outcomes.

2. The study is limited to the analysis of publicly available project documents, which do not present the full package of information required for the approval of a funding proposal.

\subsection{CONCLUSIONS}

In this chapter, I discuss climate finance allocation practices of the GCF from the perspective of the integration of women's empowerment issues. The integration of women empowerment within climate finance is an institutional strategy which is supported by the Governing Instrument of the GCF and the GCF's Gender Policy, and it is considered essential for making projects and programs more sustainable and effective (GCF/B.20/07 2020). Therefore understanding the quality of integration of women's empowerment issues as well as factors that hinder such integration is necessary for devising more effective climate change solutions. To address this problem, I answered two questions:

\section{What is the quality of integration of women's empowerment issues within the GCF energy portfolio?}

I have analysed the quality of integration of women's empowerment issues using the example of the GCF energy portfolio and applying the following criteria:

- Presence of specific references in the project documents indicating project commitments related to women's empowerment across five impact areas, i.e. education, health, governance, access to information, and economy.

- Presence of specific targets in the results framework and gender action plans related to women's empowerment outcomes across five impact areas, i.e. education, health, governance, access to information, and economy.

I conclude that based on these criteria, the quality of integration of women empowerment issues in the GCF's energy portfolio is low. Majority of approved investments (by 2019) do not commit to measurable targets to support women's empowerment. More specifically, $60 \%$ of GCF energy do not have targets for the economic empowerment of women, $80 \%$ of projects have no targets for women's empowerment in the governance area, $50 \%$ of projects have no targets for women's empowerment through education, and $75 \%$ - in women's access to information. Nor a single studied projects included targets for women's empowerment through health improvements.

The integration of references to women's empowerment issues is better however remain limited, i.e. $13 \%$ of projects do not have references to economic empowerment of women, $37 \%$ of projects do not have references to women's empowerment through health, $74 \%$ of projects do not refer to women's empowerment through governance, and 22\% do not refer to women's empowerment through access to information.

\section{What institutional, technology and implementation factors may affect the extent of the integration of women's empowerment issues within the GCF energy portfolio?}

The comparison across different categories of the GCF's energy investments indicates that there are factors that are guided by the institutional, technology and implementation differences of energy projects, which may influence the extent of the consideration of women's empowerment issues. In terms of technology factors, the study finds that small-scale investments are considerate of women's empowerment outcomes compared to utility-scale investments.

Also, the study shows that that projects developed by public sector entities have better integration of references and targets to women's empowerment in comparison to private sector entities. Also, on average, projects developed by international entities appear to be more frequently committed to women's empowerment targets in comparison to DAEs. However, more research on DAEs' capacities to integrate women's empowerment considerations in project design is required as DAEs are likely to have a better understanding of nationa contexts and women's needs.

Cross-cutting energy investments of the GCF appear to be more committed to women's empowerment targets only in two areas - governance and access to information areas. Other than that, strictly mitigation energy investments have better acknowledgment of women's empowerment issues via the inclusion of specific references and targets to economic, education and health benefits, as well as improved access to information.

The findings of the study suggest that a more in-depth exploratory study is necessary to understand institutional capacities, strengths and weaknesse of public and private sector entities, as well as international and DAE, and the influence of these factors on the extent of the consideration of women's empowerment issues in project design. 


\section{CHAPTER 7}

In addition, a more nuanced assessment of various challenges associated with technology and implementation factors is needed. For example, the following issues could be further investigated to develop approaches for improving the integration of women's empowerment issues across different types of climate investments:

1. Technical approaches for increasing the integration of women's empowerment issues within utility-scale energy investments, especially to promote women's economic empowerment

2. Methodologies for the integration of health and wellbeing considerations in project design to support women's empowerment. 


\section{CHAPTER 8:}

\section{Conclusion}

UNDERSTANDING POLICY AND INSTITUTIONAL

STRATEGIES TO SUPPORT THE PARTICIPATION

OF WOMEN AND WOMEN ORGANISATIONS WITHIN

UNFCCC-LED CLIMATE CHANGE GOVERNANCE

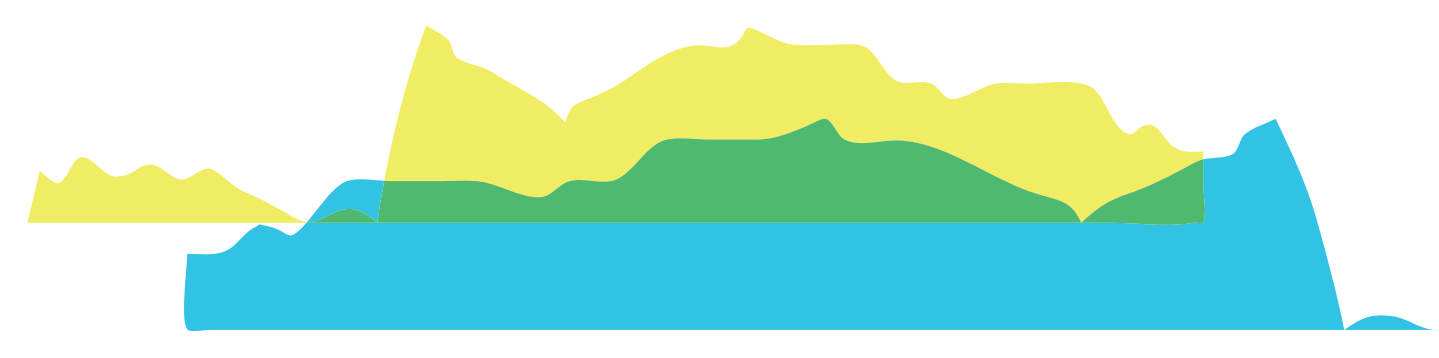


Participation is a popular topic in climate change governance scholarship, but there are still areas that are understudied and not well understood. UNFCCCled governance, which defines the context of the research for this thesis, is an important under-researched climate change governance arenas (Betsill et al. 2015; Dorsch and Flachsland, 2017; Di Gregorio, 2019). There are considerable knowledge gaps about the UNFCCC's multi-layered architecture (Bécault and Marx 2016; Pickering et al. 2013; Clapp et al. 2012), and UNFCCC-led climate finance decision making, which is an integral part of the UNFCCC architecture, is one of the least studied areas (Pickering et al. 2013; Clapp et al. 2012). Furthermore, within climate change governance scholarship, women and women organisations present new governance agents, whose participation, including inclusion, roles and contributions to decision making is understudied, and those studies that exist are full of controversies. This thesis makes a contribution to these under researched areas of climate governance scholarship.

Below I recap on the existing issues which underpinned the need for my research on the participation of women and women organisations, and the approach of the thesis to deal with these controversies. Then I summarise the key findings of the thesis and how the research questions have been addressed and highlight the key methodological, policy and theory contributions I have made. The chapter finishes with some recommendations on the areas for future research.

\subsection{KEY FINDINGS FROM THE EXISTING DISCOURSES ON THE PARTICIPATION OF WOMEN AND WOMEN ORGANISATIONS}

As demonstrated in Chapter 3, participation has been a controversial topic without consensus on how to measure its quality. Scholars argue that women and women organisations' participation is necessary to ensure the inclusiveness of the participatory processes (the rights-based perspective) and that participation could be instrumental in delivering more just climate policies, fair allocation of climate finance and better gender responsiveness of climate policies (the functionalist perspective) (Williams 2016; Larson 2002). Rightsbased and instrumental perspectives create distinctive outlooks on how the quality of participation needs to be studied, i.e. as a fundamental right to access to decision making and inclusiveness of participatory processes (Mohammad and Farjana 2018) or as an instrument to resolve climate change governance issues (Chan et al. 2015). While rights-based perspective on participation is hardly contested, it is argued that focus on processes only could be associated with high short-term costs of participation and exacerbated fragmentation of the climate-governance complex (Chan and Pauw 2014; Coenen 2009). On the other hand, functionalists are criticised for limited attention to the democratic credentials of governance practices (Nasiritousi, Hjerpe, and Bäckstrand 2016)

More specifically, within climate change governance, it is considered that focusing on inclusiveness and transparency of participatory processes in isolation is not a good practice (Hogl et al. 2012), because participation needs to be both effective in problem solving and inclusive and representative in identifying climate change solutions (Bäckstrand, Zelli, and Schleifer 2018) Chapter 2 shows that the UNFCCC's decisions already follow a similar logic for supporting the participation of women and women organisations. On the one hand, women and women organisations' right to participate in UNFCCC decision making is acknowledged by the UNFCCC's decisions 36/CP.7 (UNFCCC 2002b), 14/CP.18, 23/CP.18 (UNFCCC 2013), 25/CP.19, and 19/CP.19 (UNFCCC 2014) and the Cancun Agreement (Decision 1/CP.16) (UNFCCC 2011). On the other hand, the UNFCCC's policies acknowledge that the participation of women and women organisations is expected to improve the effectiveness of climate action and the gender responsiveness of climate finance (Decision 1/ CP.16) (UNFCCC 2011)

Generally, for addressing policy and governance dilemmas that lie on the intersection of gender, the development of innovative theories and practices is required to reduce the divide between knowledge and practice (Harcourt 2016). Within the context of the climate change governance, an integrated approach is required that needs to be based on both inclusiveness of participatory processes and the delivery of tangible policy outcomes (Bäckstrand, Zelli, and Schleifer 2018; Hogl et al. 2012; L. B. Andonova, Betsill, and Bulkeley 2009). I refer to participation that is based on such approach as "meaningful" and argue that policy and institutional strategies (that are introduced in Chapter 4 5,6 and 7 ) if designed and implemented thoughtfully could play a key role in supporting more meaningful participation.

\subsection{APPROACH OF THE THESIS}

The objectives of my thesis have been first to improve understanding on the existing policy and institutional strategies (in terms of how they are defined and implemented) and second to provide insights on how to improve these strategies to support more meaningful engagement of women and women organisations across the UNFCCC-led governance levels.

The objectives are achieved through the analysis of the UNFCCC's policy and institutional strategies that are adopted at the three levels of the UNFCCC's governance, i.e. the COP, the UNFCCC's Financial Mechanisms and at the 
national level using the example of Georgia. I argue that a better quality of policy and institutional strategies (such strategies that not only support inclusive decision making processes but also lead to the development of policy outcomes and solutions that are considerate of local and traditional knowledge) is essential for ensuring meaningful participation. While policies create guiding frameworks that legitimise and shape specific roles and expected areas of contributions of women and women organisations, institutional strategies demonstrate how policy strategies are diffused into practice and how technical and institutional practices could be deployed to enhance the participation and implementation of policies.

The thesis answers two questions:

1. What is the quality of policy strategies that support the participation of women and women organisations in the UNFCCC-led climate change governance?

2. How well are institutional strategies operationalised to support the mobilisation of women and women organisations in UNFCCC-led climate finance?

The answers to these questions are presented below.

\subsection{OVERVIEW OF THE KEY FINDINGS}

8.3.1 Policy strategies that support the participation of women and women organisations

The thesis introduced the concept of policy framing and legitimation to analyse policy strategies that are used by policymakers to make women and women organisations more visible and to define their participatory roles and contributions. The conclusions on policy strategies are drawn from the analysis of 575 UNFCCC decisions (adopted in 2009-2020), 30 GEF, 86 GCF, and 28 AF policies and guidelines, as well as 27 policies adopted at the national level in Georgia. This is complemented by interviews with experts directly involved in UNFCCC-led climate change decision making.

\section{a. Policy strategies supporting women's participation}

Attention to women as governance actors in the UNFCCC has been on the rise in the last 10 years and policy texts show the eclectic mixture of policy positions describing various women groups, their anticipated roles, entry points and governance outcomes from their participation. The existing policy strategies not only acknowledge the importance of the participation of women as a broader group of actors in UNFCCC-led climate change decision making but also recognise the specific roles of rural, indigenous, and grass-root women.

The policy frame mapping of the COP's decisions conducted in Chapter 4 demonstrates specific policy strategies in relation to women's roles, entry points and anticipated policy outcomes. Women are expected to participate in the UNFCCC's constituted bodies, national delegations, and climate change decision making at the national, regional, and local levels. Women's participation is expected to contribute to gender-responsive climate change policy. Also, women are acknowledged as representatives of vulnerable groups and as leaders and recipients of capacity building and education.

In addition to women as a broader group of stakeholders, the UNFCCC's decisions highlight specific roles for grass-root and indigenous women as owners of traditional knowledge and solution holders. The thesis concludes that the quality of policy framing that supports the participation of women is limited, because policy strategies is incomplete and inconsistent acros the three UNFCCC-led decisionmaking levels. While women are expected to participate in the development of climate finance strategies, their role as recipients of climate finance is not recognised. The incomplete policy framing is observed in relation to indigenous women, whose participation does not appear to be linked with any policy outcomes in the policy texts. In addition, the participation of grass-root women organisations does not offer a description of specific entry points and processes for their engagement.

The analysis of legitimation conducted in Chapter 5 demonstrates that women are acknowledged as governance actors by the UNFCCC's Financial Mechanisms and at the national UNFCCC-led processes (using the example of Georgia). Chapter 5 shows that the UNFCCC's Financial Mechanism policies acknowledge women, indigenous and rural women as governance actors, while rural women are recognised as specific governance actors in the nationa UNFCCC-led governance in Georgia. The existing legitimation also has limited quality. I identify two aspects. First of all, there is a misalignment between the three levels of UNFCCC-led governance in how women are referred to as governance actors. Grassroots, rural and indigenous women have limited recognition across the three studied levels of UNFCCC-led governance. For instance, grassroots women are recognised only in COP decisions, whereas rural women are overlooked in COP decisions, but recognised at the nationa level in Georgia and by one of the UNFCCC's Financial Mechanisms (the AF). Indigenous women are recognised by the COP and AF only. Secondly, while there is anecdotal evidence that women participate in UNFCCC-led national 
level decision making, there is no indication of policy outcomes associated with their participation ${ }^{88}$.

\section{b. Policy strategies for women organisations' participation}

Generally, women organisations as actors have received very limited policy attention so far across the three layers of the UNFCCC's governance. Policy strategies recognising women organisations as UNFCCC's governance actors only started emerging in 2017. The research finds that policy strategies to support the participation of women organisations are nascent and their quality is low due to incomplete and inconsistent definitions and policy framings that are used in relation to the participation of women and women organisations across international and national levels of the UNFCCC-led governance, and limited visibility and participation of women and women organisations at the national level in Georgia.

Based on the policy frame mapping presented in Chapter 4, women organisations have been described by the COP in relation to three categories of arrangements: women groups, national women and gender institutions, and grass-root women organisations. These are expected to contribute to the development and implementation of climate policies and the gender responsiveness of climate finance (Decision 3/CP.25, Enhanced Lima work programme on gender and its gender plan). The research finds that while national women and gender institutions are noted as governance actors, their expected roles are not defined in the COP's decisions.

The research demonstrates that there is no universal definition of women organisations that is consistently applied across the UNFCCC's three layers (Chapter 5). The UNFCCC's Financial Mechanisms recognise national women's machineries and institutions; women's cooperatives and community-based organisations, which are often run by women and provide services to women and their families; and nongovernment organisations focused on promoting gender equality, women's rights, or the empowerment of women. However, there is no consistency across UNFCCCled climate funds' policies. For example, national women and gender institutions, as well as private-sector-led women organisations (e.g. women's cooperatives), are recognised only by the AF. At the national level in Georgia, only the participation of women groups and private-sector-led women organisations is acknowledged.

${ }^{88}$ Difficulty with identifying policy outcomes could also be associated with methodological challenges in attributing policy outcomes to participation as noted in Chapter 5
According to the interviewed experts' opinion, the quality of legitimation of women organisations in Georgia is low not only because of inconsistent policy narratives across international and national levels, but also due to a shortage of data on the specific gendered impacts of climate change and women's vulnerabilities, and limited capacities and knowledge of women organisations on climate change and climate finance. In addition, the visibility of women and women organisations in UNFCCC-led climate finance governance in Georgia remain limited, i.e. women and women organisations actual roles are not well understood by interviewed experts, however their potential roles are perceived positively.

\subsubsection{Institutional strategies that support the participation of women} and women organisations

The thesis introduced and analysed two specific institutional strategies orchestration in relation to women organisations and allocation of climate finance to support women's empowerment. The conclusions on institutional strategies are drawn from the analysis of working documents, institutional policies and interviews with experts.

\section{a. Orchestration}

The conclusions on orchestration are based on the analysis of 214 substantive SCF documents, 31 official submissions of the WGC, 120 records of the WGC's interventions made at the UNFCCC's meetings, and interviews with key informants.

Chapter 6 describes the orchestration approaches, including agenda setting, financial assistance, and endorsement, that are used by the UNFCCC to support the participation of women organisations in climate finance decision making. The orchestration relies on the capacities of the SCF to engage the WGC and the abilities of the WGC to mobilise women organisations. The research shows that the quality of orchestration of women organisations in UNFCCC-led climate finance governance is limited due to the lack of convergence in the policy language on the purposes of orchestration, including limited correlation between how women organisations are defined as targets of orchestration and what the participation of women organisations is intended to achieve, limited engagement of the relevant intermediary (WGC) in climate finance meetings, and presence of challenges and barriers to the involvement of women organisations in UNFCCC-led climate finance decision making (as per experts' opinion). Among the key barriers and challenges are limited capacities of the WGC to deliver systemic contributions on behalf of women organisations to climate finance decision making and the lack of technical expertise on climate finance issues; and the newness and complexity of the issues on the intersection of climate finance and gender. 
Based on my research I conclude that orchestration of women organisations is likely to be used for symbolic purposes, because the participation of women organisations has so far been limited and no evidence was found of the contribution and impact of women organisations on UNFCCC-led climate finance decision making.

b. Allocation of climate finance to support women's empowerment

Chapter 7 assesses the GCF's energy portfolio to assess the extent of the integration of women's empowerment considerations within the investments of the GCF. The conclusions are based on the analysis of 32 energy generation and access projects funded by the GCF (as of June 2019). The chapter concludes that the approach to integrating women's empowerment in the GCF's investments is mostly cursory (through the development of references) with at least half of the GCF's energy projects not committing to measurable women's empowerment targets. In terms of concrete women's empowerment commitments, empowering women through education is the most popular area, followed by commitments through the creation of employment opportunities and development of women-led businesses. Empowering women through health or wellbeing related benefits is the least popular approach deployed in GCF-funded energy projects.

While the GCF's Gender Policy provides a policy framework that incentivises the inclusion of gender equality and women's empowerment considerations in project design, there are other institutional and technical factors that can affect the extent of integration of women's empowerment issues in project design. These factors include whether the projects are carried out by the public or the private sector, the scale of energy technology to be developed, and the implementing capacities of project developers, which can be either international or national, i.e. direct access, institutions.

\subsection{CONTRIBUTIONS}

\subsubsection{Theoretical contributions}

Given the urgency and scale of the climate change problems and the potential contribution of women and women organisations to making climate change policies more ambitious, equal and gender responsive, there is a need to improve the theoretical concepts of climate change governance using gender lenses.

As noted earlier there is a significant demand for the development of innovative theories that addressing the existing controversies between knowledge and practice (Harcourt 2016). The thesis responds to this demand through the following approach:

- Holistically looking at the three levels of the UNFCCC-led decision making to study the participation of women and women organisations as new governance agents.

- Analysing the participation of women and women organisations as two distinctive actors. This separation is necessary because women organisations are institutionalised actors who are set to advocate for gender equality and present the varied interests of women, while women are an informal group of individuals with diverse positions.

- Studying the inclusivity of participatory processes that target women and women organisations and the policy contribution of women and women organisations as governance actors.

- Assessing policy and institutional strategies that facilitate more meaningful participation of women and women organisations.

The current research offers insights into the structure and agency debate, using the participation of women and women organisations as an entry point. The structure and agency debate is concerned with the dynamics between 'institutional architects, institutionalized subjects and institutional environments' (Mackay, Kenny, and Chappell 2010). The relationship between structure and agency is one of the key governance concepts, because governance frameworks are not just institutions as well as shared principles and norms, i.e. governance architecture; but also governance actors or agents who drive change (F Biermann et al. 2009). From the perspective of structure, my thesis looks holistically at the participation of these new governance actors across the three layers of UNFCCC-led governance, including its climate finance components, and provides insights into specific UNFCCCgovernance processes led by the COP, Financial Mechanisms and at the national leve (using the example of Georgia). From the perspective of agency, the research contributes to the development of theory on the role of women and women organisations as new climate change governance agents.

The research offers the following contributions to theory development:

- Improving the understanding of multi-level UNFCCC-led policymaking (including associated climate-finance decision making) using participatory lenses; 
- Enhancing the knowledge of and evidence on the role of women and women organisations as new governance agents in the development of climate change policies and solutions; and

- Advancing the concept of climate change governance effectiveness, which could be adapted in policy and institutional strategies that are discussed in this thesis.

\subsubsection{Methodological contributions}

The thesis offers methodological contributions to the research on participation within climate change governance by synthesising and adapting the existing methodologies from gender and political science scholarship and proposing innovative frameworks for analysing the participation of women and women organisations as differentiated governance actors. Methodological innovation includes introducing the criteria for describing and analysing the quality of policy and institutional strategies that support the participation of women and women organisations (Table 5). The analysis of quality is based on mixed methods, using policy frame mapping, content analysis and interviews with experts.

Table 5. Assessment criteria for the quality of policy and institutional strategies (Prepared by the author)

\begin{tabular}{|c|c|}
\hline \multicolumn{2}{|l|}{ Quality of policy strategies } \\
\hline Policy framing & Legitimation \\
\hline \multirow{2}{*}{$\begin{array}{l}\text { - Completeness of policy framing: This } \\
\text { reflects missing definitions of the roles, } \\
\text { functions, or outcomes associated with } \\
\text { the engagement of identified types of } \\
\text { women and women organisations. For } \\
\text { example, in relation to certain actors, the } \\
\text { policy text could identify specific functional } \\
\text { responsibilities but not indicate processes } \\
\text { for their engagement or vice versa. }\end{array}$} & $\begin{array}{l}\text { - Participation of women and women } \\
\text { organisations in UNFCCC-led decision making } \\
\text { at the national level in Georgia (based on } \\
\text { anecdotal evidence retrieved from expert } \\
\text { interviews). }\end{array}$ \\
\hline & $\begin{array}{l}\text { - Visibility of women and women organisations } \\
\text { in UNFCCC-led decision making at the nationa } \\
\text { level in Georgia based on experts' perception } \\
\text { of their roles and contributions. }\end{array}$ \\
\hline $\begin{array}{l}\text { - Consistency of policy framing, which is } \\
\text { identified through a mismatch between } \\
\text { the scope of roles, functions, participatory } \\
\text { processes, and outcomes. }\end{array}$ & $\begin{array}{l}\text { - Consistency in definitions that are used in } \\
\text { relation to women and women organisations } \\
\text { across the UNFCCC-led legitimation channels. }\end{array}$ \\
\hline
\end{tabular}

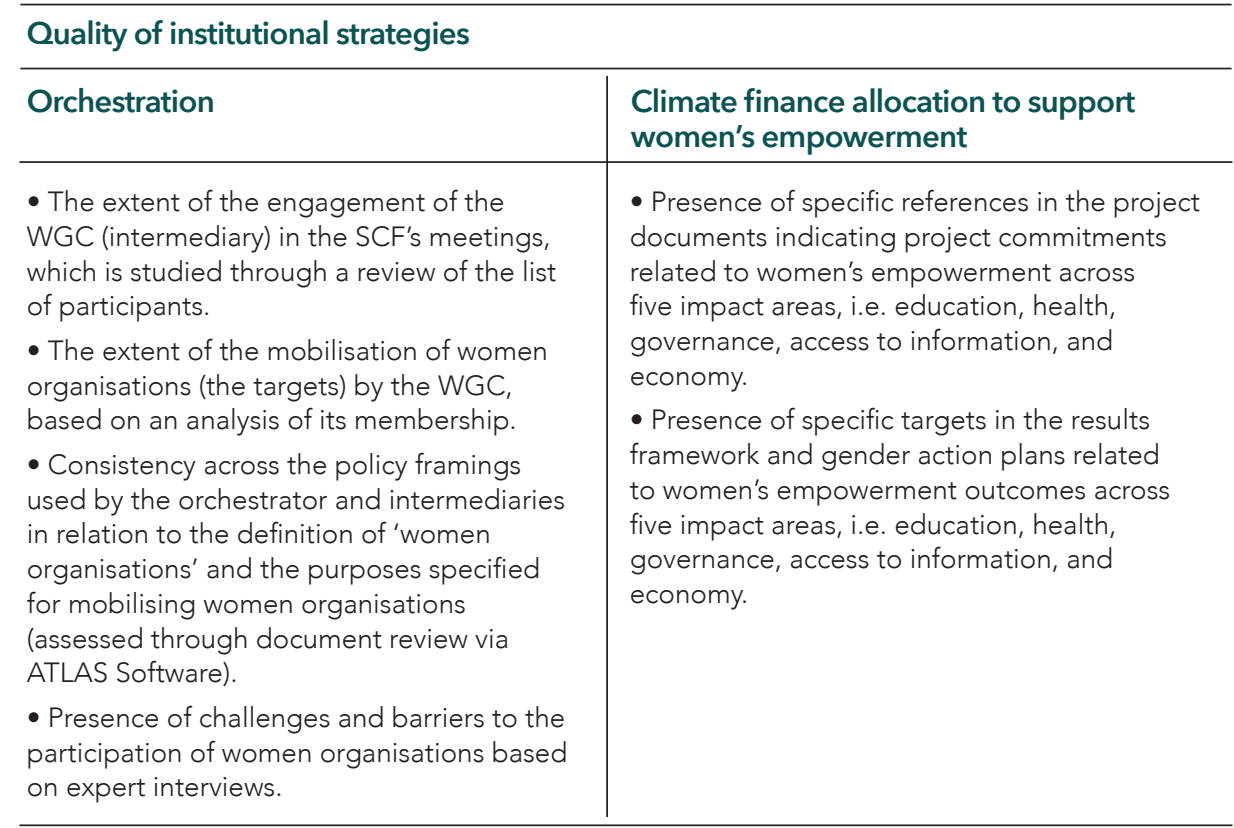

\section{a. Methodological contributions for analysing policy strategies}

Policy strategies for women and women organisations are analysed through mixed methods, i.e. policy frame mapping, content analysis and interviews with experts. While discursive methods have been gaining popularity within political scholarship, the UNFCCC's texts and their consistency have not been studied systemically across the three levels of climate change governance. In addition to traditional policy texts, the current study utilises climate finance project documents, which present a rich source of data that is rarely used for the analysis of legitimation. However, project documents are useful sources of information for understanding the effect of institutional policies on implementation.

The thesis develops and applies specific policy frames that are tailored to studying the participation of women and women organisations. Five policy frames are introduced to describe and analyse the quality of policy strategies that support the participation of women and women organisations:

- Functions, which describes policy positions that refer to the implementation of specific tasks or activities within climate change policymaking, climate finance, or broader climate actions;

- Entry points, which refers to either qualitative descriptions of participatory processes that are envisaged or specific entry points and opportunities to engage in decision making; 
- Outcomes, which includes texts that describe anticipated results of women and women organisations' engagement;

- Roles, which denotes references to women and women organisations' positions and interests; and

- Actors, which describes different stakeholders who are mentioned in the policy texts in relation to gendered policy outcomes or/and have gender and women's issues embedded in their description.

The quality of policy framing is measured through the presence of discursive controversies in policy frames (Koon, Hawkins, and Mayhew 2016). Two types of policy controversies are introduced: incomplete policy framing that reflects missing definitions of the roles, functions, or outcomes associated with the engagement of women and women organisations and inconsistent policy framing, which is a mismatch between the scope of roles, functions, participatory processes, and outcomes. The method is tested through the analysis of 575 decisions adopted by the UNFCCC's governing bodies and could be further applied to understanding policy strategies deployed in other climate change policy arenas.

With regards to legitimation, in addition to discursive inconsistencies on how women and women organisations are defined, the thesis relies on experts opinion to understand whether the existing policy strategies produced through UNFCCC-led decision-making channels have raised the visibility of women and women organisations and led to their contribution to UNFCCCled decision making at the national level in Georgia.

\section{b. Methodological contributions for measuring the quality of institutional strategies}

The thesis introduces a framework for measuring the quality of institutional strategies to support the participation of women and women organisations in climate finance decision making, using the example of orchestration at the UNFCCC COP level and the allocation of climate finance by the GCF. The quality of orchestration for women organisations is measured based on an assessment of the consistency of policy language with regards to the purposes of orchestrating women organisations and based on experts' opinions. This methodological innovation is tested using the example of the SCF (Chapter 6) and could be expanded to other climate policy settings. The quality of institutional strategies to support women's empowerment is assessed through the analysis of climate finance allocation made by the GCF. The analysis adapts Chung et al.'s framework (Chung et al. 2013) to develop the women's empowerment assessment framework for assessing climate finance allocations. The framework assesses the integration of women's empowerment issues in climate finance projects across five areas - economy, governance, education, health and access to information. This methodology is tested using the example of the GCF's energy portfolio and can be further adapted and utilised to understand the institutional strategies to support women's empowerment in other development institutions and funds (Chapter 7)

\subsubsection{Policy contributions}

The key strength of the research is that it offers critical insights for future action research that could practically support policy-makers with engaging women and women organisations more meaningfully and developing more inclusive and tangible climate change solutions. As the latest deliberations during COP 26 in Glasgow show that there is an increased need to support meaningful and equal participation of women in the UNFCCC process and strengthen genderresponsive climate action especially in light of impacts brought by global pandemic. $^{89}$

The research shows that, to ensure a meaningful participation of women and women organisations, the quality of the existing policy and institutional strategies is low. In order to make that participation more meaningfu improvements in institutional and policy practices can be made at three levels of UNFCCC-led governance. The thesis is strongly oriented to provide practical policy assistance. Each chapter of the thesis concludes with recommendations for policymakers on how to support meaningful participation of women and women organisations in UNFCCC-led climate finance decision making through enhanced policy and institutional strategies. These recommendations are summarised here.

\section{a. Recommendations for improving policy strategies}

The lack of consistency and completeness of policy framing and legitimation that support the participation of women and women organisations across the three levels of UNFCCC-led governance I studied is the key limitation of the existing policy strategies. The thesis shows that there are a variety of definitions used to describe women (i.e. rural, indigenous and grassroots) and women organisations (i.e. women groups, national women and gender institutions, private-sector-led women organisations, etc). In addition to the variety in terms and definitions that are used to describe women and women organisations, their roles and anticipated contributions within multi-level UNFCCC-led

${ }^{89}$ Gender and climate change - Draft conclusions proposed by the Chair. Recommendation of the Subsidiary Body for Implementation: https://unfccc.int/ sites/default/files/resource/sbi2021_L13E.pdf (accessed in December 2021) 
decision making are not fully described. To improve policy strategies there is a need to:

- Create consistent definitions for various women groups and women organisations that acknowledge their specific roles, with special attention to rural, indigenous and grassroot women and national women and gender institutions and private-sector-led women organisations.

- Increase policy attention and visibility of women organisations, whose roles could be critical in orchestrating more meaningful participation of women and integrating a gender dimension in UNFCCC-led policies.

- Enhance synergies across narratives of various UNFCCC-led levels of decision making, including the COP, Financial Mechanisms, and the national level.

\section{b. Recommendations for improving institutional strategies}

My research shows that the quality of the existing institutional strategies is limited. Nevertheless, there are opportunities to enhance technical and institutional approaches to ensure meaningful participation of women and women organisations. For improving the orchestration of women organisations (Chapter 6), the study concludes with the following recommendations for policymakers:

- Supporting innovation and entrepreneurial efforts for improving the engagement with women organisations and exploring possibilities for diversifying the existing orchestration practices.

- Reducing policy divergence on the purposes of orchestration and the roles of meta-intermediaries, intermediaries, and targets.

- Investing in the technical knowledge and skills of women and women organisations to ensure their meaningful participation.

For improving climate finance allocation to support women's empowerment, the study concludes that while the GCF's Gender Policy provides opportunities for integrating women's empowerment issues within climate finance, the policy on its own is unlikely to be enough for seeing consistent and tangible integration of these issues. Other institutional policies and the investment frameworks need to be sensitised to ensure that climate finance is allocated to and offers opportunities for women's empowerment. The study found that there are currently significant variations in how women's empowerment issues are integrated in the design of the GCF's energy projects (Chapter 7). The study suggests that in addition to institutional policies, there is a number of factors that could influence the consideration of women's empowerment issues. These factors include the scale of technology targeted by energy investments and the capacities of implementing entities. From this perspective, there is a need to not only improve policies but also offer capacity building to project developers and implementers.

\subsection{AREAS FOR FUTURE RESEARCH}

The research presented in this thesis lays the foundation for expanding the theory and methodologies on the role of women organisations in climate change governance and assisting policymakers in devising better policies that deliver climate solutions on more inclusive processes. The thesis introduces and analyses two policy and two institutional strategies to advance knowledge on the participation of women and women organisations. However, to support theory development on the participation of women and women organisations in climate change governance, there is a need to explore additional policy and institutional approaches for supporting the participation of women and women organisations. For example, the creation of Gender Focal points at the national level or orchestration through national climate change coordination mechanisms (as briefly noted in Chapter 5) would have the potential to enhance the participation of women and women organisations. Mapping and assessing the role of discursive and behavioural legitimation approaches is another area for future research for advancing understanding on policy strategies that support the development of the agency of women and women organisations.

The thesis introduces and tests methodologies for analysing the quality of policy and institutional strategies at the three levels of UNFCCC-led governance, including at the national level in Georgia. However, these levels are not exhaustive. Further fine tuning and application of methodologies to different settings is necessary for advancing understanding on the role of women and women organisations in supporting UNFCCC-led mandates and policy implementation. More evidence needs to be collected on the quality and impact of policy and institutional strategies across various entry points and levels and within different national settings. As Chapter 4 highlights, additional entry points could include UNFCCC subsidiary bodies and national climate change adaptation processes. In addition, various regional, national and local levels of climate change decision making could be considered for further analysis.

The thesis presents a starting point in understanding the role of policy and institutional strategies in supporting more meaningful participation of women and women organisations. For these purposes, the research looks at broader categories of women and women organisations, although these categories do not capture various social and economic situations and factors that could define the participatory experience of these stakeholders. These additiona 


\section{CHAPTER 8}

factors could intersect and exacerbate the existing barriers (including those that are caused by institutional and policy strategies of low quality) and prevent meaningful participation of women and women organisations. Therefore, further research on policy and institutional strategies and their impact on meaningful participation of women and women organisations could be expanded with the consideration of intersectional gender dimensions (e.g. generation, class, race and ethnicity).

Finally, access to data on participation is often limited and it is not possible to create controlled experiments within UNFCCC settings. This creates challenges for the collection of evidence and the development of theories on the instrumental value of the participation of women and women organisations.

Further research is required to support the development of innovative methods for understanding the impact of participation on policy outcomes. 


\section{REFERENCES}

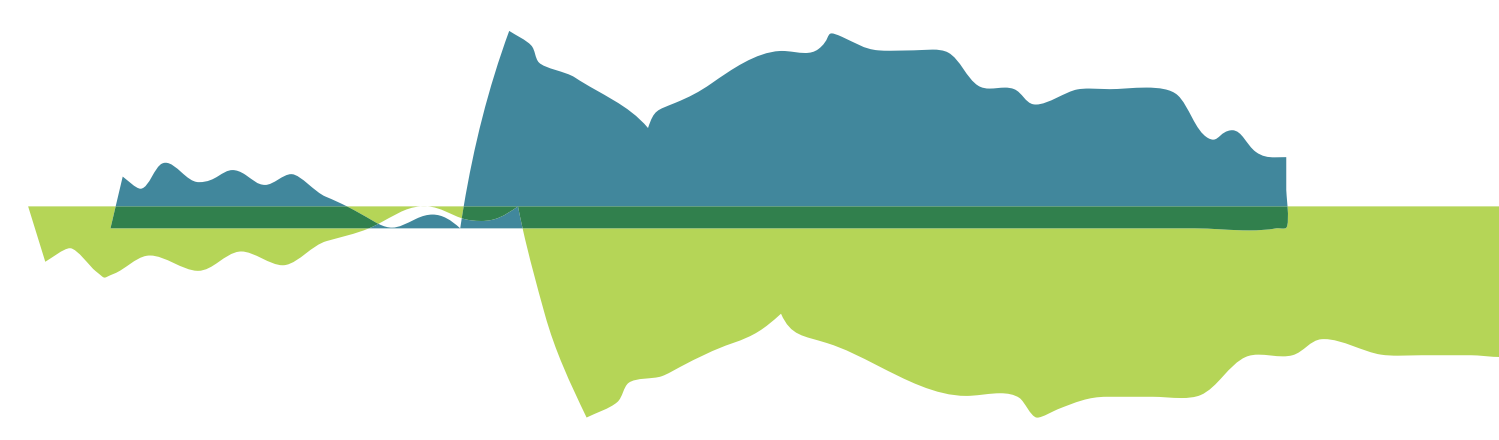

UNDERSTANDING POLICY AND INSTITUTIONAL

STRATEGIES TO SUPPORT THE PARTICIPATION

OF WOMEN AND WOMEN ORGANISATIONS WITHIN

UNFCCC-LED CLIMATE CHANGE GOVERNANCE 
Aasgaard, H. S., Borg, M. and Karlsson, B. (2012) 'Emancipation or symbolic participation: How can we "do" action research as a democratic process?', 2(1), pp. 1-7. Available at: https://www.fons.org/resources/documents/journal/ vol2no1/ipdj_0201_08.pdf.

Abbott, K.W. (2014) "Strengthening the Transnational Regime Complex for Climate Change." Transnational Environmental Law 3 (1): 57-88. https://doi. org/10.1017/S2047102513000502.

Abbott, K. W. et al. (2015) "Orchestrating Global Governance." International Organizations as Orchestrators, 349-79. https://doi.org/10.1017/cbo978113997 9696.018.

_. (2015b) "Orchestration: Global Governance through Intermediaries." International Organizations as Orchestrators, 3-36. https://doi.org/10.2139/ ssrn.2125452.

. (2016) "Two Logics of Indirect Governance: Delegation and Orchestration." British Journal of Political Science 46 (4): 719-29. https://doi. org/10.1017/S0007123414000593.Adams, L. et al. (2014) Effective. Efficient. Equitable. Making climate finance work for women. Available at: https://www. adb.org/sites/default/files/publication/ 42881/ climate-finance-workwomen.pdf.

Adams, R. B. and Funk, P. (2012) 'Beyond the glass ceiling: Does gender matter?', Management Science, 58(2), pp. 219-235. doi: 10.1287/mnsc.1110.1452.

Ajani, E., Onwubuya, E. and Mgbenka, R. (2013) 'Approaches to Economic Empowerment of Rural Women for Climate Change Mitigation and Adaptation: Implications for Policy', Journal of Agricultural Extension, 17(1), p. 23. doi: 10.4314/jae.v17i1.3.

Allan, J. I. (2021) The New Climate Activism: NGO Authority and Participation in Climate Change Governance. University of Toronto Press. doi: 10.1017/ S2047102521000133.

Alston, M. (2013) 'Women 's Studies International Forum Gender mainstreaming and climate change', Women's Studies International Forum, 47, pp. 1-8. doi: 10.1016/j.wsif.2013.01.016.

Andonova, L. B., Betsill, M. M. and Bulkeley, H. (2009) 'Transnational climate governance', Global Environmental Politics, 9(2), pp. 52-73. doi: 10.1162/ glep.2009.9.2.52.

Andrea, C. (2000) Making a difference? Gender and participatory development. Available at: https://www.participatorymethods.org/sites/participatorymethods. org/files/Dp378.pdf.

Annesley, C. and Gains, F. (2010) 'The Core Executive: Gender, Power and Change', Political Studies, 58(5), pp. 909-929. doi: 10.1111/j.1467-9248.2010.00824.x.
Antimiani, A. et al. (2017) 'The Green Climate Fund as an effective compensatory mechanism in global climate negotiations', Environmental Science and Policy, 77, pp. 49-68. doi: 10.1016/j.envsci.2017.07.015.

Arnall, A., Kothari, U. and Kelman, I. (2014) 'Introduction to politics of climate change: Discourses of policy and practice in developing countries', Geographical Journal, 180(2), pp. 98-101. doi: 10.1111/geoj.12054.

Arnstein, S. R. (1969) 'A Ladder Of Citizen Participation', Journal of the American Planning Association, 35(4), pp. 216-224. doi: 10.1080/01944366908977225.

Arora-Jonsson, S. (2011) 'Virtue and vulnerability: Discourses on women, gender and climate change',

Global Environmental Change, 21(2), pp. 744-751. doi: 10.1016/j.gloenvcha. 2011.01.005.

Baatz, C. (2018) 'Climate adaptation finance and justice. A criteria-based assessment of policy instruments', Analyse und Kritik, 40(1), pp. 73-105. doi: 10.1515/auk-2018-0004

Bach, T. and Davidson, R. (2016) 'Turning the Corner in Lima: The Language of Differentiation and the "Democratization" of Climate Change Negotiations', SSRN Electronic Journal, (3). doi: 10.2139/ssrn.2735012.

Bäckstrand, K. and Kuyper, J.W. (2017) 'The democraticlegitimacy of orchestration: the UNFCCC, non-state actors, and transnational climate governance', Environmental Politics, 26(4), pp. 764-788. doi: 10.1080/09644016.2017.1323579.

Bäckstrand, K., Zelli, F. and Schleifer, P. (2018) 'Legitimacy and Accountability in Polycentric Climate Governance', in Jordan, A. et al. (eds) Governing Climate Change. Polycentricity in Action? Cambridge University Press, pp. 338-356. doi: 10.1017/9781108284646.020

Baksh, R. and Harcourt, W. (2015) Introduction, The Oxford Handbook of Transnational Feminist Movements. Edited by R. Baksh and W. Harcourt. Oxford University Press. doi: 10.1093/oxfordhb/9780199943494.013.35.

Balmori, H. H. (2003) Gender and budgets - Overview Report, BRIDGE (development - gender). Available at: http://people.umass.edu/econ797f/ Syllabus and Readings/Readings/Gender/bridge.gendersensbud.pdf.

Bécault, E. and Marx, A. (2016) The global governance system for climate finance: towards greater institutional integrity? Available at: https://ghum.kuleuven.be/ ggs/publications/working_papers/2016/173becault.

Beckwith, K. (2007) 'Numbers and newness: The descriptive and substantive representation of women', Canadian Journal of Political Science, 40(1), pp. 2749. doi: 10.1017/S0008423907070059. 
Belfer, E. et al. (2019) 'Pursuing an indigenous platform: Exploring opportunities and constraints for indigenous participation in the UNFCCC', Global Environmental Politics, 19(1), pp. 12-33. doi: 10.1162/glep_a_00489.

Bendlin, L. (2020) Orchestrating Local Climate Policy in the European Union. Wiesbaden: Springer VS. doi: https://doi-org.libproxy.viko.lt/10.1007/978-3-65826506-9.

Betsill, M. et al. (2015) 'Building productive links between the UNFCCC and the broader global climate governance landscape', Global Environmental Politics, 15(2), pp. 1-12. doi: 10.1162/GLEP_a_00294.

Beunen, R. and Patterson, J. J. (2019) 'Analysing institutional change in environmental governance: exploring the concept of "institutional work"', Journal of Environmental Planning and Management, 62(1), pp. 12-29. doi: 10.1080/09640568.2016.1257423.

Bhatia, V. K. (2007) 'Discursive Practices in Disciplinary and Professional Contexts', Linguistics and the Human Sciences, 2(1). doi: 10.1558/lhs.v2i1.5.

Biermann, F. et al. (2009) Earth System Governance: People, Places and the Planet. Science and Implementation Plan of the Earth System Governance Project, Earth System Governance Project Report 1. doi: 10.7551/ mitpress/9780262028226.001.0001.

Biermann, F. (2014) Earth System Governance, Earth System Governance. The MIT Press. doi: 10.7551/mitpress/9780262028226.001.0001.

Biermann, F. and Gupta, A. (2011) 'Accountability and legitimacy in earth system governance: A research framework', Ecological Economics. Elsevier B.V., 70(11), pp. 1856-1864. doi: 10.1016/j.ecolecon.2011.04.008.

Biermann, F. and Kim, R. E. (2020) Architectures of Earth System Governance, Architectures of Earth System Governance. Cambridge University Press. doi: 10.1017/9781108784641.001.

Bird, N. (2015) Climate finance and public finance management. Available at: www.gsdrc.org.

Bird, N., Watson, C. and Schalatek, L. (2017) The Global Climate Finance Architecture, Climate Finance Fundamentals. Available at: https://odi.org/ en/publications/climate-financefundamentals-2-the-global-climate-financearchitecture-2017-update/.

Birdsall, N. and Nevers, M. De (2012) Adaptation Finance How to Get Out from between a Rock and a Hard Place, CGD Policy Paper 001. Available at: https:// www.cgdev.org/publication/adaptation-finance-how-get-out-between-rockand-hardplace.
Blaxekjær, L. $\varnothing$. and Nielsen, T. D. (2015) 'Mapping the narrative positions of new political groups under the UNFCCC', Climate Policy, 15(6), pp. 751-766. doi: 10.1080/14693062.2014.965656.

Boodoo, Z., Mersmann, F. and Olsen, K. H. (2018) 'The implications of how climate funds conceptualize transformational change in developing countries', Climate and Development, pp. 673-686. doi: 10.1080/17565529.2018.1442788.

Brunnée, J. and Streck, C. (2013) 'The UNFCCC as a negotiation forum: Towards common but more differentiated responsibilities', Climate Policy, 13(5), pp. 589607. doi: 10.1080/14693062.2013.822661.

Bulkeley, H. et al. (2014) Transnational climate change governance, Transnational Climate Change Governance. doi: 10.1017/CBO9781107706033.

Burch, S. et al. (2019) 'New directions in earth system governance research', Earth System Governance, 1, p. 100006. doi: 10.1016/j.esg.2019.100006.

Burns, D. and Heywood, F. (2004) 'Making Community Participation Meaningful. A Handbook for Development and Assessment'. Policy Press, p. 71. Available at: https://www.jrf.org.uk/sites/default/files/jrf/migrated/files/jr163-communityparticipationdevelopment.pdf.

Byrne, J. et al. (2007) 'Evaluating the potential of small-scale renewable energy options to meet rural livelihoods needs: A GIS- and lifecycle cost-based assessment of Western China's options', Energy Policy, 35(8), pp. 4391-4401. doi: 10.1016/j.enpol.2007.02.022.

Cameron, E., Shine, T. and Bevins, W. (2013) Climate Justice: Equity and justice informing a new climate agreement. Available at: http://pdf.wri.org/climate justice_equity_and_justice_informing_a_new_climate_agreement.pdf

Capello, S. and Harcourt, W. (2009) 'Gender and climate justuce', Green economics, 3(3/4), pp. 343-350.

Carter, C. (2005) 'The Role of participatory processes in environmental governance: The example of agricultural GMOs', Partizipation, Öffentlichkeitsbeteiligung, Nachhaltigkeit: Perspektiven der politischen Ökonomie, pp. 175-201.

Cavaghan, R. (2012) 'Gender Mainstreaming as a Knowledge Process: towards an understanding of perpetuation and change in gender blindness and gender bias'. Available at: https://www.era.lib.ed.ac.uk/handle/1842/6595\%5Cnhttps:// www.era.lib.ed.ac.uk/bitstream/1842/6595/1/Cavaghan 2012.pdf.

Celis, K. et al. (2008) 'Rethinking women's substantive representation', Representation, 44(2), pp. 99-110. doi: 10.1080/00344890802079573.

Chan, S. and Amling, W. (2019) 'Does orchestration in the Global Climate Action Agenda effectively prioritize and mobilize transnational climate adaptation 
action?', International Environmental Agreements: Politics, Law and Economics, 19(4-5), pp. 429-446. doi: 10.1007/s10784-019-09444-9.

Chan, S. et al. (2015) 'Reinvigorating International Climate Policy: A Comprehensive Framework for Effective Nonstate Action', Global Policy, 6(4), pp. 466-473. doi: 10.1111/1758-5899.12294.

Chan, S. and Pauw, P. (2014) A Global Framework for Climate Action (GFCA) Orchestrating Non-State and Subnational Initiatives for More Effective Global Climate Governance, Discussion paper.

Chase, A. T. (2012) 'Legitimizing Human Rights: Beyond Mythical Foundations and Into Everyday Resonances', Journal of Human Rights, 11(4), pp. 505-525. doi: 10.1080/14754835.2012.730914.

Chattopadhyay, R. and Duflo, E. (2004) 'Women as Policy Makers Evidence from a Randomized', Econometrica, 72(5), pp. 1409-1443.

Chauhan, N. and Vinaya Kumar, H. (2016) 'Gender Responsive Climate Change Strategies for Sustainable Development', Productivity, 57(2), pp. 182-186.

Cherni, J. A. and Hill, Y. (2009) 'Energy and policy providing for sustainable rural livelihoods in remote locations - The case of Cuba', Geoforum, 40(4), pp. 645654. doi: 10.1016/j.geoforum.2009.04.001.

Childs, S. and Krook, M. L. (2008) 'Critical mass theory and women's political representation', Political Studies, 56(3), pp. 725-736. doi: 10.1111/j.14679248.2007.00712.x

Chung, B. et al. (2013) 'Indicators of Women 's Empowerment in Developing Nations By', Robert M.La Follette School Of Public Affairs, pp. 1-95.

Clancy, J. et al. (2020) 'Engendering the Energy Transition: Setting the Scene', in Engendering the Energy Transition. Cham: Springer International Publishing, pp. 3-9. doi: 10.1007/978-3-030-43513-4_1.

Clancy, J. S. and Mohlakoana, N. (2020) 'Gender audits: An approach to engendering energy policy in Nepal, Kenya and Senegal', Energy Research and Social Science, 62. doi: 10.1016/j.erss.2019.101378.

Clancy, J. S., Batchelor, S. and Skutsch, M. (2003) 'The Gender-Energy-Poverty Nexus', Sustainable Development, p. 24. Available at: https://esmap.org/sites/ default/files/esmap-files/The Gender Energy Poverty Nexus.pdf.

Clapp, C. et al. (2012) Tracking Climate Finance: What and How? Available at: http://www.oecd.org/environment/cc/50293494.pdf.

Coenen, F. H. J. M. (2009) Public participation and better environmental decisions: The promise and limits of participatory processes for the quality of environmentally related decision-making, Public Participation and Better Environmental Decisions: The Promise and Limits of Participatory Processes for the Quality of Environmentally Related Decision-making. Springer Science + Business Media. doi: 10.1007/978-1-4020-9325-8.

Coenen, F. H. J. M., Huitema, D. and O'Toole, L. J. J. (1998) 'Participation and the Quality of Environmental Decision Making', Environment \& Policy, 14, pp. 307-324. Available at: http://link.springer.com/10.1007/978-94-011-5330-0.

Cohen, M. G. (2018) 'Gender and Climate Change Financing: Coming Out of the Margin', Feminist Economics, 24(3), pp. 188-190. doi: 10.1080/13545701.2017.1421319

Colenbrander, S., Dodman, D. and Mitlin, D. (2018) 'Using climate finance to advance climate justice: the politics and practice of channelling resources to the locallevel', ClimatePolicy, 18(7), pp.902-915. doi:10.1080/14693062.2017.1388212.

Cornwall, A. (2008) 'Unpacking "Participation" Models, meanings and practices', Community Development Journal, 43(3), pp. 269-283. doi: 10.1093/cdj/bsn010.

Dahlerup, D. (2006) 'The Story of the Theory of Critical Mass', Politics and Gender, 2(4), pp. 511-522. doi: 10.1017/S1743923X0624114X.

Dankelman, I. (2012) Gender and climate change: An introduction, Gender and Climate Change: An Introduction. doi: 10.4324/9781849775274.

Dauvellier, M. et al. (2016) 'Gender in environment and climate change'. Available at: https://eige.europa.eu/publications/gender-environment-and-climate-change.

Daviter, F. (2011) 'Policy Framing Analysis', Policy Framing in the European Union, pp. 26-53. doi: 10.1057/9780230343528_2.

Dekker, R. (2017) 'Frame ambiguity in policy controversies: critical frame analysis of migrant integration policies in Antwerp and Rotterdam', Critical Policy Studies 11(2), pp. 127-145. doi: 10.1080/19460171.2016.1147365.

Dellas, E., Pattberg, P. and Betsill, M. (2011) 'Agency in earth system governance: Refining a research agenda', International Environmental Agreements: Politics, Law and Economics, 11(1), pp. 85-98. doi: 10.1007/s10784-011-9147-9.

Denscombe, M. (2017) The good research guide for small-scale social research projects. 6th edn. London: Open University Press.

Derman, B. B. (2014) 'Climate governance, justice, and transnational civil society', Climate Policy, 14(1), pp. 23-41. doi: 10.1080/14693062.2014.849492.

Djou, J. A. G. et al. (2017) 'Symbolic participation in community-based tourism in Kelimutu National Park, Ende, East Nusa Tenggara', IOSR Journal of Business and Management, 19(01), pp. 15-20. doi: 10.9790/487x-1901071520.

Dorsch, M. J. and Flachsland, C. (2017) 'A polycentric approach to global climate governance', Global Environmental Politics, 17(2), pp. 45-64. doi: 10.1162/ GLEP_a_00400. 
Doshi, D. and Garschagen, M. (2020) 'Understanding adaptation finance allocation: Which factors enable or constrain vulnerable countries to access funding?', Sustainability (Switzerland), 12(10), pp. 1-18. doi: 10.3390/su12104308.

Doss, C. et al. (2011) 'The role of women in agriculture', Food and Agriculture Organization of the United NAtions, (11), pp. 1-48. doi: 10.1002/2014GB005021.

Ebi, K. L. (2009) 'Facilitating Climate Justice through Community-Based Adaptation in the Health Sector', Environmental Justice, 2(4), pp. 191-195. doi: 10.1089/env.2009.0031

Egli, F. and Stünzi, A. (2019) 'A dynamic climate finance allocation mechanism reflecting the Paris Agreement', Environmental Research Letters. IOP Publishing, 14(11). doi: 10.1088/1748-9326/ab443b.

Ergas, C. and York, R. (2012) 'Women's status and carbon dioxide emissions: A quantitative crossnational analysis', Social Science Research, 41(4), pp. 965-976. doi: 10.1016/j.ssresearch.2012.03.008.

Eyben, R. and Napier-Moore, R. (2009) 'Choosing words with care? Shifting meanings of women's empowerment in international development', Third World Quarterly, 30(2), pp. 285-300. doi: 10.1080/01436590802681066.

Ferreira, M. O. V. and Coronel, M. C. V. K. (2017) 'About the legitimation of gender studies in the ANPEd', Educacao e Pesquisa, 43(3), pp. 815-832. doi: 10.1590/S1517-9702201707159961.

Figueres, C., Tovar-Restrepo, M. and Eddy, N. (2013) Gender equality and the United Nations Framework Convention on Climate Change: A Compilation of Decision Text, Women's Environment \& Development Organization and Global Gender and Climate Alliance. Available at: http://www.wedo.org/themes/ sustainable-development-themes/climatechange/acompilation-of-unfcccgender-equality-decision-text.

Finnemore, M. (1996) National interests in international society, National Interests in International Society. Cornell University Press. doi: 10.7591/9781501707384.

GCF/B.09/23 (2015) Decisions of the Board - Ninth Meeting of the Board. https:// www.greenclimate.fund/documents/20182/24949/GCF_B.09_23_-_Decisions_

of_the_Board__Ninth_Meeting_of_the_Board_24_-_26_March_2015. pdf/2f71 ce99-7aef-4b04-8799-15975a1f66ef.

GCF/B.20/07 (2020) Updated Gender Policy and Action Plan 2018 - 2020. https:// www.greenclimate.fund/documents/20182/1087995/GCF_B.20_07_-_Updated_ Gender_Policy_and_Action_Plan_2018_2020.pdf/9bd48527-6e35-a72a-2f52fd401d16d358.
GCF/B.23/Inf.1 (2019) "Status of the GCF Portfolio: Approved Projects and Fulfilment of Conditions." file:///D:/University of Edinburgh/Winter Internship/ Sources/gcf.pdf.

GCF (2017) 'Mainstreaming Gender in Green Climate Fund Projects'. Available at: https://www.greenclimate.fund/documents/20182/194568/Guidelines__GCF_ Toolkit_Mainstreaming_Gender.pdf/860d1d03-877d-4c64-9a49-c0160c794ca7.

Gerlak, A. et al. (2018) Earth System Governance. Science and Implementation Plan of the Earth System Governance Project, Encyclopedia of Environmental Change. doi: 10.4135/9781446247501.n1164.

Germain, A. (2009) 'Integrating gender into HIV/AIDS programmes in the health sector: tool to improve responsiveness to women's needs', Bulletin of the World Health Organization, 87(11), pp. 883-883. doi: 10.2471/blt.09.071522.

Godfrey, C. P. (2012) 'Introduction: Race, Gender, Class and Climate Change', Race, Gender \& Class, 19(1/2), pp. 3-11.

Gomez-Echeverri, L. (2013) 'The changing geopolitics of climate change finance', Climate Policy, pp. 632-648. doi: 10.1080/14693062.2013.822690.

Gomez-Echeverri, L. and Muller, B. (2010) 'The Reformed Financial Mechanism of the UNFCCC', (April), p. Available at: http://www.oxfordenergy.org/pdfs/EV51.pdf.

Goodman, M. S. and Sanders Thompson, V. L. (2017) 'The science of stakeholder engagement in research: classification, implementation, and evaluation' Translational Behavioral Medicine, 7(3), pp. 486-491. doi: 10.1007/s13142-017-0495-z.

Di Gregorio, M. (2019) 'Multi-level governance and power in climate change policy networks', Global Environmental Change, 54, pp. 65-77.

Di Gregorio, M. et al. (2019) 'Multi-level governance and power in climate change policy networks', Global Environmental Change. Elsevier Ltd, 54(August 2018), pp. 64-77. doi: 10.1016/j.gloenvcha.2018.10.003.

Hale, T. and Roger, C. (2014) 'Orchestration and transnational climate governance', Review of International Organizations, 9(1), pp. 59-82. doi: 10.1007/s11558-013 9174-0.

Halimanjaya, A., Nakhooda, S. and Barnard, S. (2014) A review of the Indonesia Climate Change Trust Fund. Available at: http://www.odi.org/sites/odi.org.uk/ files/odi-assets/publicationsopinion-files/8898.pdf

Hall, L. C., Granat, M. and Daniel, T. (2019) 'Women's organizations and climate finance: Engaging in processes and accessing resources'. Available at: https://wedo.org/wpcontent/uploads/2019/06/WomensOrgsClimateFinance_ EngaginginProcesses.pdf. 
Harcourt, W. (2016) 'Gender Dilemmas in International Development Studies', European Journal of Development Research, 28(2), pp. 167-174. doi: 10.1057/ ejdr.2016.6.

Harcourt, W. (2018) 'Gender and Development: Looking Back, Looking Forward', Development (Basingstoke), 61(1-4), pp. 9-13. doi: 10.1057/s41301-018-0185-2.

Harmeling, S. et al. (2013) How can the Green Climate Fund initiate a paradigm shift? Available at: https://www.researchgate.net/publication/311746805_How_ can_the_Green_Climate_Fund_initiate_a_paradigm_shift.

Hebtezion, S. (2013) Overview of linkages between gender and climate change. Available at: https://reliefweb.int/report/world/gender-and-climate-changeoverview-linkages-betweengender-and-climate-change.

Hogl, K. et al. (2012) 'Legitimacy and effectiveness of environmental governance - concepts and perspectives', in Environmental Governance: The Challenge of Legitimacy and Effectiveness, pp. 1-26. doi: 10.4337/9781849806077.00008.

van Hulst, M. and Yanow, D. (2016) 'From Policy "Frames" to "Framing": Theorizing a More Dynamic, Political Approach', American Review of Public Administration, 46(1), pp. 92-112. doi: 10.1177/0275074014533142.

Huyer, S. (2016) Gender equality in national climate action: Planning for gender-responsive nationally determined contributions. Available at: https:// www.uncclearn.org/sites/default/files/inventory/gender_equality_in_national_ climate_action_1.pdf.

Inglehart, R. and Norris, P. (2003) Rising tide: Gender equality and cultural change around the world, Rising Tide: Gender Equality and Cultural Change Around the World. Cambridge University Press. doi: 10.1017/CBO9780511550362.

Jahan, R. (1995) 'The elusive agenda: mainstreaming women in development', The elusive agenda: mainstreaming women in development. doi: 10.5860/ choice.33-2237.

Jerneck, A. (2018) 'Taking gender seriously in climate change adaptation and sustainability science research: Views from feminist debates and sub-saharan small-scale agriculture', Sustainability Science, pp. 403-416. doi: 10.1007/s11625017-0464-y.

Jernnäs, M. et al. (2019) 'Cross-national patterns of governance mechanisms in nationally determined contributions (NDCs) under the Paris Agreement', Climate Policy, 19(10), pp. 1239-1249. doi: 10.1080/14693062.2019.1662760.

Jordan, A., Forster, J. and Huitema, D. (2018) Governing climate change: polycentricity in action?, Local Government Studies. Cambridge University Press.
Kabeer, N. (2021) 'Three faces of agency in feminist economics: Capabilities, empowerment, and citizenship', The Routledge Handbook of Feminist Economics, pp. 99-107.

Khapung, S. (2016) 'Transnational feminism and women's activism: Building resilience to climate change impact through women's empowerment in climate smart agriculture', Asian Journal of Women's Studies, 22(4), pp. 497-506. doi: 10.1080/12259276.2016.1242946.

Kirton, J. J. and Larionova, M. (2017) 'Accountability for effectiveness in global governance', Accountability for Effectiveness in Global Governance, pp. 1-290. doi: $10.4324 / 9781315565484$.

Kochskämper, E. et al. (eds) (2018) Participation for Effective Environmental Governance. Evidence from European Water Framework Directive Implementation. Routlege.

Koczberski, G. (1998) Women in development: a critical analysis, Third World Quarterly. doi: 10.1080/01436599814316.

Konte, M. and Tirivayi, N. (2020) 'Introduction', in Konte, M. and Tirivayi, N. (eds) Women and Sustainable Human Development. Gender, Development and Socia Change. Palgrave Macmillan. doi: https://doi.org/10.1007/978-3-030-14935-2_1.

Koon, A. D., Hawkins, B. and Mayhew, S. H. (2016) 'Framing and the health policy process: A scoping review', Health Policy and Planning, 31(6), pp. 801-816. doi: 10.1093/heapol/czv128.

Krizsan, A., Skjeie, H. and Squires, J. (2012) 'Institutionalizing Intersectionality: A Theoretical Framework', in Krizsan, A., Skjeie, H., and Squires, J. (eds) Institutionalizing Intersectionality. Gender and Politics series. London: Palgrave Macmillan UK, pp. 1-32. doi: 10.1057/9781137031068_1.

Kronsell, A. (2013) 'Gender and transition in climate governance', Environmental Innovation and Societal Transitions. Elsevier B.V., 7, pp. 1-15. doi: 10.1016/j. eist.2012.12.003.

Kuyper, J., Bäckstrand, K. and Schroeder, H. (2017) 'Institutional Accountability of Nonstate Actors in the UNFCCC: Exit, Voice, and Loyalty', Review of Policy Research, 34(1), pp. 88-109. doi: 10.1111/ropr.12213.

Kuyper, J., Linnér, B. O. and Schroeder, H. (2018) 'Non-state actors in hybrid global climate governance: justice, legitimacy, and effectiveness in a postParis era', Wiley Interdisciplinary Reviews: Climate Change, 9(1), pp. 1-18. doi: 10.1002/wcc.497.

Larson, M. J. (2002) 'Transforming power relationships: Building capacity for ecological security', Gender \& Development, 10(2), pp. 92-101. doi: 10.1080/13552070215901. 
Lawrence, T. B., Suddaby, R. and Leca, B. (2009) 'Institutional work: Actors and agency in institutional studies of organizations', Institutional Work: Actors and Agency in Institutional Studies of Organizations, pp. 1-324. doi: 10.1017/ CBO9780511596605

Lovenduski, J. (2005) State Feminism and Political Representation, State Feminism and Political Representation. Edited by J. Lovenduski. Cambridge University Press. doi: 10.1017/CBO9780511490996.

Mackay, Fiona, Meryl Kenny, and Louise Chappell. 2010. "New Institutionalism through a Gender Lens: Towards a Feminist Institutionalism?" International PoliticalScienceReview31(5):573-88.https://doi.org/10.1177/0192512110388788.

Mackay, F., Kenny, M. and Chappell, L. (2010) 'New institutionalism through a gender lens: Towards a feminist institutionalism?', International Political Science Review, 31(5), pp. 573-588. doi: 10.1177/0192512110388788.

Malhotra, A., Schuler, S. R. and Boender, C. (2002) 'Women's empowerment as a variable in International Development', World Bank.org, pp. 71-88. doi: 10.1596/0-8213-6057-4.

Manara, K. (2012) 'The Instrumental Versus the Symbolic: Investigating Members' Participation in Civil Society Networks in Tanzania', Research on Poverty Alleviation. Available at: http://www.repoa.or.tz/documents/SP_12-2_.pdf.

Manga, S. J. T. (2018) 'Post-paris climate agreement unfccc cop-21: Perspectives on international environmental governance', African Journal of International and Comparative Law, 26(3), pp. 309-338. doi: 10.3366/ajicl.2018.0235.

Markham, S. (2013) Women as agents of change: having voice in society and influencing policy, Women's Voice Agency \& Participation Research Series. Available at: http://www.worldbank.org/content/dam/Worldbank/document/ Gender/Markham 2013. Women as Agents of Change Having voice in society and influencing policy_ Dec 17.pdf.

Marquardt, J. (2017) 'Conceptualizing power in multi-level climate governance', Journal of Cleaner Production, 154, pp. 167-175. doi: 10.1016/j. jclepro.2017.03.176.

Marshall, M., Ockwell, D. and Byme, R. (2017) 'Sustainable energy for all or sustainable energy for men? Gender and the construction of identity within climate technology entrepreneurship in Kenya', Progress in development studies, 17(2), pp. 148-172.

Mavisakalyan, A. and Tarverdi, Y. (2019) 'Gender and climate change: Do female parliamentarians make difference?', European Journal of Political Economy, 56, pp. 151-164. doi: 10.1016/j.ejpoleco.2018.08.001.
McBride, D. E. and Mazur, A. G. (2013) 'Women's Policy Agencies and State Feminism', in Waylen, G. et al. (eds) Oxford handbook on gender and politics, pp. 654-678. Available at: https://pppa.wsu.edu/documents/2017/02/mazurand-mcbride2012.pdf/.

McBride, D. and Mazur, A. (2012) Gender machineries worldwide. Available at: http://hdl.handle.net/10986/9118.

McCright, A. M. (2010) 'The effects of gender on climate change knowledge and concern in the American public', Population and Environment, 32(1), pp. 66-87. doi: 10.1007/s11111-010-0113-1.

McKenzie, M. (2021) 'Climate change education and communication in global review: tracking progress through national submissions to the UNFCCC Secretariat', Environmental Education Research, 27(5), pp. 631-651. doi: 10.1080/13504622.2021.1903838

Mcleod, E. et al. (2018) 'Raising the voices of Pacific Island women to inform climate adaptation policies', Marine Policy, pp. 178-185. doi: 10.1016/j. marpol.2018.03.011.

McMurry, N. (2019) 'Applying human rights to enable participation', International Journal of Human Rights, 23(7), pp. 1049-1073. doi: 10.1080/ 13642987.2019.1582524.

Meadowcroft, J. (2009) 'Background Paper to the 2010 World Development Report', World Bank Policy Research Working Paper, (May 2009), pp. 1-42. Available at: http://www.mitpressjournals.org/doi/abs/10.1162/glep.2008.8.3.1.

Mees, H. and Driessen, P. (2019) 'A framework for assessing the accountability of local governance arrangements for adaptation to climate change', Journal of Environmental Planning and Management, 62(4), pp. 671-691. doi: 10.1080/09640568.2018.1428184.

Mishra, A. K. and Pede, V. O. (2017) 'Perception of climate change and adaptation strategies in Vietnam: Are there intra-household gender differences?', International Journal of Climate Change Strategies and Management, 9(4), pp. 501-516. doi: 10.1108/IJCCSM-01-2017-0014.

Mizuno, O. (2011) 'GEF as the Financial Mechanism of UNFCCC', Environmental Research Quaterly, (160), pp. 23-31.

Mohammad, N. and Farjana, Y. (2018) 'Participation as a human right: A rightsbased approach to development', Developments in Corporate Governance and Responsibility, 24, pp. 33-45. doi: 10.1108/S2043-052320180000014002.

Morgan, J. and Waskow, D. (2014) 'A new look at climate equity in the UNFCCC' Climate Policy, pp. 17-22. doi: 10.1080/14693062.2014.848096. 
Moynihan, D. P. (2003) 'Normative and Instrumental Perspectives on Public Participation: Citizen Summits in Washington, D.C.', American Review of Public Administration, 33(2), pp. 164-188. doi: 10.1177/0275074003251379.

Murray, U. (2019) Gender and NDCs: Country Progress and Key Findings. Available at: https://www.ndcs.undp.org/content/ndc-support-programme/en/home/impactandlearning/library/gender-and-ndcs--country-progress-and-key-findings.html.

Nagel, J. (2015) Gender and Climate Change, Impacts, Science, Policy. Routledge. doi: 10.4324/9781315675275.

Nakhooda, S. (2013) 'The Effectiveness of International Climate Finance', pp. 1-27. Available at: https://cdn.odi.org/media/documents/8344.pdf.

Nasiritousi, N. (2017) Assessing legitimacy and effectiveness in a fragmented global climate and energy governance landscape.

Nasiritousi, N., Hjerpe, M. and Bäckstrand, K. (2016) 'Normative arguments for non-state actor participation in international policymaking processes: Functionalism, neocorporatism or democratic pluralism?', European Journal of International Relations, 22(4), pp. 920-943. doi: 10.1177/1354066115608926.

Nasiritousi, N. and Linnér, B. O. (2016) 'Open or closed meetings? Explaining nonstate actor involvement in the international climate change negotiations', International Environmental Agreements: Politics, Law and Economics, 16(1), pp. 127-144. doi: 10.1007/s10784-014-9237-6.

Newig, J. and Fritsch, O. (2009) 'Environmental governance: Participatory, multilevel - And effective?', Environmental Policy and Governance, 19(3), pp. 197-214. doi: 10.1002/eet.509.

Newig, J. and Kvarda, E. (2012) 'Participation in environmental governance: Legitimate and effective?', in Environmental Governance: The Challenge of Legitimacy and Effectiveness, pp. 29-45. doi: 10.4337/9781849806077.00010.

Newman, K. and Stephenson, J. (2010) 'Response to: The empowerment of women and the population dynamics of climate change', Journal of Public Health, 32(4), p. 591. doi: 10.1093/pubmed/fdq067.

O'Neil, T. and Domingo, P. (2016) Women and power - overcoming barriers to leadership and influence. Available at: https://odi.org/en/publications/womenand-power-overcoming-barriersto- leadership-and-influence/.

Van Oers, L. M., Boon, W. P. C. and Moors, E. H. M. (2018) 'The creation of legitimacy in grassroots organisations: A study of Dutch community-supported agriculture', Environmental Innovation and Societal Transitions. Elsevier, 29(March), pp. 55-67. doi: 10.1016/j.eist.2018.04.002.
Okereke, C. and Coventry, P. (2016) 'Climate justice and the international regime: before, during, and after Paris', Wiley Interdisciplinary Reviews-Climate Change, 7(6), pp. 834-851. doi: 10.1002/wcc.419.

Olsen, K. H. and Fenhann, J. V (2016) Transformational Change Taxonomy. UNEP DTU Partnership. Available at: https://orbit.dtu.dk/en/publications/ transformational-change-taxonomymethodological-framework-for-the.

Ostrom, E. (2010) 'Polycentric systems for coping with collective action and global environmental change', Global Environmental Change, 20(4), pp. 550557. doi: 10.1016/j.gloenvcha.2010.07.004.

Page, A. and Larsen, M. (2010) 'The empowerment of women and the population dynamics of climate change', Journal of Public Health, 32(4), pp. 590-591. doi: 10.1093/pubmed/fdq066.

Park, J. (2012) 'Investing in Climate Governance and Equity in a Post-Durban World', Ethics, Policy and Environment. doi: 10.1080/21550085.2012.730237.

Parpart, J. L. (2014) 'Eploring the transformative potential of gender mainstreaming in international development institutions', Journal of International Development, 26(3), pp. 382-395. doi: 10.1002/jid.2948.

Pauw, W. P. and Klein, R. J. T. (2020) 'Beyond ambition: increasing the transparency, coherence and implementability of Nationally Determined Contributions', Climate Policy. Taylor \& Francis, 3062. doi: 10.1080/14693062.2020.1722607.

Pelling, M. (2011) Adaptation to climate change: from resilience to transformation. Routlege.

Phillips, F.-K. (2018) 'Participation of Non-party Stakeholders under the UNFCCC: Options for Future Engagement', (CIGI Papers No. 205). Available at: https:// www.cigionline.org/publications/participation-non-party-stakeholders-underunfcccoptions-future-engagement.

Pickering, Jonathan et al. (2013) 'Crawford School of Public Policy Centre for Climate Economic \& Policy Acting on Climate Finance Pledges: Inter-Agency Dynamics and Relationships with Aid in Contributor States'.

Raj, A. (2017) 'Gender Empowerment Index: a choice of progress or perfection', The Lancet Global Health. doi: 10.1016/S2214-109X(17)30300-5.

Razavi, S. and Miller, C. (1995) From WID to GAD: conceptual shifts in the women and development discourse, Occasional Paper - United Nations Research Institute for Social Development.

Reeves, H. and Baden, S. (2000) Gender and Development: Concepts and Definitions, Institute of Development Studies / Bridge Development-Gender. Brighton. 
Resurrección, B. P. (2013) 'Persistent women and environment linkages in climate change and sustainable development agendas', Women's Studies International Forum, 40, pp. 33-43. doi: 10.1016/j.wsif.2013.03.011.

Reyes, A. (2011) 'Strategies of legitimization in political discourse: From words to actions', Discourse and Society, 22(6), pp. 781-807. doi: 10.1177/09579 26511419927.

Roberts, J. T. (2009) 'The International Dimension of Climate Justice and the Need for International Adaptation Funding', Environmental Justice, pp. 185190. doi: 10.1089/env.2009.0029.

Salehi, S. et al. (2013) 'Gender, responsible citizenship and global climate change', Women's Studies International Forum, 50, pp. 1-8. doi: 10.1016/j. wsif.2013.01.016.

Schalatek, L. (2018) Gender and Climate Finance. Climate Finance Fundamentals. Climate Funds Update. Available at: https://climatefundsupdate.org/wpcontent/uploads/2018/11/CFF10-2018-ENG-DIGITAL.pdf.

Schalatek, L. (2019) 'Gender and Climate Finance', Climate Finance Fundamentals, p. 8. Available at: https://us.boell.org/sites/default/files/2019-11/CFF10 2019 \%5BENG\%5D DIGITAL.pdf.

Schatalek, L. and Nakhooda, S. (2014) 'Gender and Climate Finance'. Available at: https://cdn.odi.org/media/documents/10065.pdf.

Schalatek, L. and Nakhooda, S. (2014) Gender and Climate Finance Gender in recent UNFCCC Agreements, Heinrich Boll Stiftung Climate Funds Update 10.

Schmelzle, C. (2012) 'Evaluating Governance: Effectiveness and Legitimacy in Areas of Limited Statehood', SSRN Electronic Journal. doi: 10.2139/ssrn.1986017.

Schmidt, V. A. (2008) 'Discursive institutionalism: The explanatory power of ideas and discourse', Annual Review of Political Science, 11, pp. 303-326. doi: 10.1146/ annurev.polisci.11.060606.135342.

Schwerhoff, G. and Konte, Maty (2020) 'Gender and Climate Change: Towards Comprehensive Policy Options', in Konte, M and Tirivayi, N. (eds) Women and Sustainable Human Development. Cham: Springer International Publishing, pp. 51-67. doi: 10.1007/978-3-030-14935-2_4

Seckinelgin, H. (2009) NGO Diplomacy: The Influence of Nongovernmental Organizations in International Environment Negotiations, Journal of Comparative Policy Analysis: Research and Practice. MIT Press. doi: 10.1080/13876980902888137.

Sharma, A. (2010) The Reformed Financial Mechanism of the UNFCCC: Renegotiating the role of civil society in the governance of climate finance. Available at: http://www.oxfordenergy.org/pdfs/EV50.pdf.
Siulemba, G. and Moodley, V. (2014) 'A Gendered Analysis of Sustainable Agricultural Practices with Changing Climate in the Chankumba Agricultural Community, Zambia', Agenda: Empowering Women for Gender Equity, pp. 135-146. doi: 10.1080/10130950.2014.932126.

Skovgaard, J. and Gallant, J. (2015) 'National delegations to UNFCCC Conferences of the Parties: Who participates?', Earth System Governance, (November), p. 15. Available at: http://www.earthsystemgovernance.org/sites/ default/files/publications/files/ESGWorkingPaper-35_Skovgaard-and-Gallant.pdf.

Speer, J. (2012) 'Participatory Governance Reform: A Good Strategy for Increasing Government Responsiveness and Improving Public Services?', World Development, 40(12), pp. 2379-2398. doi: 10.1016/j.worlddev.2012.05.034

Squires, J. (2007) The New Politics of Gender Equality, The New Politics of Gender Equality. Red Globe Press. doi: 10.1007/978-1-137-03653-7.

Steffek, J. and Nanz, P. (2008) Emergent Patterns of Civil Society Participation in Global and European Governance, Civil Society Participation in European and Global Governance. doi: 10.1057/9780230592506_1.

Stephenson, S. R. et al. (2019) 'Convergence and Divergence of UNFCCC Nationally Determined Contributions', Annals of the American Association of Geographers. doi: 10.1080/24694452.2018.1536533.

Sundström, A. et al. (2017) 'Women's Political Empowerment: A New Global Index, 1900-2012', World Development, 94(c), pp. 321-335. Available at: http:// www.sciencedirect.com/science/article/pii/S0305750X17300323.

Suškevičs, M. (2012) 'Legitimacy Analysis of Multi-Level Governance of Biodiversity: Evidence from 11 Case Studies across the EU', Environmental Policy and Governance, 22(4), pp. 217-237. doi: 10.1002/eet.1588.

Sweetman, C. (2002) '1. Gender, Development, and Climate Change', Gender Development, and Climate Change, pp. 10-112. doi: 10.3362/9780855987374.001. Taibi, F.-Z. and Konrad, S. (2018) 'Pocket guide to NDC under UNFCCC'. ECBI. Available at: https://pubs.iied.org/pdfs/G04320.pdf.

Tallberg, J. and Zürn, M. (2019) 'The legitimacy and legitimation of international organizations: introduction and framework', Review of International Organizations. The Review of International Organizations, 14(4), pp. 581-606. doi: 10.1007/s11558-018-9330-7.

Tanaka, S. and Bhandari, P. (2016) 'Building Gender into Climate Finance: ADB Experience with the Climate Investment Funds', Asian Development Bank. Available at: https://www.adb.org/sites/default/files/publication/186020/genderclimate-finance.pdf. 
Terpstra, P., Carvalho, A. P. and Wilkinson, E. (2013) 'The plumbing of adaptation finance: accountability, transparency and accessibility at the local level', (November), pp. 1-32.

Thew, H., Middlemiss, L. and Paavola, J. (2021) 'Does youth participation increase the democratic legitimacy of UNFCCC-orchestrated global climate change governance?', Environmental Politics, pp. 1-22. doi: 10.1080/09644016.2020.1868838.

Thomann, L. (2008) 'The ILO, Tripartism, and NGOs: Do Too Many Cooks Really Spoil the Broth?', Civil Society Participation in European and Global Governance, pp. 71-94. doi: 10.1057/9780230592506_4.

Thornton, N. et al. (2011) 'Realising the potential: making the most of climate change finance in Africa. A synthesis report from six country studies: Cameroon, Ghana, Kenya, Morocco, South Africa and Tanzania', pp. 1-51. Available at: http://www.oecd.org/dac/environmentdevelopment/48597031.pdf.

True, J. (2003) 'Mainstreaming gender in global public policy', International Feminist Journal of Politics, 5(3), pp. 368-396. doi: 10.1080/1461674032000122740.

True, J. and Mintrom, M. (2001) 'Transnational networks and policy diffusion: The case of gender mainstreaming', International Studies Quarterly, 45(1), pp. 27-57. doi: 10.1111/0020-8833.00181

Trujillo, N. C. and Nakhooda, S. (2013) 'The effectiveness of climate finance: a review of the Adaptation Fund', (March), p. 40.

Tuana, N. (2013) 'Research, Action and Policy: Addressing the Gendered Impacts of Climate Change. Gendering Climate Knowledge for Justice: Catalyzing a New Research Agenda', pp. 17-31.

UN Women (2016) 'Leveraging co-benefits between gender equality and climate action for sustainable development', (October), p. 66. Available at: http://unfccc. int/files/gender_and_climate_change/application/pdf/leveraging_cobenefits.pdf.

UNDP (2013) Overview of linkages between gender and climate change. Available at: https://www.undp.org/content/dam/undp/library/gender/Gender and Environment/UNDP Linkages Gender and CC Policy Brief 1-WEB.pdf.

UNDP (2018) Gender Equality in Georgia : Barriers and Recommendations. Available at: https://www.ge.undp.org/content/georgia/en/home/library/ democratic_governance/genderequality-in-georgia.html.

UNFCCC (1996) Network of National Focal Points to the UNFCCC. Available at: https://unfccc.int/sites/default/files/resource/designation_of_unfccc_national_ focal_point.pdf.
UNFCCC (2002a) Guidelines for the preparation of national communications from Parties not included in Annex I to the Convention. FCCC/CP/2002/7/ Add.2 Decision 17/CP.8. Available at: http://unfccc.int/files/meetings/cop_15/ application/pdf/cop15_cph_auv.pdf.

UNFCCC (2002b) Report of the Conference of the Parties on its seventh session hel at Marrakesh from 29 October to 10 November 2001. Improving the participation of women in the representation of Parties in bodies established under the UNFCCC. Available at: http://climateactiontracker.org/ countries/turkey.html\%5Cnpapers3://publication/uuid/511BD0B8-89CA-44F09EBODE2B572F85F2.

UNFCCC (2003) 'Decision 17/CP.8 Guidelines for the preparation of national communications from Parties not included in Annex I to the Convention, Report of the Conference of the Parties on its Eight Session, held at New Delhi from 23 October to 1 November 2002: Part Two'. Available at: https://unfccc.int/ resource/docs/cop8/07a02.pdf\#page=2.

UNFCCC (2011) 'Report of the Conference of the Parties on its sixteenth session, held in Cancun from 29 November to 10 December 2010 - Decisions adopted by the Conference of the Parties', Conference of the Parties on its sixteenth session, 01418(March), pp. 1-31. doi: 10.1039/c0em00401d.

UNFCCC (2012) 'Report of the Conference of the Parties on its seventeenth session, held in Durban from 28 November to 11 December 2011'. Available at: https://unfccc.int/resource/docs/2011/cop17/eng/09a01.pdf.

UNFCCC (2013) 'Report of the Conference of the Parties on its eighteenth session, held in Doha from 26 November to 8 December 2012.', (February), p. Decision 15/CP.18. Available at: https://unfccc.int/resource/docs/2012/cop18/ eng/08a01.pdf.

UNFCCC (2014) Report of the Conference of the Parties on its nineteenth session held in Warsaw from 11 to 23 November 2013. Available at: https://unfccc.int/ resource/docs/2013/cop19/eng/10a01. pdf\#page=20.

UNFCCC (2015a) 'Paris Agreement', Conference of the Parties on its twenty-first session, (December), p. 32. Available at: http://unfccc.int/resource/docs/2015/ cop21/eng/l09r01.pdf.

UNFCCC (2015b) Report of the Conference of the Parties on its twentieth session, held in Lima from 1 to 14 December 2014. Available at: http://unfccc. int/resource/docs/2014/cop20/eng/10a02.pdf\#page=20.

UNFCCC (2016) Report of the Conference of the Parties on its twenty-second session, held in Marrakech from 7 to 18 November 2016. Available at: https:// unfccc.int/sites/default/files/resource/docs/2016/cop22/eng/10a02.pdf. 
UNFCCC (2017) Report of the Conference of the Parties serving as the meeting of the Parties to the Kyoto Protocol on its twelfth session, held in Marrakech from 7 to 18 November 2016. Available at: https://www.adaptation-fund.org/wpcontent/uploads/2015/09/AFB.EFC_.17.3-.

UNFCCC / Technology Executive Committee (2017) Updated paper on linkages between the TNA and NDC process Background paper I. Background. Available at: http://unfccc.int/ttclear/pages/tec_home.html.

UNFCCC (2018a) Entry points for integrating gender considerations into UNFCCC workstreams. Technical paper by the secretariat. Available at: https:// unfccc.int/sites/default/files/resource/TP overview_Gender Dialogue.pdf.

UNFCCC (2018b) 'Report of the Conference of the Parties on its twenty-third session, held in Bonn from 6 to 18 November 2017', 01342(February), pp. 181342. Available at: https://unfccc.int/sites/default/files/resource/docs/2017/ cop23/eng/11a01.pdf.

UNFCCC (2019a) Enhanced Lima work programme on gender and its gender action plan, Conference of the Parties Twenty-fifth session. Available at: https:// unfccc.int/sites/default/files/resource/cp2019_13a01E.pdf.

UNFCCC (2019b) Report of the Conference of the Parties on its twenty-fourth session, held in Katowice from 2 to 15 December 2018. Available at: https:// unfccc.int/sites/default/files/resource/10a1.pdf.

UNFCCC (2020) Report of the Conference of the Parties on its twenty-fifth session, held in Madrid from 2 to 15 December 2019. Available at: https://unfccc. int/sites/default/files/resource/cp2019_13E.pdf.

USAID and IUCN (2018) 'Advancing gender in the environment: Making the case for gender equality in large-scale renewable energy infrastructure development'. Available at: https://www.usaid.gov/sites/default/files/documents/1865/IUCNUSAIDMaking_the_case_for_INFRASTRUCTURE.pdf.

Vandenbeld, A. (2015) 'International Trends in Women's Political Participation and Representation', The Oxford Handbook of Transnational Feminist Movements, pp. 215-246.

Vargas, V. and Wieringa, S. (1998) 'The triangle of empowerment: Processes and actors in the making of public policy for women', in Women's Movements and Public Policy in Europe, Latin America, and the Caribbean: The Triangle of Empowerment, pp. 3-23.

Verloo, M. (2016) 'Mainstreaming Gender Equality in Europe. a Critical Frame

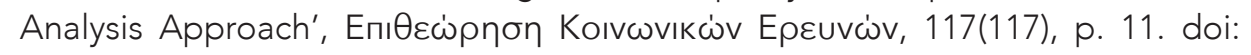
10.12681/grsr.9555.
Villagrasa, D. (2002) 'Kyoto Protocol negotiations: Reflections on the role of women', Gender \& Development, 10(2), pp. 40-44. doi: 10.1080/13552070215902.

Wahlström, N. and Sundberg, D. (2018) 'Discursive institutionalism: towards a framework for analysing the relation between policy and curriculum', Journal of Education Policy, 33(1), pp. 163-183. doi: 10.1080/02680939.2017.1344879.

Wakefield, S. (2017) 'Transformative and Feminist Leadership for Women's Rights', Oxfam America Research Backgrounder series.

Waylen, G. (2007) 'Engendering Transitions: Women's Mobilization, Institutions and Gender Outcomes', Engendering Transitions: Women's Mobilization, Institutions and Gender Outcomes, pp. 1-256. doi: 10.1093/acprof:oso/ 978019 9248032.001.0001.

WECF (2015) Women's Rights in EWA Project: Georgia, Kyrgyzstan, Tajikistan and South Africa. An analysis of CEDAW Reports and Recommendations.

Weldon, S. L. (2002) 'Beyond bodies: Institutional sources of representation for women in democratic policymaking', Journal of Politics, 64(4), pp. 1153-1174. doi: 10.1111/1468-2508.00167.

Westphal, M. I. et al. (2015) 'Getting to $\$ 100$ billion: Climate finance scenarios and projections to 2020', World Resources Institute, (Working Paper), pp. 1-20.

WHO (2009) 'Integrating Gender into HIV/AIDS Programmes in the Health Sector: Tool to Improve Responsiveness to Women's Needs.'

Williams, M. (2015) Gender and Climate Change Financing. Routledge. doi: $10.4324 / 9781315694764$.

Winkler, H. (2016) 'Who determines transformational change', Climate policy, Volume 16(6), pp. 783-791.

Wong, S. (2016) 'Can Climate Finance Contribute to Gender Equity in Developing Countries?', Journal of International Development, pp. 428-444. doi: 10.1002/ jid.3212.

World Resources Institute (2015) 'Designing and Preparing Intended Nationally Determined Contributions (INDCs)', World Resource Institut, p. 124. Available at: http://www.wri.org/publication/designing-and-preparing-indcs.

Worlen, C., Altevvogt, J. and Keppler, L. (2020) Between Climate Finance Mechanisms. 


\section{SUMMARY}

Participation is a very popular topic in climate change governance scholarship, nonetheless, there are still areas that are understudied and not well understood. The research analyses the participation of women and women organisations within the UNFCCC-led governance (and the associated climate finance decisionmaking), which remains one of the most important climate change governance arenas (Betsill et al., 2015; Dorsch and Flachsland, 2017; Di Gregorio, 2019).

Within climate change governance, women and women organisations present "new governance agents" whose participation is considered in academic iterature from two perspectives, i.e rights-based and instrumental perspectives. From the rightsbased perspective, women and women organisation participation is necessary to ensure gender equality and inclusiveness of participatory processes. On the other hand, their participation could be instrumental in delivering more just climate policies, fair allocation of climate finance and better gender responsiveness, sustainability and innovativeness of climate policies (Larson, 2002; Alston, 2013; Hebtezion, 2013; Salehi et al., 2013; Williams, 2016).

The research aims at enhancing the knowledge on the role of women and women organisations within the UNFCCC-led decision making, including largely understudied UNFCCC-led climate-finance decision-making. This knowledge is necessary to support more meaningful participation of women and women organisations and the implementation of climate change goals, which requires an unprecedented amount of funding, innovation, and efforts across scales (Pickering et al., 2013; Bird, 2015; Williams, 2016).

The objectives of the research are achieved through describing and analysing the quality of the UNFCCC's policy and institutional strategies that guide the participation of women and women organisations across the three levels of the UNFCCC-led decision making, i.e. the decision-making by the Conference of the Parties (COP), decision-making by the UNFCCC's Financial Mechanisms, as well as UNFCCC-led decision-making at the national level.

The research relies on an integrated outlook for studying participation. The term "meaningful" is used in the thesis to describe such participation that considers both the inclusivity of participatory processes that target women and women organizations and the instrumental contribution of women and women organisations to policymaking. The analysis of UNFCCC policy strategies attempts to understand both the inclusiveness of policy language and the acknowledgment of various women groups and women organisations in UNFCCC-led decision-making processes as well as anticipated outcomes noted in policies as a result of the participation of women and women organisations.
In addition to policy strategies (which describe discursive practices used by the UNFCCC), the research studies institutional strategies for understanding how knowledge produced by policies is transmitted and diffused to practice.

The research offers theoretical, policy and methodological contribution through improving understanding of multi-level UNFCCC-led governance using participation as an entry point, providing recommendations for more meaningful participation through better designed policy and institutional strategies; proposing and testing frameworks for analysing the quality of policy and institutional efforts to support the participation of women and women organisations.

Chapter 1 introduces the problem statement and research questions.

Chapter 2 presents a historical outlook on the development of gender narratives within the UNFCCC policy discourse and introduces the three levels of the UNFCCC architecture.

Chapter 3 summarises existing literature from both climate governance and feminist scholarship to identify how participation is studied and what analytical constructs are emerging around the participation of women and women organisations within climate change decision-making.

Chapter 4 introduces policy framing as a strategy that guides the participation of women and women organisations based on the analysis of the UNFCCC's policies adopted by the Conference of the Parties to the UNFCCC, and the associated Paris Agreement and Kyoto Protocol (COP, CMP and CMA). The chapter untangles the logic of complex UNFCCC decisions and offers insights into how the participation of women and women organisations is constructed discursively in UNFCCC COP, CMA and CMP decisions. In addition, the chapter provides recommendations for policymakers on improving the existing policy strategies.

Chapter 5 describes the existing legitimation approaches (as a policy strategy) across the three levels of the UNFCCC-led governance using the example of Georgia. The Chapter identifies how women and women organisations are defined in the policy texts adopted by the COP, UNFCCC Financial Mechanism and at the national level of the UNFCCC-led climate change planning; and analyse the consistency of these definitions.

Chapter 6 provides evidence on the quality of orchestration (as an institutional strategy) to support the participation of women organisations in the UNFCCC led climate finance governance and concludes with policy recommendations for 
enhancing the mobilisation of women organisations in the UNFCCC-led climate finance decision making.

Chapter 7 provides evidence on how the allocation of climate finance by the GCF (the key UNFCCC Financial Mechanism) supports women empowerment using the example of the GCF's energy portfolio. The chapter offers insights for policymakers on what institutional and capacity factors appear to affect the consideration of women empowerment issues within climate finance projects.

Chapter 8 concludes with a summary of the key findings on the limitations of the existing policy and institutional strategies and recommendations to support more meaningful participation of women and women organisations in the UNFCCC-led climate change governance. In addition, the chapter presents methodological, theoretical and policy reflections that could guide further policy development and research.

\section{SAMENVATTING}

Participatie is een zeer populair onderwerp bij studiebeurzen voor onderzoek naar klimaatverandering maar er zijn nog steeds gebieden, die onvoldoende worden bestudeerd en nog niet goed worden begrepen. Dit onderzoek analyseert de deelname van vrouwen en vrouwenorganisaties de door de UNFCCC geleide klimaatverandering governance (en de bijbehorende besluitvorming over de klimaatfinanciering), dat één van de belangrijkste geschilpunten voor klimaatverandering blijft. (Betsill et al., 2015; Dorsch and Flachsland, 2017: Di Gregorio, 2019).

Binnen de klimaatverandering governance presenteren vrouwen en vrouwenorganisaties 'nieuwe governance gemachtigden' wiens deelname in de academische literatuur vanuit twee perspectieven worden beschouwd. Namelijk op rechten gebaseerde perspectieven en instrumentele perspectieven. Vanuit het rechtsperspectief is de deelname van vrouwen en vrouwenorganisaties noodzakelijk om gendergelijkheid en inclusiviteit van de participatieprocessen te kunnen waarborgen. Aan de andere kant zou hun deelname instrumentee kunnen zijn voor een rechtvaardiger klimaatbeleid, een eerlijkere toewijzing van de klimaatfinanciering, een betere genderrespons en duurzaamheid en innovatie van het klimaatbeleid (Larson, 2002; Alston, 2013; Hebtezion, 2013; Salehi et al., 2013; Williams, 2016).

Het onderzoek is gericht op het vergroten van de kennis over de rol van vrouwen en vrouwenorganisaties op de besluitvormende posities binnen de UNFCCC. Dit geldt ook voor de grotendeels onderbelichte besluitvormende posities binnen de UNFCCC over klimaatfinanciering. Deze kennis is noodzakelijk om een zinvollere deelname van vrouwen en vrouwenorganisaties te ondersteunen en de implementatie van de klimaatveranderingsdoelen te bewerkstelligen. Hiervoor zal een ongekende hoeveelheid financiering, innovatie en inspanningen op alle niveaus nodig zal zijn (Pickering et al., 2013; Bird, 2015; Williams, 2016).

De doelstellingen van het onderzoek worden bereikt door het beschrijven en het analyseren van de kwaliteit van het UNFCCC-beleid en de institutionele strategieën, die tot de participatie van vrouwen en vrouwenorganisaties leidt. Deze participatie vindt op drie niveaus van de plats: de besluitvorming door de Conferentie van de Partijen (COP), de besluitvorming door de financiële mechanismen van de UNFCCC en de door de UNFCCC geleide besluitvorming op nationaal niveau.

Het onderzoek is gebaseerd op een geïntegreerde kijk op het bestuderen van participatie. De term 'betekenisvol' wordt in het proefschrift gebruikt on de deelname te beschrijven die zowel rekening houdt met de inclusiviteit van 
participatieve processen, die gericht zijn op vrouwen en vrouwenorganisaties, als met de instrumentele bijdrage van vrouwen en vrouwenorganisaties aan de beleidsvorming. De analyse van de beleidsstrategieën van de UNFCCC probeert zowel de inclusiviteit van de beleidstaal als de erkenning van verschillende vrouwengroepen en vrouwenorganisaties in de besluitvormingsprocessen van de UNFCCC te begrijpen. Dit geldt ook voor de verwachte resultaten, die in het beleid worden opgemerkt als gevolg van de deelname van vrouwen en vrouwenorganisaties. Naast de beleidsstrategieën (die de discursieve praktijken beschrijven, die door de UNFCCC worden gehanteerd), bestudeert het onderzoek ook de institutionele strategieën om te begrijpen hoe de kennis, die door het beleid wordt geproduceerd, wordt overgedragen en naar de praktijk wordt verspreid.

Het onderzoek biedt theoretische, beleidsmatige en methodologische bijdragen om op meerdere niveaus van de door de UNFCCC geleide governance een beter begrip te krijgen. Hierbij wordt participatie als startpunt gebruikt om aanbevelingen te doen voor een betekenisvollere participatie. Dit kan worden bereikt door middel van beter ontworpen beleids- en institutionele strategieën, zoals het voorstellen en het testen van kaders voor het analyseren van de kwaliteit van het beleid en de institutionele inspanningen voor de ondersteuning van de participatie van vrouwen en vrouwenorganisaties.

\section{Hoofdstuk 1 introduceert de probleemstelling en de onderzoeksvragen.}

Hoofdstuk 2 geeft een historische kijk op de ontwikkeling van genderverhalen binnen het beleidsdiscours van de UNFCCC en introduceert de drie niveaus van het beleid van de UNFCCC.

Hoofdstuk 3 vat de bestaande literatuur over zowel klimaat governance als de wetenschap over vrouwen of gender samen. Dit om te identificeren hoe de participatie wordt bestudeerd en welke analytische constructies rond de participatie van vrouwen en vrouwenorganisaties in de besluitvorming over klimaatverandering ontstaan.

Hoofdstuk 4 introduceert beleidsframing als een strategie, die de deelname van vrouwen en vrouwenorganisaties stuurt op basis van de analyse van het UNFCCCbeleid. Dit beleid is aangenomen door de Conferentie van de Partijen van de UNFCCC en het bijbehorende Klimaatakkoord van Parijs en het Kyoto-protocol (COP, CMP en CMA ). Dit hoofdstuk ontwart de logica van de complexe beslissingen van de UNFCCC en biedt inzicht in hoe de deelname van vrouwen en vrouwenorganisaties bij beslissingen van de COP, de CMA en de CMP is geconstrueerd. Daarnaast geeft het hoofdstuk ook aanbevelingen voor beleidsmakers over het verbeteren van de bestaande beleidsstrategieen.
Hoofdstuk 5 beschrijft aan de hand van het voorbeeld van Georgië de bestaande legitimatiebenaderingen (als een beleidsstrategie) op de drie niveaus van de door de UNFCCC geleide governance. Dit hoofdstuk identificeert hoe vrouwen en vrouwenorganisaties in de beleidsteksten worden gedefinieerd. Dit zijn beleidstukken die zijn aangenomen door de COP, de financiële mechanismen van de UNFCCC en op national niveau de door de UNFCCC geleide governance. Ook wordt in dit hoofdstuk de consistentie van deze definities geanalyseerd.

Hoofdstuk 6 levert bewijs over de kwaliteit van het arrangement (als een institutionele strategie) om de deelname van vrouwenorganisaties aan de door de UNFCCC geleide governance te ondersteunen. Hoofdstuk 6 sluit af met beleidsaanbevelingen voor het verbeteren van de mobilisatie van vrouwenorganisaties met betrekking tot de besluitvorming over de door de UNFCCC geleide klimaatfinanciering.

Hoofdstuk 7 levert aan de hand van het voorbeeld van de energieportfolio van de GCF (het belangrijkste financiële mechanisme van de UNFCCC) bewijs over hoe de toewijzing van de klimaatfinanciering door de GCF de empowerment van vrouwen ondersteunt. Dit hoofdstuk biedt beleidsmakers inzicht welke institutionele- en/of capaciteitsfactoren van invloed lijken te zijn op de overweging van de empowerment van vrouwen binnen de projecten voor klimaatfinanciering.

Hoofdstuk 8 wordt afgesloten met een samenvatting van de belangrijkste bevindingen over de beperkingen van de bestaande beleids- en institutionele strategieën. Er worden aanbevelingen gedaan om een betekenisvollere deelname van vrouwen en vrouwenorganisaties inzake de door de UNFCCC geleide governance te ondersteunen. Daarnaast formuleert het hoofdstuk ook methodologische, theoretische en beleidsreflecties, die als leidraad voor verdere beleidsontwikkeling en onderzoek kunnen dienen. 


\section{ABOUT THE AUTHOR}

Svetlana is an international gender and climate change expert with a postgraduate degree in Social Geography and over 15 years of experience supporting more inclusive and just transition to low-carbon and climate resilient development.

During her career, she has been advising UN agencies, development funds as well as a wide range of international and governmental organisations on the implementation and design of impactful gender-responsive policies and programs. Also, she has contributed to the mobilisation and implementation of climate finance in over 30 countries in Eastern Europe, Asia Pacific and Noth Africa.

Svetlana has developed knowledge products that supported policymakers and the broader development community in the integration of gender equality and women empowerment issues within institutional, policy and program design. For example, she led the development of the framework for enhancing the integration of gender dimension in public, private and innovative climate finance for UNDP. She also contributed to the analysis of the impact associated with the engagement of women and gender-related groups in Climate Investment Funds' portfolio.

At the end of 2018, she embarked on the PhD journey under the supervision of the Prof. Dr. Joy S. Clancy and Dr. Frans Coenen. Her thesis significantly benefited from the wealth of experience and practical insights that she gained through her work with gender responsive policy development, investment planning as well as program and project design.

Her latest peer reviewed publications include:

- Frenova, Svetlana. 2021. "Orchestrating the Participation of Women Organisations in the UNFCCC Led Climate Finance Decision Making"

Climate 9, no. 9: 135

https://doi.org/10.3390/cli9090135

- Frenova, Svetlana. 2021. "A Framework for Enhancing Gender and Poverty Integration in Climate Finance", UNDP.

https://www.undp.org/sites/g/files/zskgke326/files/2021-12/UNDP-A-

Framework-for-Enhancing-Gender-and-Poverty-Integration-in-Climate-

Finance_0.pdf
- CIF/WEDO. 2020. "Engagement of Women and Gender-related Groups in the Climate Investment Funds: An Assessment".

https://www.climateinvestmentfunds.org/sites/cif_enc/files/ knowledgedocuments/wedo_final_report_7april2020.pdf?blm_aid=52555 (as a contributing author)

- Frenova, Svetlana. 2020. "Climate finance allocation practices to support gender responsive energy transitions". In Engendering the Energy Transition. Theory meets policy and practice: South meets North. Eds: Clancy, Joy, Gül Özerol, Nthabiseng Mohlakoana, Mariëlle Feenstra, and Lillian Sol Cueva. Palgrave Macmillan.

- Bayraktar H, Waissbein O, Frenova S, Ballard-Tremeer G, Isaac M. 2018 "Kazakhstan: Derisking renewable energy investments. Selecting public instruments to promote utility-scale renewable energy investments in Kazakhstan", UNDP.

http://www.undp.org/content/undp/en/home/librarypage/ environmentenergy/low_emission_climateresilientdevelopment/deriskingrenewable-energyinvestment/drei-kazakhstan.htm 
ANNEX 1. POLICY FRAME ANALYSIS OF WOMEN'S ENGAGEMENT IN UNFCCC-LED CLIMATE CHANGE GOVERNANCE

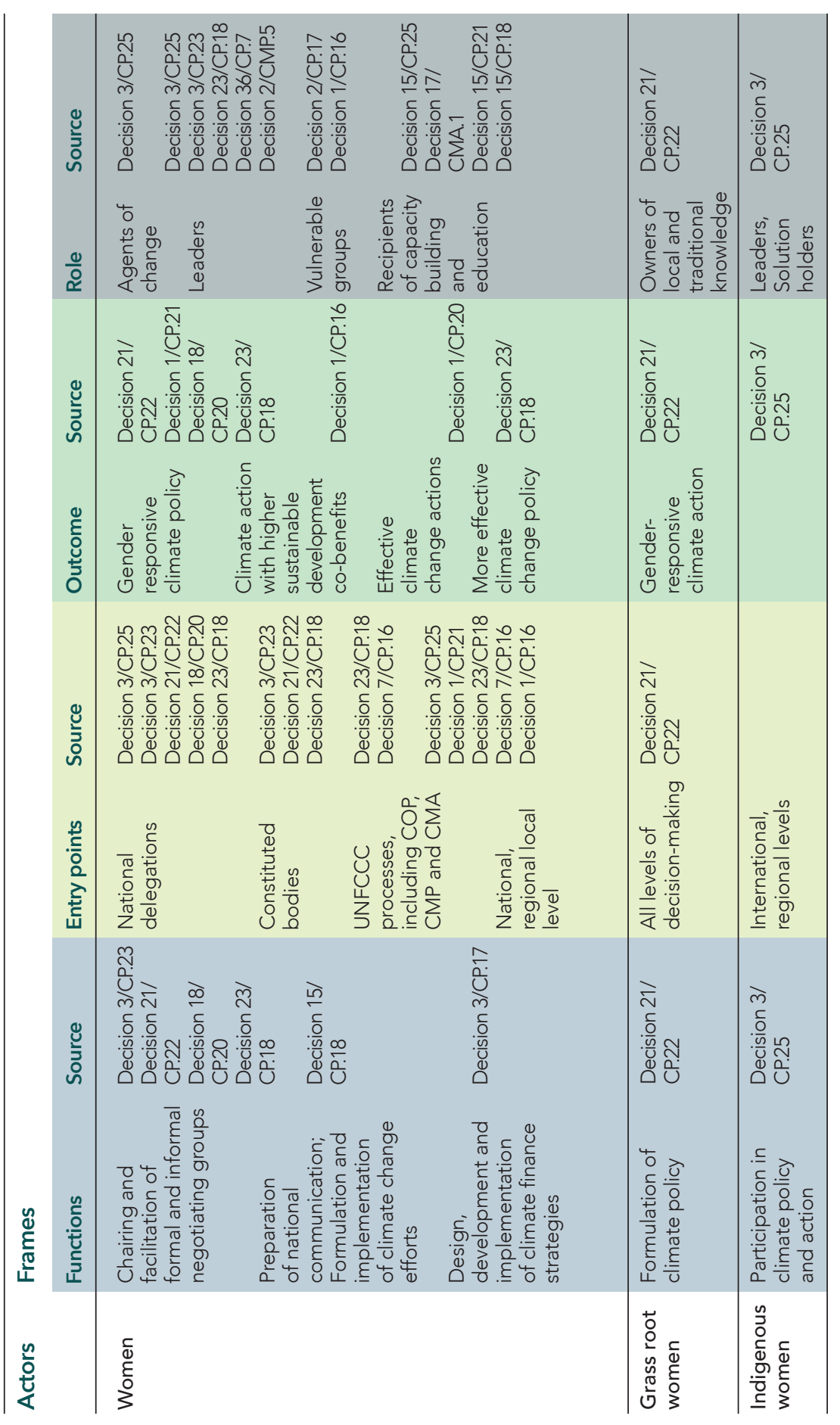

ANNEX 2. POLICY FRAME ANALYSIS OF THE ENGAGEMENT OF WOMEN ORGANISATIONS IN UNFCCC-LED CLIMATE CHANGE GOVERNANCE

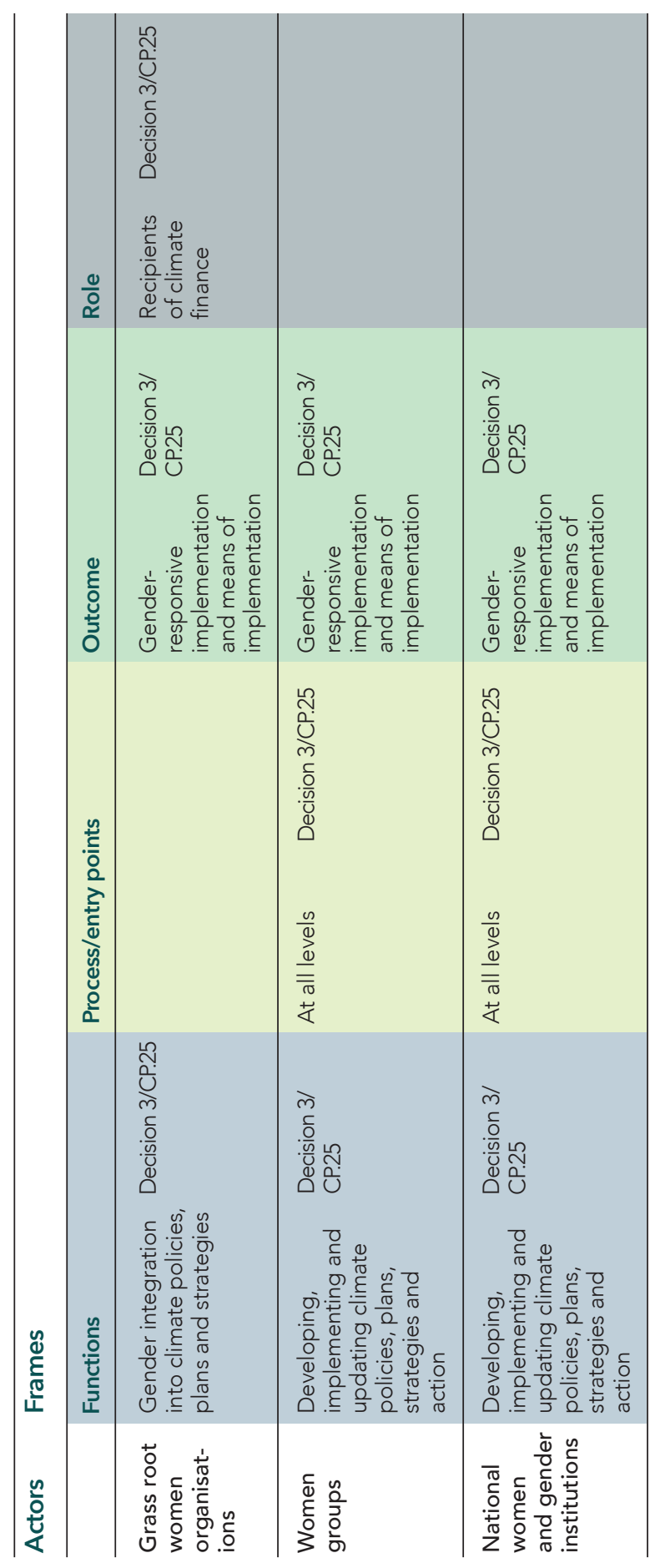


CHANGE GOVERNANCE
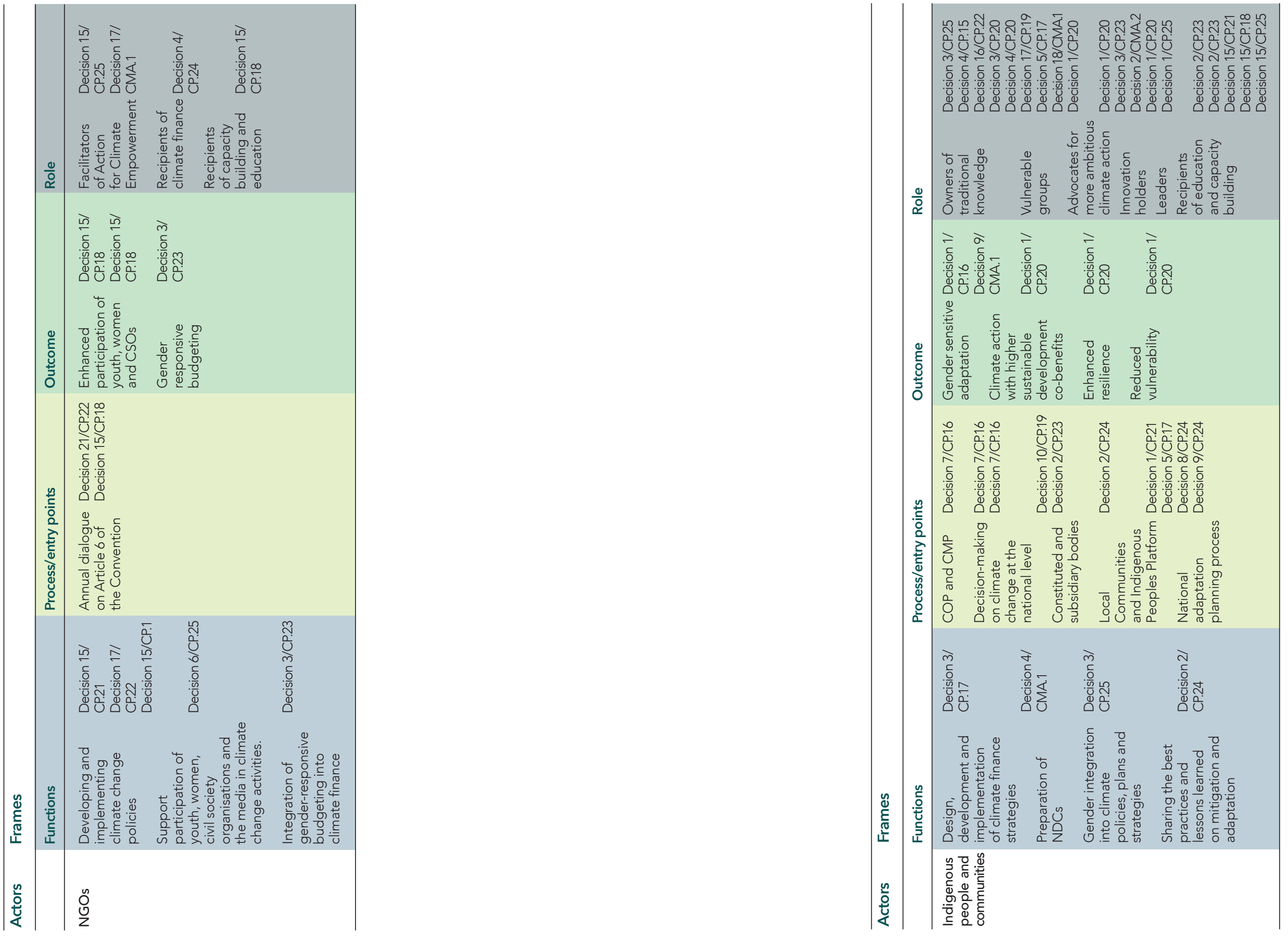

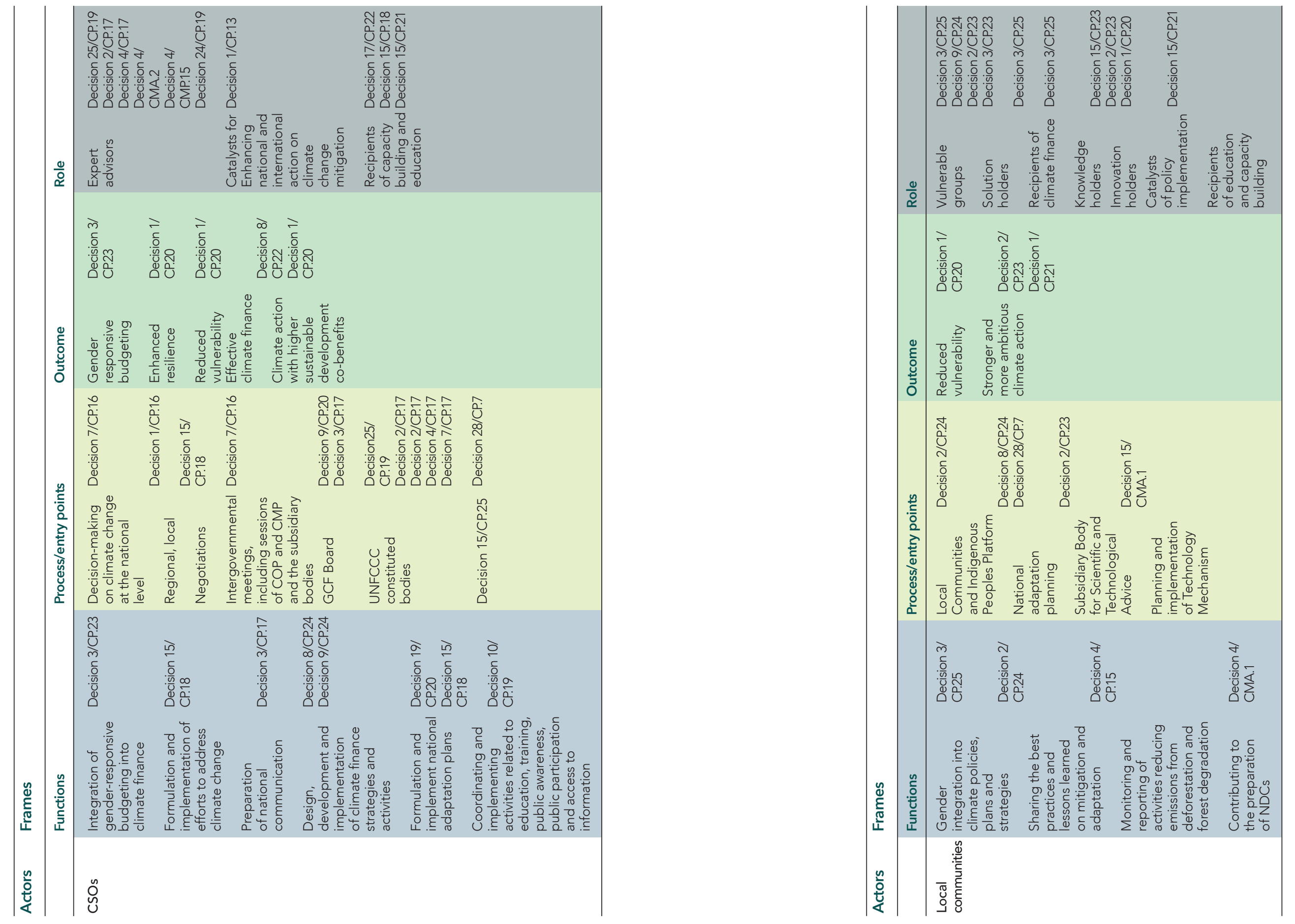
ANNEX 4. ANALYSIS OF GCF ENERGY PORTFOLIO

FROM THE PERSPECTIVE OF WOMEN EMPOWERMENT

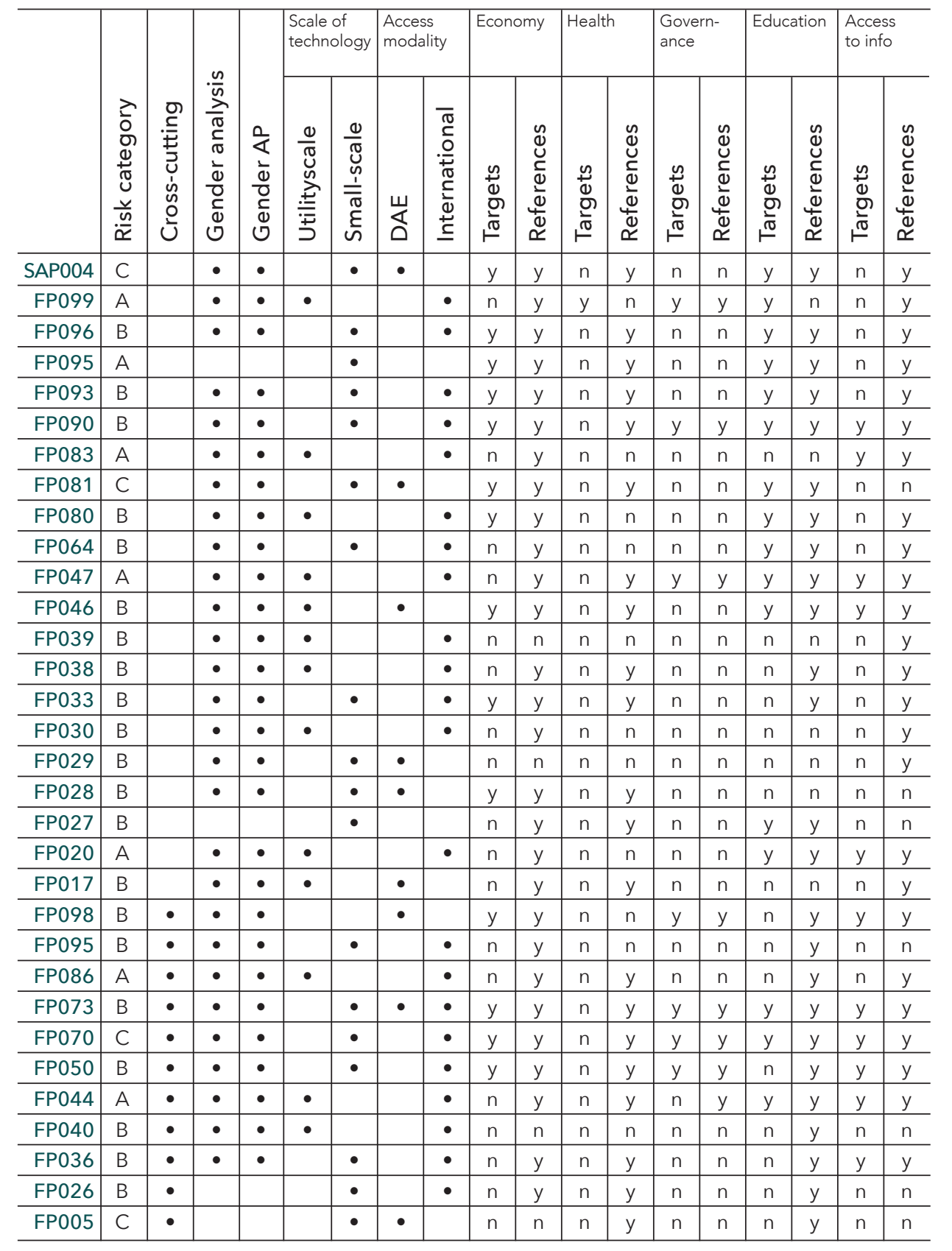



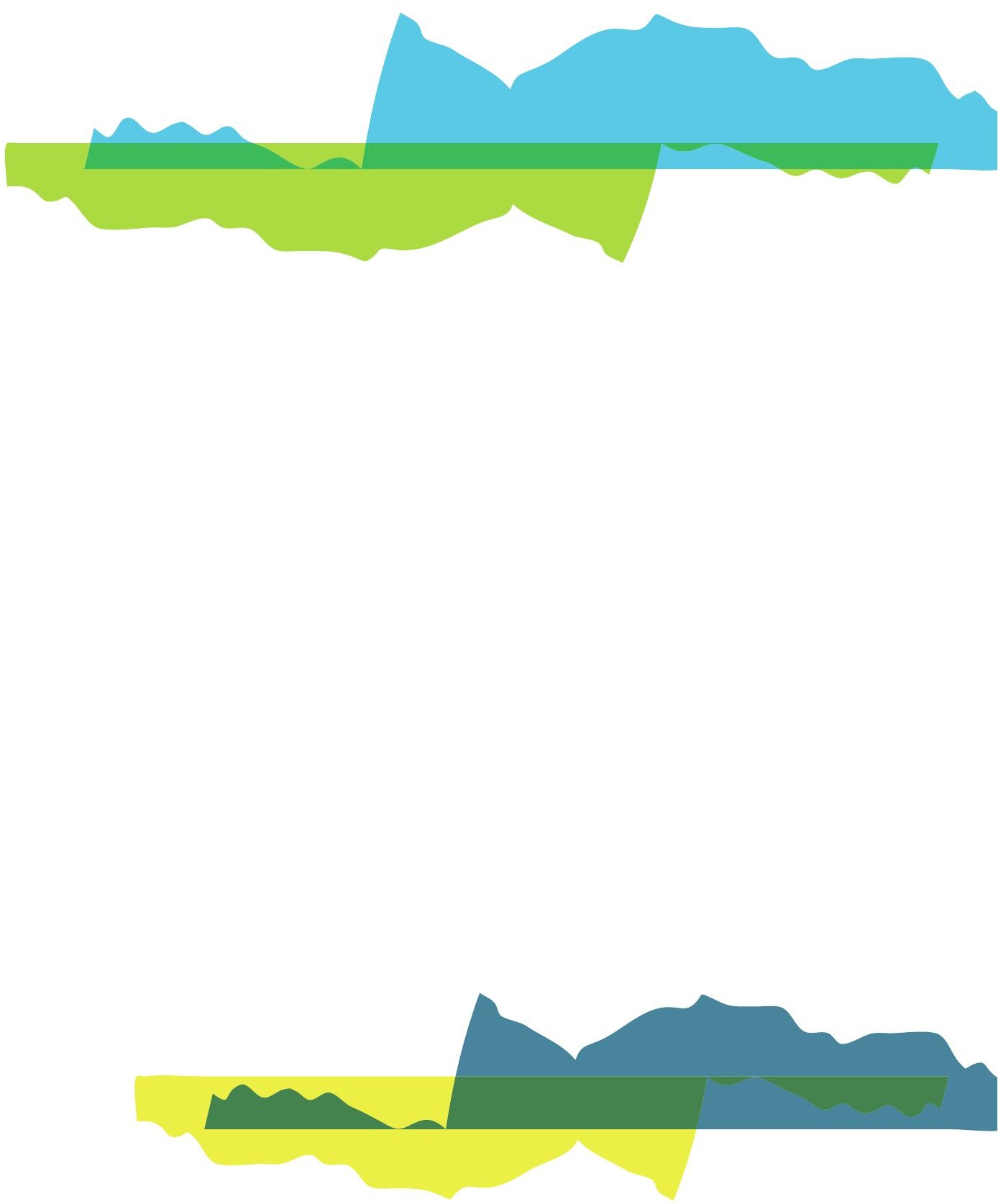